
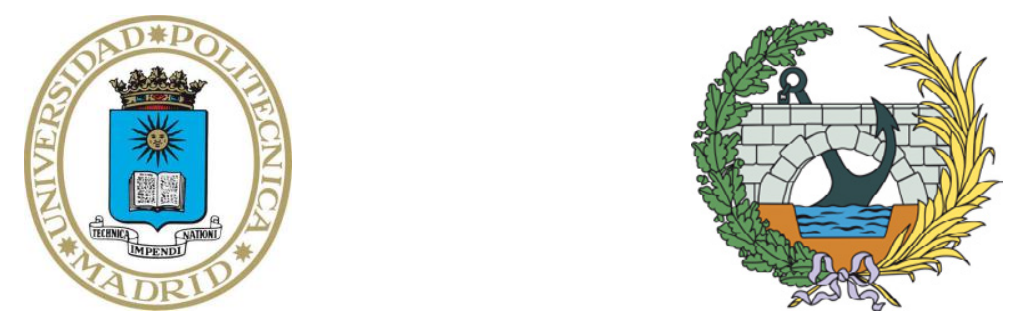

Universidad Politécnica de Madrid

\author{
Escuela Técnica Superior de \\ Ingenieros de Caminos, Canales y Puertos
}

\title{
Dynamic Fracture of High-Strength Metallic Alloys: Experiments and Modelling
}

Tesis doctoral

María Jesús Pérez Martín Ingeniera Técnica Industrial Ingeniera de Materiales 


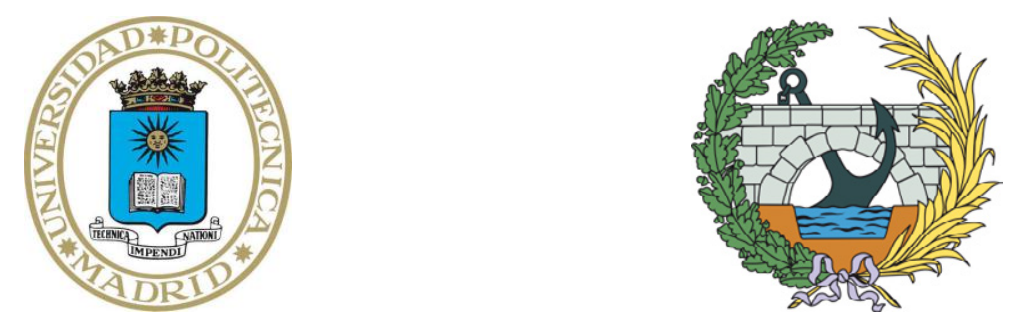

Departamento de Ciencia de Materiales

Escuela Técnica Superior de Ingenieros de Caminos, Canales y Puertos

Universidad Politécnica de Madrid

\section{Dynamic Fracture of High-Strength Metallic Alloys: Experiments and Modelling}

\section{Tesis doctoral}

María Jesús Pérez Martín Ingeniera Técnica Industrial Ingeniera de Materiales

Directores de tesis

Francisco Gálvez Díaz-Rubio

Dr. Ingeniero Aeronáutico

Borja Erice Echávarri

Dr. Ingeniero de Materiales 

A mis padres 

There is a crack in everything, that's how the light gets in.

- Leonard Cohen 



\section{ACKNOWLEDGEMENTS}

En primer lugar, quiero expresar mi agradecimiento a mis directores de tesis, los doctores Francisco Gálvez y Borja Erice, por haberme guiado durante todos estos años de doctorado y haberme enseñado tanto. A Curro por darme la oportunidad de realizar esta tesis doctoral y no haber perdido nunca la fe en mí. A Borja por su apoyo, su tiempo y por ser el mejor guía en la realización de esta tesis.

Este agradecimiento se hace extensivo a todos y cada uno de mis compañeros del Departamento de Ciencia de Materiales de la UPM, por sus enseñanzas, ayuda, consejos y por haberme hecho sentir siempre muy querida. Me gustaría agradecer especialmente a Álex, Álvaro y Víctor, su predisposición a ayudarme y "venir a explotar cosas conmigo". A los profesores Jesús Ruiz, David A. Cendón y a la profesora Mihaela lordachescu, por guiarme en mis inicios en el mundo de la fractura. A Josemi y a Bea, por su ayuda y apoyo siempre desinteresado. Por supuesto, a Álex, a Tere y a Elena, gracias por todos los buenos momentos dentro $y$ fuera del laboratorio. 
I would like to express my gratitude to Prof. Dr. Dirk Mohr for the great opportunity of developing part of this $\mathrm{PhD}$ research in the Laboratoire de Mécanique des Solides of l'École Polytechnique (Université Paris-Saclay) and in the Department of Mechanical and Process Engineering of the Swiss Federal Institute of Technology (ETH Zürich). I am grateful to the extraordinary people I met in Paris and Zurich, for their help and nice moments during my time there.

I would also like to acknowledge the work made by the external reviewers of the thesis, Dr. Mikko Hokka and Dr. Sidney Chocron.

También quisiera agradecer la financiación recibida por el gobierno español a través del programa FPI mediante la beca BES-2012-051973 para la realización de esta tesis doctoral.

Quiero expresar mi eterno agradecimiento a mis madrileñas y mis zamoranas, mis amigas, mis hermanas; las que a pesar de la lejanía siempre están muy cerca.

Desde un punto de vista personal, quiero expresar $\mathrm{mi}$ más profundo agradecimiento a Borja. Por su paciencia, por su amor, por no soltarme nunca la mano. Sin su ayuda y su apoyo no habría sido posible acabar esta tesis.

Por último y más importante, quisiera dar las gracias a mis hermanos; por su amor, cariño y apoyo incondicional. Y por supuesto, a mis padres. Porque me lo han dado todo y siempre han sido mi mayor apoyo. Esta tesis está dedicada a ellos con todo mi amor. 


\section{ABStRACT}

Fracture toughness is a property which describes the ability of a material containing a crack to resist fracture. Such a characteristic is one of the most important properties for describing the failure criteria of materials and may be a function of loading rate and temperature. Therefore, in the case of materials that may be subjected to dynamic loads or extreme conditions, it is crucial to be aware of the evolution of their fracture behaviour with such variables.

The main objective of this $\mathrm{PhD}$ thesis was to design and develop a novel experimental technique that allowed measuring the dynamic fracture-initiation toughness in a systematic manner for a wide range of loading rates. For such a purpose, two different high-strength metallic alloys, the AA7017-T73 and Mars $®$ 240 steel were studied. Both materials were initially characterised at different strain rates and variying temperatures through uniaxial tensile tests performed in a universal servo-hydraulic machine equipped with a temperature chamber and a Hopkinson pressure bar system. As expected, the aluminium alloy presented a very mild strain rate hardening. Conversely, the armour steel exhibited a significant strain rate dependency. 
The load obtained from properly calibrating the strain measurements of a strain gauge bonded close to the crack tip together with the stationary crack hypothesis, made possible the calculation of the dynamic fracture-initiation toughness from direct experimental measurements of three-point bending experiments in a wide range of loading rates. The obtained results corroborated the experimental observations of the uniaxial tensile tests, which helped to validate the experimental technique.

A numerical study on the mechanical response of both materials under three-point bending loading was conducted by comparing representative experimental measurements with their virtual counterparts. The anisotropic elastic-viscoplastic models employed for such a task were initially calibrated with the results obtained from the uniaxial tensile experiments. The numerical results showed reasonable agreement with the experimental response. In order to complete the numerical study, the accuracy on the fracture-initiation prediction was analysed with two stress-based fracture-initiation criteria. 


\section{CONTENTS}

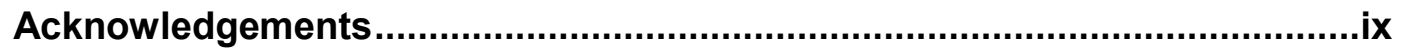

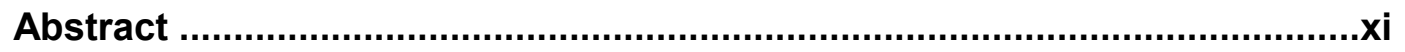

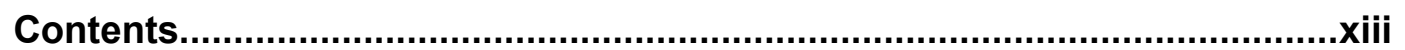

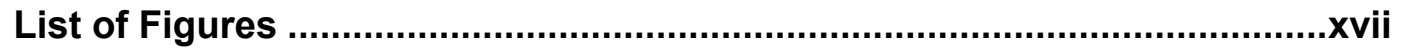

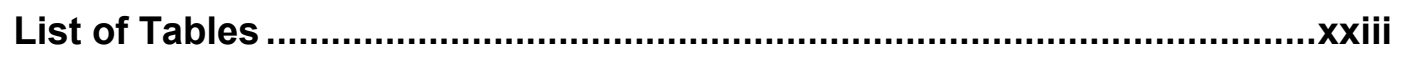

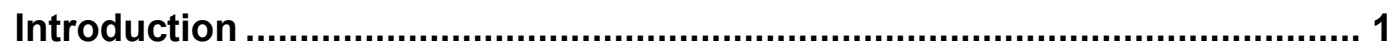

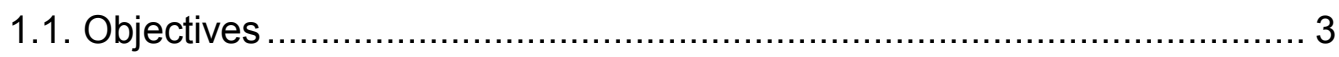

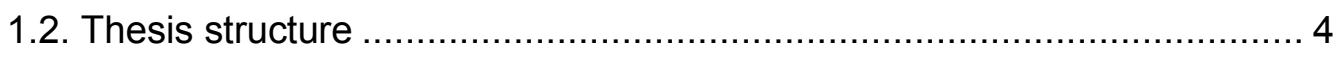

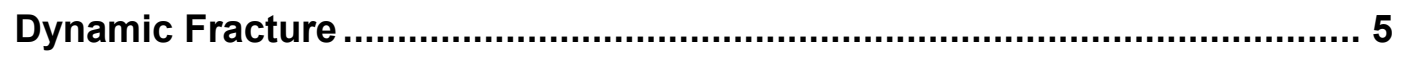

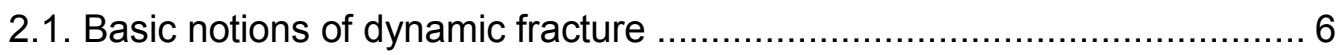

2.1.1. Dynamic fracture criteria for a stationary crack ............................. 8

2.1.2. Experimental procedures for dynamic fracture.............................. 11 


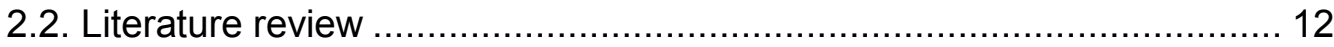

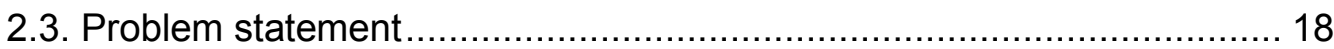

2.3.1. Experimental method and procedures ........................................ 18

2.3.2. Numerical modelling of the constitutive and fracture behaviour ...... 18

2.4. Materials Description .................................................................. 19

2.4.1. Aluminium $7017-T 73$ alloy …….................................................... 19

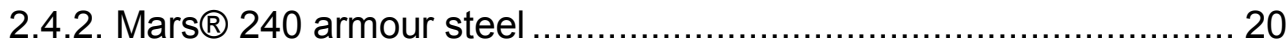

Experimental Characterisation of the Materials ...........................................23

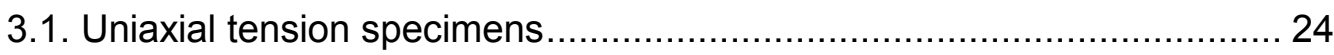

3.2. Experimental set-up for low strain rates ........................................... 25

3.3. Experimental set-up for intermediate strain rates .............................. 26

3.4. Experimental set-up for high strain rates ........................................ 27

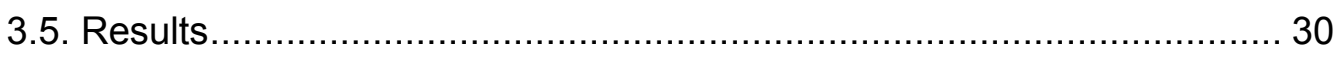

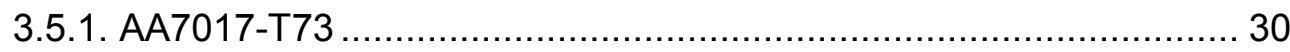

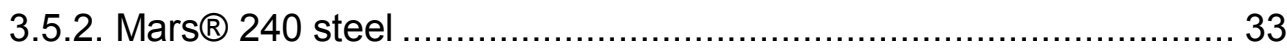

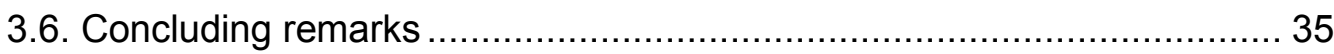

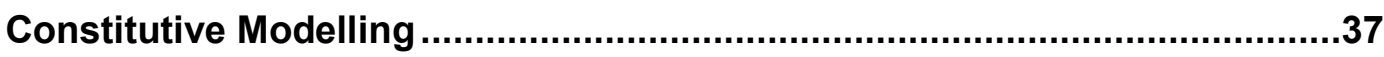

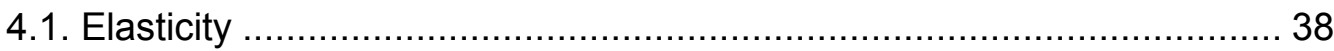

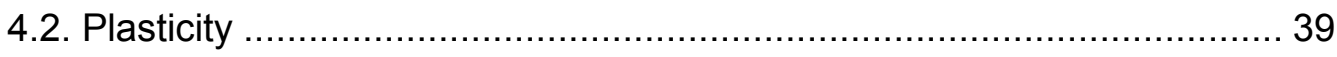

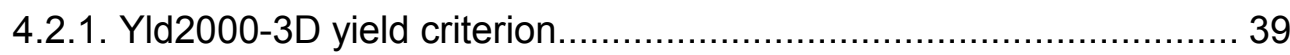

4.2.2. Non-associated Hill 48' plasticity ................................................. 41

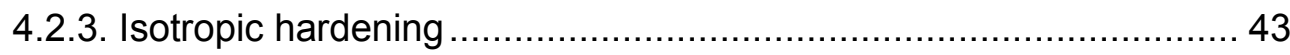

4.3. Numerical simulations of the uniaxial tension experiments................... 44

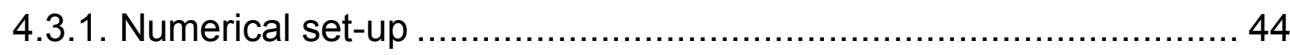

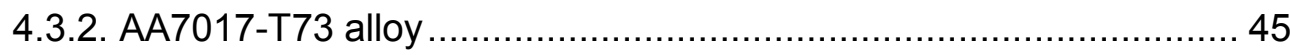


4.3.3. Mars $® 240$ steel 49

4.4. Concluding remarks 53

\section{Experimental Determination of the Dynamic Fracture-Initiation}

Toughness .55

5.1. Standard test method for linear-elastic plane-strain fracture thoughness $\mathrm{K}_{\mathrm{IC}}$

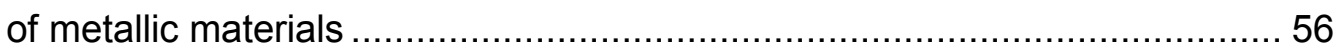

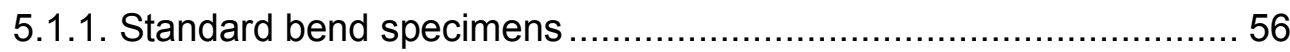

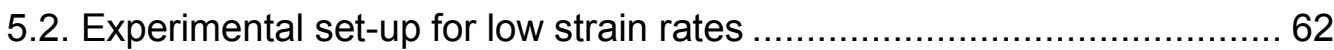

5.3. Experimental set-up for drop weight impact tests ........................... 63

5.4. Experimental set-up for modified split Hopkinson pressure bar tests..... 64

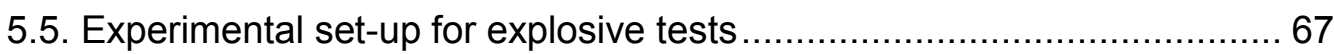

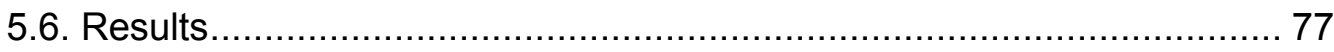

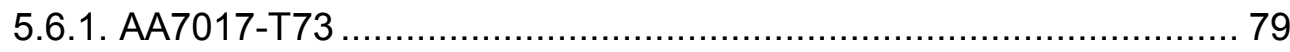

5.6.2. Mars $₫ 240$ steel ......................................................... 81

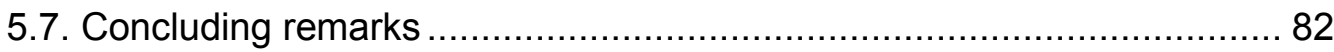

A Numerical Study on Three-Point Bending Specimens under Dynamic

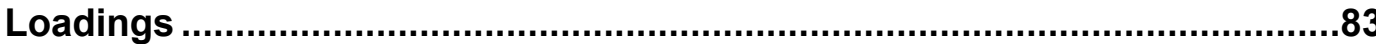

6.1. Extrapolation-based methods to determining fracture-initiation toughness 84

6.1.1. Displacement extrapolation method ................................. 84

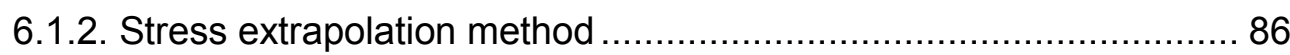

6.2. Numerical simulations of pre-fatigued three-point bending specimens ... 86

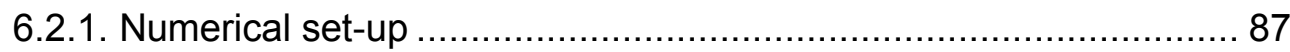

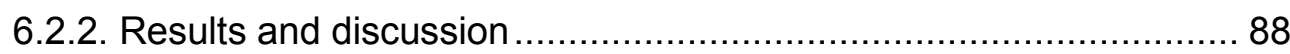

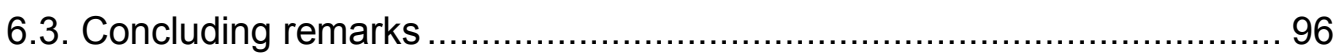

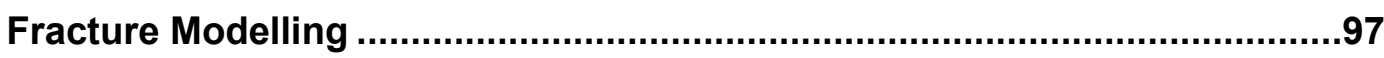


7.1. Description of the stress state for isotropic materials ......................... 98

7.2. Anisotropic Cockroft-Latham fracture-initiation criterion ...................... 99

7.3. Anisotropic Mohr-Coulomb fracture-initiation criterion ....................... 100

7.4. Calibration procedure ............................................................. 101

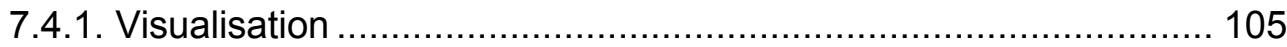

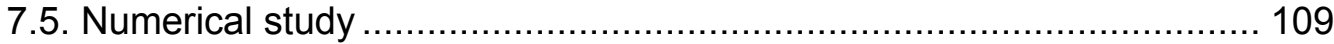

7.5.1. Numerical set-up .......................................................... 109

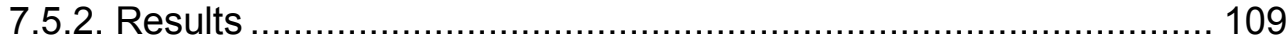

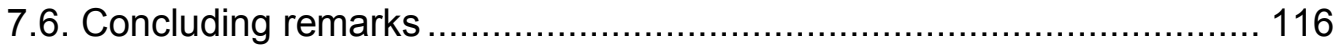

Conclusions and Future Work ..............................................................117

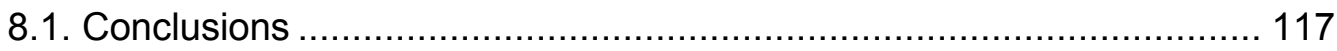

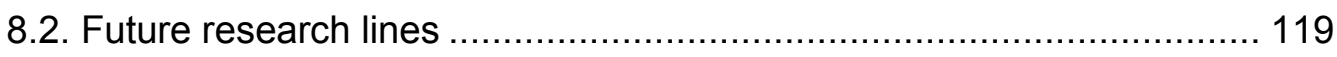

8.2.1. Further experimental improvements ................................ 119

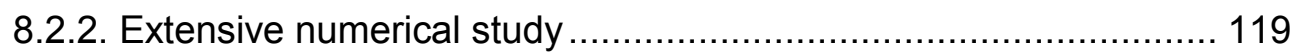

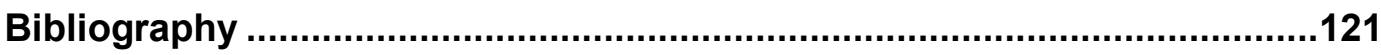




\section{LIST OF FIGURES}

Figure 1.1. Examples of land, marine and aerospace armoured vehicles.

2

Figure 2.1. Dynamic fracture criterion. ................................................... 9

Figure 3.1. AA7017-T73 alloy (a, b) and Mars ${ }^{\circledR} 240$ (c, d) UT specimens for the (a, c) quasi-static, $(a, c)$ intermediate and $(b, d)$ dynamic testing. ....................... 24

Figure 3.2. Experimental set-up for UT tests at low strain rates...................... 25 Figure 3.3. (a) Custom-made high pressure clamps. (b) The environmental chamber for high temperature experiments. ............................................. 26

Figure 3.4. The high speed camera and the high-powered lamps used for recording intermediate and high strain rate experiments. ...................................... 26

Figure 3.5. Scheme with the geometry and dimensions of the modified Split

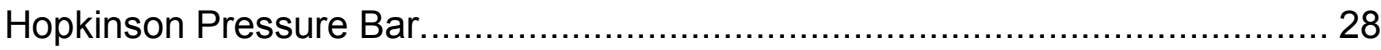
Figure 3.6. The load inversion device mounted on an independent bearing system for high strain rate tensile testing. 29 Figure 3.7. The UT specimen mounted on the set-up with two red solid lines highlighting the position of the virtual extensometer for measuring the relative displacement. 29

Figure 3.8. Sequence of images of an experiment at high strain rate taken with the high speed camera. 29 
Figure 3.9. Engineering stress-strain curves of AA7017-T73 alloy obtained from uniaxial tensile quasi-static experiments along three different directions $\left(0^{\circ}, 45^{\circ}\right.$ and $\left.90^{\circ}\right)$

Figure 3.10. Engineering stress-strain curves of AA7017-T73 alloy obtained from uniaxial tensile experiments at three different strain rates $\left(5 \cdot 10^{-4} \mathrm{~s}^{-1}, 0.5 \mathrm{~s}^{-1}\right.$ and $\left.250 \mathrm{~s}^{-1}\right)$

Figure 3.11. Engineering stress-strain curves of AA7017-T73 alloy obtained from uniaxial tensile experiments at $75^{\circ} \mathrm{C}, 150^{\circ} \mathrm{C}$ and room temperature. 32

Figure 3.12. Engineering stress-strain curves of Mars ${ }^{\circledR} 240$ steel obtained from uniaxial tensile quasi-static experiments along three different directions $\left(0^{\circ}, 45^{\circ}\right.$ and $\left.90^{\circ}\right)$ 34

Figure 3.13. Engineering stress-strain curves of Mars ${ }^{\circledR} 240$ steel obtained from uniaxial tensile quasi-static experiments at three different strain rates $\left(5 \cdot 10^{-4} \mathrm{~s}^{-1}\right.$, $0.5 \mathrm{~s}^{-1}$ and $\left.250 \mathrm{~s}^{-1}\right)$.........

Figure 4.1. Finite element meshes used for the numerical simulations of the (a) AA7017-T73 and the Mars $® 240$ steel.

Figure 4.2. Hardening for $0^{\circ}$ orientation with parameters reported in Table 4.2 for constant strain rates of $5 \cdot 10^{-4} \mathrm{~s}^{-1}, 10 \mathrm{~s}^{-1}$ and $1000 \mathrm{~s}^{-1}$. 46

Figure 4.3. Engineering stress-strain curves of AA7017-T73 alloy obtained from UT quasi-static experiments along three different directions $\left(0^{\circ}, 45^{\circ}\right.$ and $\left.90^{\circ}\right)$ compared with the corresponding numerical simulations. 48

Figure 4.4. Engineering stress-strain curves of AA7017-T73 alloy obtained from UT experiments at three different strain rates $\left(5 \cdot 10^{-4} \mathrm{~s}^{-1}, 0.5 \mathrm{~s}^{-1}\right.$ and $\left.250 \mathrm{~s}^{-1}\right)$ compared with the corresponding numerical simulations. 48

Figure 4.5. Engineering stress-strain curves of AA7017-T73 alloy obtained from UT experiments at $75^{\circ} \mathrm{C}$ and room temperature compared with the corresponding numerical simulations. 49

Figure 4.6. Hardening with parameters reported in Table 4.4 for constant strain rates of of $5 \cdot 10^{-4} \mathrm{~s}^{-1}, 10 \mathrm{~s}^{-1}$ and $1000 \mathrm{~s}^{-1}$ 51 Figure 4.7. Engineering stress-strain curves of Mars ${ }^{\circledR} 240$ steel obtained from UT quasi-static experiments along three different directions $\left(0^{\circ}, 45^{\circ}\right.$ and $\left.90^{\circ}\right)$ compared with the corresponding numerical simulations. 
Figure 4.8. Engineering stress-strain curves of Mars ${ }^{\circledR} 240$ steel obtained from UT experiments at three different strain rates $\left(5 \cdot 10^{-4} \mathrm{~s}^{-1}, 0.5 \mathrm{~s}^{-1}\right.$ and $\left.250 \mathrm{~s}^{-1}\right)$ compared with the corresponding numerical simulations.

Figure 5.1. Principal types of force-displacement (CMOD) records................... 58

Figure 5.2. Crack growth monitored while fatigue pre-cracking......................... 59

Figure 5.3. Specimens extracted from the original plate. 60

Figure 5.4. Geometry and dimensions requirements of the standard bend specimen 60

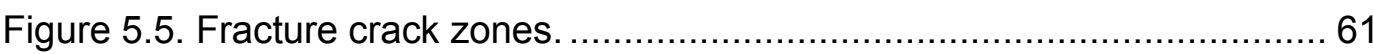

Figure 5.6. Crack growth monitored while fatigue pre-cracking........................ 62

Figure 5.7. Experimental set-up of the quasi-static fracture toughness tests. .... 63 Figure 5.8. Experimental set-up of the drop weight fracture toughness impact tests.

Figure 5.9. Schematic view of the modified SHPB used to carry out the fracture toughness tests on TPB specimen without supports 66

Figure 5.10. Schematic view of the modified SHPB used to carry out the fracture toughness tests on TPB specimen with two output bars as supports 66 Figure 5.11. Images of the modified SHPB used to carry out TPB tests without (a) and with two output bars (b). 66

Figure 5.12. Experimental set-up of the modified SHPB used to carry out fracture toughness tests.

Figure 5.13. Steel frame used to bear the device for the fracture toughness explosive tests. 68

Figure 5.14. The new device used for the fracture toughness explosive tests and the explosive placed on a horizontal plane above the ground. 69 Figure 5.15. A sketch of the set-up used in the fracture toughness explosive tests.

Figure 5.16. The developed new deviced for fracture toughness explosive tests mounted on the steel frame. 71

Figure 5.17. The device for fracture toughness explosive tests consisted of a steel box with a composite laminate cover. 71

Figure 5.18. Interior layout of the device for fracture toughness explosive tests: two 
cylindrical supports, the load applier attached to the composite laminate and the specimen with an attached strain gauge.

Figure 5.19. Two specimens mounted on the cylindrical supports in the device for fracture toughness explosive tests.

Figure 5.20. The device for fracture toughness explosive tests allowed the simultaneous testing of up to two TPB samples. 73

Figure 5.21. The explosive was presented in bars, tied together forming a cylindrical bunch. 74

Figure 5.22. Data acquisition systems set on a bunker located at a strand-off distance of $20 \mathrm{~m}$ from the detonation point. 74

Figure 5.23. (a) An image captured when the detonation occurred. (b) A piezoelectric pressure sensor for measuring the reflected pressure history of each detonation. 75

Figure 5.24. Experimental device with the piezoelectric pressure sensor (yellow narrow) and the accelerometer (red narrow) coupled to the cover of the device for fracture toughness explosive tests. 76

Figure 5.25. Reflected pressure histories of two detonations performed the same day with the same amount of explosive but with different atmospheric conditions.

Figure 5.26. A slide potentiometer, attached to the device for fracture toughness explosive tests, used to verify the accelerometer signal. 77

Figure 5.27. Post-mortem standard bend specimen. Fracture was brittle and the specimen satisfied the requirements of crack length and plane of fatigue precrack.

Figure 5.28. Post-mortem standard bend specimen. Fracture was brittle but the specimen did not satisfy the requirements of crack length. 78 Figure 5.29. Dynamic fracture-initiation toughness of AA7017-T73 alloy at different loading rates. 80

Figure 5.30. Dynamic fracture-initiation toughness mean value and its standard deviation of AA7017-T73 alloy using four different experimental set-ups. 80 Figure 5.31. Dynamic fracture-initiation toughness of Mars ${ }^{\circledR} 240$ steel at different loading rates. 
Figure 6.1. Isocontours of equivalent plastic strain in the crack tip vicinity of the AA7017-T73 quasi-static simulation. Points $A$ and $B$ were used for the displacement (in red) and stress (in blue) extrapolation methods. 85

Figure 6.2. Finite element meshes used to simulate the pre-fatigued three-point bending specimens of (a) AA7017-T73 alloy and (b) Mars ${ }^{\circledR} 240$ steel. 88

Figure 6.3. Equivalent plastic strain iso-contours in the crack tip vicinity compared to the elements used to extract the strain histories. 89

Figure 6.4. (Left) Comparison between the experimental and numerical response of AA7017-T73. (Right) The dynamic fracture-initiation toughness value computed with DEM and SEM compared to those obtained experimentally. Results for quasistatic, SHPB and explosive tests are reported in (a-b), (c-d) and (e-f) respectively.

Figure 6.5. Drop-weight tower tests and simulations of the AA7017-T73. (a) Equivalent plastic strain iso-contours near the crack tip. (b) Numerical vs. experimental strain histories extracted from the strain gauges. (c) DEM and SEM vs. experimental results 93

Figure 6.6. (Left) Comparison between the experimental and numerical response of Mars ${ }^{\circledR}$ 240. (Right) The dynamic fracture-initiation toughness value computed with DEM and SEM compared to those obtained experimentally. Results for quasistatic, SHPB and explosive tests are reported in (a-b), (c-d) and (e-f) respectively 95

Figure 7.1. Ilustrative sketch of the fracture plane on a solid loaded with a tensile stress. 100

Figure 7.2. AA7017-T73 alloy UT specimens extracted at $0^{\circ}(\mathrm{a}), 45^{\circ}(\mathrm{b})$ and $90^{\circ}(\mathrm{c})$ with respect to the rolling direction. On the left, post-mortem pictures of the specimens. On the right, von Mises equivalent strain corresponding to fracture.

Figure 7.3. Mars ${ }^{\circledR} 240$ steel UT specimens extracted at $0^{\circ}(\mathrm{a}), 45^{\circ}$ (b) and $90^{\circ}$ (c) with respect to the rolling direction. On the left, post-mortem pictures of the specimens. On the right, von Mises equivalent strain corresponding to fracture.

Figure 7.4. Schematical illustration of polar figures used to visualise the loading 
paths to fracture of an anisotropic material.

106

Figure 7.5. Loading paths to fracture of AA7017-T73. ACL model predictions (a) in plane $\left\{\sigma_{11}, \sigma_{22}\right\}$ and (b) in plane $\left\{\sigma_{12}, \sigma_{d}\right\}$. AMC model predictions (c) in plane $\left\{\sigma_{11}, \sigma_{22}\right\}$ and (d) in plane $\left\{\sigma_{12}, \sigma_{d}\right\}$. 107

Figure 7.6. Loading paths to fracture of Mars $® 240$ steel. ACL model predictions (a) in plane $\left\{\sigma_{11}, \sigma_{22}\right\}$ and (b) in plane $\left\{\sigma_{12}, \sigma_{d}\right\}$. AMC model predictions (c) in plane $\left\{\sigma_{11}, \sigma_{22}\right\}$ and (d) in plane $\left\{\sigma_{12}, \sigma_{d}\right\}$ 108

Figure 7.7. $A C L$ and $A M C$ damage indicators extracted from the element located ahead the crack tip and adjacent to the vertical symmetry plane for the TPB (a) quasi-static, (b) SHPB and (c)explosive tests of the AA7017-T73 compared to the results in Figure 6.4.

Figure 7.8. (Left) Damage indicator contours of $A C L$ and AMC failure criteria plotted at fracture onset for AA7017-T73. (Right) Polar plots in $\left\{\sigma_{22}, \sigma_{33}\right\}$ plane depicting the loading paths to fracture from the element located ahead the crack tip and adjacent to the vertical symmetry plane. Hollow and solid dots are the ACL and $\mathrm{AMC}$ predictions.

Figure 7.9. (a) Damage indicator extracted from the critical element compared against the results from Figure 6.5. (b) Damage indicator contours at onset of fracture for $A C L$ and $A M C$ models. (c) Loading paths to fracture from the most critical element in the $\left\{\sigma_{22}, \sigma_{33}\right\}$ plane 113

Figure 7.10. ACL and AMC damage indicators extracted from the element located ahead the crack tip and adjacent to the vertical symmetry plane for the TPB (a) quasi-static, (b) SHPB and (c)explosive tests of Mars ${ }^{\circledR} 240$ steel compared to the results in Figure 6.6 114

Figure 7.11. (Left) Damage indicator contours of $A C L$ and $A M C$ failure criteria plotted at fracture onset for Mars ${ }^{2} 240$ steel. (Right) Polar plots in $\left\{\sigma_{22}, \sigma_{33}\right\}$ plane depicting the loading paths to fracture from the element located ahead the crack tip and adjacent to the vertical symmetry plane. Hollow and solid dots are the ACL and $\mathrm{AMC}$ predictions 115 


\section{LIST OF TABLES}

Table 2.1. Certified chemical composition of AA7017-T73 alloy (weight \%) (The Aluminum Association, 2001). 20

Table 2.2. Mechanical properties of AA7017-T73 alloy (The Aluminum Association, 2001) 20

Table 2.3 Chemical composition of Mars ${ }^{\circledR} 240$ steel (weight \%) (ASMInternational, 2012). 21

Table 2.4. Mechanical properties of Mars ${ }^{\circledR} 240$ steel (ASM-International, 2012). 21

Table 3.1. Uniaxial yield stresses and Lankford coefficients of AA7017-T73 alloy. 30

Table 3.2. Uniaxial yield stresses and Lankford coefficients of Mars $₫ 240$ steel. 33

Table 4.1. Uniaxial yield stresses and Lankford coefficients of AA7017-T73 alloy. 47

Table 4.2. Material constants for the AA7017-T73 alloy. 47

Table 4.3. Uniaxial yield stresses and Lankford coefficients of Mars ${ }^{\circledR} 240$ steel. 
Table 4.4. Material constants of Mars ${ }^{\circledR} 240$ steel.

50

Table 5.1. Dimensions of the specimens

60

Table 7.1. Calibrated parameters for the anisotropic Cockcroft-Latham and MohrCoulom failure criteria of AA7017-T73 alloy. 102

Table 7.2. Calibrated parameters for the anisotropic Cockcroft-Latham and MohrCoulom failure criteria of Mars $® 240$ steel. 102 


\section{CHAPTER 1}

\section{INTRODUCTION}

In general, constitutive equations and failure criteria of materials are ratedependent. Therefore, in the case of materials that may be subjected to both low and high loading rates it is necessary to know how their mechanical properties vary with the strain rate and temperature. Particularly, it is crucial for critical engineering applications such as defence-oriented protection. Evaluation of the protection ability of a material at quasi-static or low strain rates may lead to erroneous predictions or design characteristics. The necessary requirement for a protective material is to keep the damage factor (to personnel or structure) of a projectile or an explosion, that have a certain shape and relatively large kinetic energy, at a minimum level.

Nowadays, the combination of modern firearms and/or improvised explosive devices (IEDs), in war or politically unstable scenarios accross the world, cause high level threat for both military and civilian targets. The development and improvement of armour materials, such as metals, ceramics and composite 
materials, play an important role in the present demands for armoured vehicles. Protective materials have to defeat bullets, fragments, ammunitions, IEDs or blast, and keep their structural integrity intact. Armour materials are present in land, marine and aerospace applications for both civil and military markets (examples in Figure 1.1.).

Armour steels are extensively used as protective materials due to their high strength, hardness and toughness properties, having a high level of energy absorbtion capability. They are primarily used in cast and rolled forms and they are less expensive than the new generation of armour materials such as hybrid material or reactive armours.

Operational requirements for vehicles result in a constant trade-off between protection and mobility. The present demands for armoured vehicles tend towards reduction in the armour mass. The need to produce lightweight vehicles has resulted in an increased interest in utilisation of aluminium alloys for automotive body structures. The advantage of aluminium lying in its high strength-to-weigth ratio.
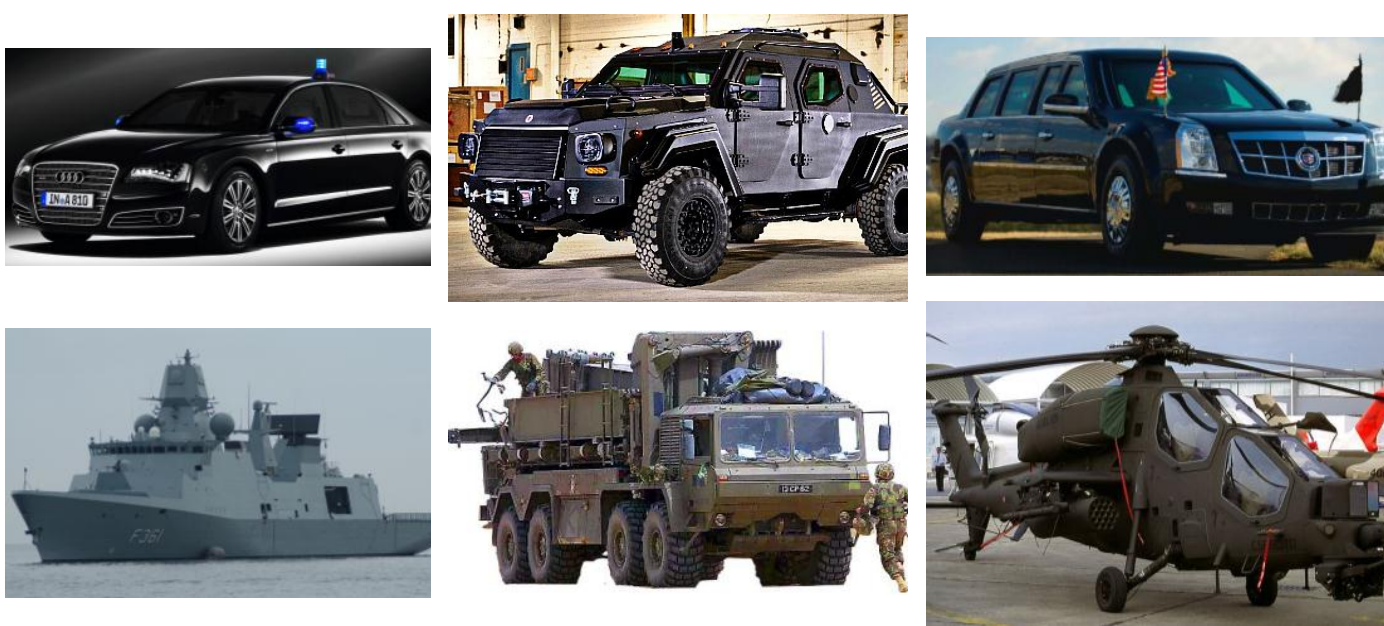

Figure 1.1. Examples of land, marine and aerospace armoured vehicles.

In order to properly design an armoured structure, it is necessary to have a thorough knowledge of its fracture behaviour. Providing a successful protection is not just about creating a ground-breaking material, but to perfectly define the fracture material properties and to know how to efficiently implement it. 
In order to describe the fracture behaviour of a material, its fracture toughness needs to be determined. Such a property describes the ability of a material containing a crack to resist fracture and it may be a function of loading rate and temperature. The static fracture toughness is a widely studied and standardised parameter. Nevertheless, obtaining the fracture toughness under dynamic conditions is quite complex because the specimen might not be in stress equilibrium. Nowadays, although some methods have been proposed for particular cases, there are no standards or guidelines on how to obtain the dynamic fracture toughness of any material.

\subsection{Objectives}

The aim of this research is to design and develop an experimental procedure and robust and reliable numerical models that allow future calculation of fractureinitiation toughness at a wide range of loading rates. To such a purpose, the following will be pursued:

- Selection of two suitable armour metallic materials to study.

- Mechanically characterise those high-strength metals at different loading rates and temperatures.

- From such characterisation, obtain the rate and temperature dependency of the plasticity and failure models of both materials.

- Design and development of a new experimental technique to obtain dynamic fracture-initiation toughness at wide range of loading rates.

- Employ the mentioned new technique to obtain the dynamic fractureinitiation toughness of the armour materials.

- Numerically analise the conditions and results of the performed fracture toughness experiments. 


\subsection{Thesis structure}

This PhD thesis is comprised of eight chapters. Chapters 1 and 2 introduce the motivation of the research and the fundamentals of dynamic fracture. In Chapters 3 and 4 the material characterisation and the constitutive material models are presented. Chapters 5 to 7 describe a new experimental technique to obtain dynamic fracture-initiation toughness at different loading rates and a numerical study of the dynamic fracture tests. Chapter 8 shows the final conclusions and the future work. The contents of the chapters are summarised below:

CHAPTER 1. Introduction, motivation and objectives of the thesis.

CHAPTER 2. Elastic linear fracture mechanics theory under dynamic loadings. Literature review on the experimental methods used to obtain the dynamic fracture toughness. Material description.

CHAPTER 3. Experimental methodology employed to mechanically characterise the high-strength metallic materials at different strain rates and temperatures.

CHAPTER 4. Description and calibration of rate and temperature dependent plasticity criteria employing the experimental results obtained in the previous chapter.

CHAPTER 5. A new experimental technique to obtain dynamic fracture-initiation toughness at very wide range of loading rates.

CHAPTER 6. Numerical study of pre-fatigued three-point-bending specimens under dynamic loading conditions.

CHAPTER 7. Description and calibration of fracture criteria employing the experimental results obtained in previous chapters.

CHAPTER 8. Conclusions and future work. 


\section{CHAPTER 2}

\section{DYNAMIC FRACTURE}

A brief overview of the elastic linear fracture mechanics theory under dynamic loadings is addressed in this chapter. Additionally, a literature review on the most relevants experimental methiods to obtain dynamic fracture toughness is presented.

The problem statement is described and the description of the materials employed for the present study is introduced. 


\subsection{Basic notions of dynamic fracture}

Rapidly applied loads, whether deliberately or from accidental conditions, can be found in many applications. Regardless of the origin, it is necessary to understand the fundamental constitutive and fracture behaviour of materiasl under dynamic loadings in order to predict the complex material response and accumulation of damage resulting from a dynamic event.

It is essential to identify the range of loading rates in order to identify those cases where there is a truly transient dynamic condition, and then a full elastodynamic analysis of the problem is necessary; and those where just a quasi-static analysis might be sufficient if a steady vibratory state after several stress wave reflections has been reached. In practice, whether these regimes are present or not in material system depends on the nature of the specimen and their properties.

Here, an overview of dynamic fracture in nominal brittle materials is presented. Early researchs into dynamic brittle fracture were performed without the presence of a dominant crack in the specimen, causing spalling of the material. Over the years, such researchs have been directed towards a crack-dominated approach. (Irwin, 1957) and (Williams, 1957) were the first describing the magnitude of crack tip stresses with asymptotic linear elastic crack tip solutions by means of the stress intensity factor. The stress intensity factor is a parameter that predicts the stress state near the tip of a crack caused by a remote load.

One of the most important properties for describing the failure criteria of materials is the fracture toughness. It describes the ability of a material containing a crack to resist fracture and it may be a function of loading rate and temperature. The fracture toughness of a material can be established by measuring the stress intensity factor at incipient crack initiation.

In some materials, such some aluminium alloys (e.g. (Loya and Fernández-Sáez, 2008)), dynamic fracture toughness value at high loading rates may be lower than its quasi-static counterpart. That means, designing to quasi-static values might be non-conservative and even unsafe. 
A dynamic event is not just a fast static process. Inertia and elastic wave propagation effects have to be taken into account. According to (Ireland, 1976), if the time-to-fracture is longer than three times the time of the characteristic oscillation $\tau$, then a static evaluation of the force signal gives sufficiently accurate toughness values. However, it is possible to induce crack initiation for times $t_{f}<3 \tau$ at higher loading rates or altering the specimen dimensions. Under this condition, a dynamic analysis is necessary.

Two methods have been used to determine the dynamic stress intensity factor: impact response curves (Kalthoff, 1990) and key curves (Böhme, 1990). The impact response curve is the true dynamic time variation of the stress intensity factor for a stationary crack determined through analysis, numerical simulation or experimental measurements. Measuring only the time to initiate the crack, the dynamic stress intensity factor can be read-off from the impact response curve. In the key curve method, the impact event is modelled with a spring-mass model and an estimate of the stress intensity factor is obtained from it and compared with the dynamic stress intensity factor from analysis, numerical simulation or experimental measurements.

Theories about failure under dynamic conditions based on fracture mechanics are relatively new. Therefore, many empirical methods have been used in evaluating the susceptibility of materials and structures to dynamic failure. Here, a brief review of these empirical criteria and the experimental procedures for analysing the dynamic fracture is presented.

The following references are fundamental to understand the physics that underlay dynamic fracture problem. (Freund, 1990) is a key book that gives a through and comprehensive descriptiion of dynamic fracture mechanics, while (Ravi-Chandar, 2004) provides a very-well presented overview of the basics and an extensive review of the experimental techniques used for studying dynamic fracture.

Note that this $\mathrm{PhD}$ thesis is only constrain to study Mode-I fracture with increasing loading-rates. 


\subsubsection{Dynamic fracture criteria for a stationary crack}

As in the case of quasi-static fracture, for Mode-I, the asymptotic stress field near a stationary crack tip is be expressed by

$$
\sigma_{\alpha \beta}(r, \theta)=\frac{K_{I}^{d y n}(t)}{\sqrt{2 \pi r}} f_{\alpha \beta}^{I s}(\theta)+\ldots \quad \text { as } r \rightarrow \theta
$$

where $K_{I}^{d y n}(t)$ is the Mode-I dynamic stress intensity factor. The angular variation of the function $f_{\alpha \beta}^{I s}(\theta)$, considering that Greek subscripts take the range 1,2 , is

$$
\begin{aligned}
& f_{11}^{I s}(\theta)=\cos \frac{1}{2} \theta\left(1-\sin \frac{1}{2} \theta \sin \frac{3}{2} \theta\right) \\
& f_{22}^{I s}(\theta)=\cos \frac{1}{2} \theta\left(1+\sin \frac{1}{2} \theta \sin \frac{3}{2} \theta\right) \\
& f_{12}^{I s}(\theta)=\cos \frac{1}{2} \theta \sin \frac{1}{2} \theta \cos \frac{3}{2} \theta
\end{aligned}
$$

Comparing to quasi-static, two main changes appear in the dynamic field:

- The amplitude of the singularity, that is the dynamic stress intensity factor $K_{I}^{d y n}(t)$, is a function of time.

- Due to the time-dependent character of the problem, the dynamic stress intensity factor is valid only within a limited region, which must be determined for each problem.

The dynamic fracture criterion has been traditionally understood as a combination of three parts: a dynamic fracture-initiation criterion, a dynamic fracturepropagation criterion and a dynamic fracture-arrest criterion. The three criteria can be imposed independently on the growing crack. Corresponding to each criterion, dynamic fracture-initiation toughness $K_{I d}$, dynamic fracture-propagation toughness $K_{I D}$ and dynamic fracture-arrest toughness $K_{I a}$ are defined as independent material properties. The process for imposing of the fracture criteria is shown schematically in Figure 2.1. Fracture initiation occurs at a value of $K_{I d}\left(\dot{K}_{I}^{d y n}, T\right)$. Once the fracture has been initiated then the solution jumps to a point $\left(v / C_{R}, K_{I D}\right)$ on the dynamic fracture growth curve, being $v$ the crack 
propagation velocity and $C_{R}$ the Rayleigh wave velocity on the crack surface. The crack growth arrests if the stress intensity factor reaches the value $K_{I a}(T)$. Note that the fracture initiation point is not on the curve characterising the dynamic fracture criterion: $K_{I D}\left(v \rightarrow 0 ; \dot{K}_{I}^{d y n}, T\right) \neq K_{I d}\left(\dot{K}_{I}^{d y n}, T\right)$. The crack will jump to a large finite velocity immediately upon inititation as indicated by the blue arrow in Figure 2.1.

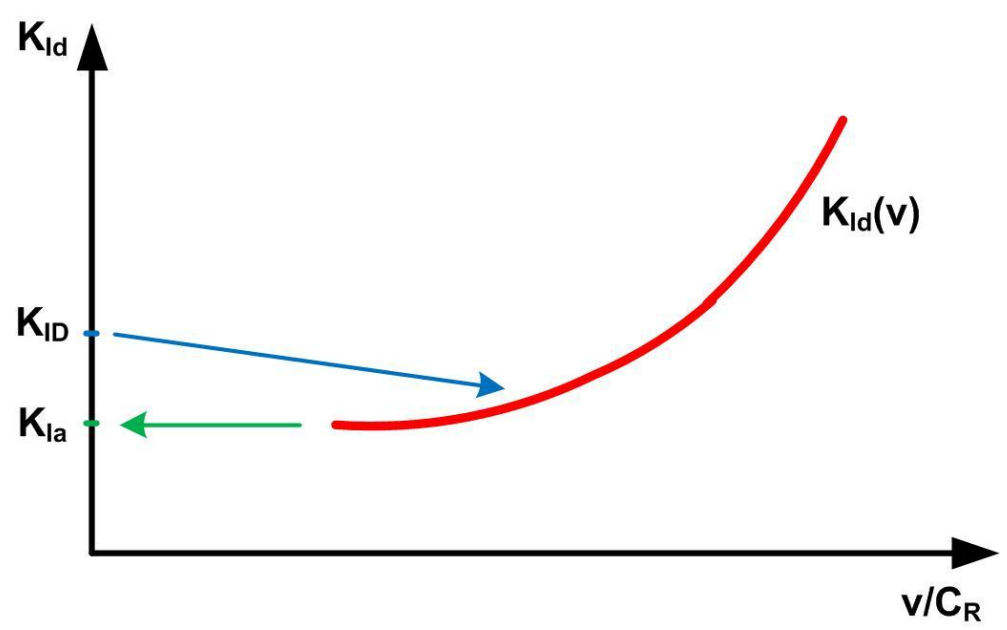

Figure 2.1. Dynamic fracture criterion.

This PhD thesis is focused on the study of the determination of the dynamic fracture-initiation toughness of high-strength materials. It has long been recognised (Freund, 1990; Freund et al., 1981) that the dynamic fracture-initiation toughness may be dependent on the loading rate and, in certain materials, may be drastically different from the fracture-initiation toughness obtained under quasi-static conditions.

The dynamic fracture-initiation toughness, $K_{I d}$, is the critical stress intensity factor at the time of fracture, $t_{f}$,

$$
K_{I d}=K_{I}^{d y n}\left(t=t_{f}\right)
$$

Since the state of stress near the crack tip is described in terms of dynamic stress intensity factor (see equation (2.1)), fracture initiation can be identified with the stress intensity factor reaching a critical value. That is an extension of the Irwin 
criterion (Irwin, 1957) used in the case of quasi-static fracture. Hence, the fractureinitiation criterion can be postulated as follows,

$$
K_{I}^{d y n}\left(t_{f}\right)=K_{I d}\left(\dot{K}_{I}^{d y n}, T\right)
$$

The right-hand side of equation (2.4) represents the dynamic fracture-initiation toughness being its dependence on the loading rate and temperature indicated through the arguments. The left-hand side represents the applied dynamic stress intensity factor at time $t_{f}$, that is when the crack starts to grow.

Since the fracture initiation is being evaluated, the stress intensity factor for a stationary crack is

$$
K_{I}^{d y n}\left(t=t_{f}\right)=P\left(t_{f}\right) \sqrt{\frac{2}{\pi(L+l)}}
$$

being $P$ the load on the crack surface at a point $L$ behind the crack tip. The variation of the dynamic stress intensity factor is given by

$$
K_{I}^{d y n}(t, 0)=P(t) \sqrt{\frac{2}{\pi L}} \quad \text { for } t \leq t_{f}
$$

Imposing the dynamic fracture initiation criterion at $t=t_{f}$, fracture propagation begins when

$$
P\left(t_{f}\right) \sqrt{\frac{2}{\pi L}}=K_{I d}\left(\dot{K}_{I}^{d y n}, T\right)
$$

If the load $P$ at fracture initiation is measured, equation (2.7) provides a convenient way of determining the dynamic fracture-initiation toughness and its dependence on the strain-rate and temperature.

In metallic materials, such as aluminium alloys, steels, titanium alloys, etc., fracture initiation depends on both the constitutive and micromechanical characteristics of the material (Freund, 1990). Thus, the dynamic fracture toughness may be affected by additional mechanisms other than pure elastic inertia as observed in ceramics and brittle polymers (Liu et al., 1998; Ravi-Chandar and Knauss, 1984; Rittel and Maigre, 1996). In the case of metallic materials, there may be a finite time necessary to attain a critical stress (or strain) to nucleate a void at a given distance 
from the crack tip and to grow it to a critical size leading to the failure of the ligament between the crack tip and the void. That would be its fracture initiation.

\subsubsection{Experimental procedures for dynamic fracture}

The experimental procedures used for analysing the material dynamic fracture behaviour comprise of high-rate experimental devices, appropriate specimens, reliable high-rate measuring and recording systems and hybrid experimentalnumerical techniques.

In order to simulate dynamic loading situations under well-defined conditions in the laboratory, a quite extensive variety of testing devices, such as fast-driven servohydraulic testing machines, pendulums, drop weight towers, Hopkinson bars, gas guns and explosive-driven machines, have been designed and modified for different loading rates. Over the years, these experimental techniques have been further developed in order to obtain more detailed and reliable information.

For studying the material fracture behaviour in Mode-I, precracked specimens should be used. In quasi-static regime, the most commonly used geometry is the compact specimen (C(T)) (E399-12e3, 2012). At higher loading rates, this type of specimen has also been used for experiments with fast-driven servohydraulic machines. However, when using $\mathrm{C}(\mathrm{T})$ specimens at higher loading rates, a mixedmode fracture initiation can be produced because of a crack initiation at a certain angle of deviation from the crack plane. Therefore, at higher loading rates, bend specimens $(\mathrm{SE}(\mathrm{B}))$ or precracked Charpy specimens are the most frequently used for dynamic fracture testing.

In order to study the dynamic fracture of the specimen, it is necessary to determine the crack tip loading. And for that, the measuring system should be close to the crack tip, inertia free and with high time resolution. Among the different measuring techniques of experimental mechanics, the ones normally used for dynamic fracture are based on strain measurements (electromechanical methods), on consumed energies (thermomechanical methods), on displacements (optomechanical methods) or on components of the stress-strain field (purely optical methods). 
The most extended electromechanical method is the strain gauge measurement (Böhme and Kalthoff, 1982). In this method, strain gauges are attached close to the crack tip in the K-dominated region but outside the crack tip plastic zone. While the measurement is done in the range of validity of linear elastic fracture mechanics (LEFM), there is a direct proportionality between the stress intensity factor and the strain gauge output voltage. The absolute value of the stress intensity factor can be obtained with a static calibration previous to the dynamic fracture test. Representative examples of this particular methodology can be found in (Anderson and Rosakis, 2005; Joudon et al., 2014; Kalthoff, 1985; Rubio-González et al., 2008; Shuter, 2002; Xu et al., 2012; Yokoyama, 1993)

Purely optical methods are also very extended since, in general, they are inertia free. The shadow optical method of caustics (Kalthoff, 1986; Manogg, 1964) was the first successful optical method. The method is sensitive to stress gradients and therefore is an appropriate tool for quantifying crack tip stress. The coherent gradient sensing method (CGS) (Rosakis, 1993; Tippur et al., 1991a, b) is other well-known optical method to obtain a full-field characterisation of the crack-tip subjected to transient loading. Over the years, high speed cameras are getting more powerful, being able not only to directly measure displacement variations but to obtain the crack tip strain fields by using digital image correlation (DIC) softwares.

Nowadays, the Mode-I dynamic stress intensity factor history $K_{I}^{d y n}(t)$ is usually calculated via numerical finite element simulations, which to take into account wave propagation and inertia effects.

\subsection{Literature review}

As it has been mentioned before, there are several experimental procedures for analysing the dynamic fracture and they are frequently combined with numerical techniques. Here, a brief literature review of the most significant studies on the experimental determination of dynamic fracture toughness is presented. 
(Couque et al., 1992a) investigated the use of coupled pressure bars (CPB) to induce dynamic fracture in tough materials using small compact specimens of a nuclear pressure vessel steel and of a low-strength high-toughness steel (Couque et al., 1992b). The CPB technique consisted on two pressure bars to store energy by preloading. The dynamic fracture initiation toughness was deduced from the simulation of the fracture experiment with a dynamic viscoplastic finite-element fracture code. In 1994, (Couque, 1994) investigated the effect of loading rate on the plane stress fracture toughness properties of thin 2219-T87 aluminium alloy plate with center-cracked panels using the same experimental technique. For such material, fracture-initiation and propagation toughnesses were found to increase with an increased loading rate.

A novel impact bend test procedure for determining the dynamic fracture-initiation toughness of fatigue-precracked bend specimen of a 7075-T6 aluminium alloy, a Ti-6246 alloy and an AISI 4340 steel, adopting a special arrangement of the split Hopkinson pressure bar was described by (Yokoyama, 1993). The dynamic stress intensity factor history was evaluated by means of a dynamic finite element technique and the onset of crack initiation was detected using a strain gauge attached near the crack tip.

(Owen et al., 1998) undertook an experimental investigation to characterise the dynamic fracture characteristics of 2024-T3 aluminium thin sheets. The critical dynamic stress intensity factor was determined over a wide range of loading rates using a servo-hydraulic loading frame and a split Hopkinson bar in tension. A dramatic increase in the critical dynamic stress intensity factor was observed with increasing loading rate.

The Master Curve is a concept developed by (Wallin, 1998) to quantify the variation of fracture toughness with the temperature throughout the ductile-to-brittle transition region. (Viehrig et al., 2002) linked the Master Curve concept and Charpy impact test to determine dynamic fracture mechanical parameters of a nuclear reactor pressure vessel steel.

(Shuter, 2002) studied the dynamic fracture behaviour of a low alloy pressure vessel steel measuring the load-time data by two different methods: a piezoelectric 
force transducer mounted on the specimen striker and strain gauges on the specimen surface near the crack tip. It was found that at higher velocities the transducer was affected by the inertia of the specimen.

A new method involving direct measurement of the load-line displacement during Charpy testing was developed by (Tronskar et al., 2002). The method used a He$\mathrm{Ne}$ laser interferometer to measure displacement and in addition allowed detection of crack initiation.

(Rubio et al., 2003) presented a procedure for measuring the dynamic fractureinitiation toughness of AA7075-T651 aluminium alloy based on three-point bending tests using a modified split Hopkinson pressure bar (SHPB). The stress intensity factor was calculated and compared by three different methods: using the input load from the SHPB, obtaining the load point displacement from high speed camera and measuring the crack mouth opening displacement (CMOD) by high speed photography. The results were evaluated by a $2 \mathrm{D}$ numerical analysis of the dynamic bending fracture test and the time to fracture was obtained from a crack gauge.

(Loya et al., 2003) performed a 3D numerical analysis of dynamic three-point bending tests carried out in a modified SHPB to obtain the fracture-initiation toughness of AA7075-T651 aluminium alloy at high strain rates. They examined the relationship between the stress intensity factor and the CMOD and compared those results with the 2D analysis performed by (Rubio et al., 2003). Their results indicated that the use of $2 \mathrm{D}$ plane strain solutions can underestimate the fracture properties. In (Loya and Fernández-Sáez, 2008), the authors presented a numerical analysis of the 3D effects of the previous tests modelling the whole experimental device. The possible effect on the CMOD and the critical stress intensity factor of the thickness of the specimen, the crack-to-length ratio and impact velocity was studied.

A new procedure for measuring the dynamic fracture toughness using a SHPB loaded instrumented Charpy impact test was presented (Jiang et al., 2004). The authors proposed an approximate formula for calculating the dynamic stress intensity factor. One year later, (Rokach, 2005) discussed that all of the tests 
reported by (Jiang et al., 2004) were one-point bending results and since the finite element analysis presented contained several important drawbacks, the theoretical model proposed by (Jiang et al., 2004) hardly could be accepted as a test of accuracy.

(Anderson and Rosakis, 2005) compared and presented the advantages and disadvantages of three different techniques for measuring dynamic stress intensity factor time histories of dynamically loaded starionary Mode-I cracks of pre-cracked 6AI-4V titanium alloy specimens: crack opening displacement (COD), dynamic strain gauge measurement and coherent gradient sensing (CGS) techniques.

(Rittel et al., 2005) compared the available data on static properties of infiltrated TiC-1080 steel cermets with some results the authors obtained on the dynamic mechanical and fracture behaviour of such materials. They compared quasi-static three-point bending results with the dynamic fracture toughness results determined from one-point impact bend tests. The procedure of the dynamic tests was described in detail by (Weisbrod and Rittel, 2000), where the main idea was that the evolution of the stress intensity factor can be determined if the loading force was known and if the response of the structure to unit impulse was determined. Such an idea was based on the linearity of the fracture process, that meant, LEFM assumptions. The validity of such procedure was assessed in (Rittel and Weisbrod, 2001) where it was applied to characterise the dynamic fracture toughnes of a commercial tungsten base heavy alloy, and in (Rittel et al., 2002) where it was applied for the assessment of the dynamic fracture energy of notched Charpy A508 steel specimens. In (Rittel and Rosakis, 2005), the results of dynamic fractureinitiation toughness of a bulk metallic glass system and a composite obtained by the one-point impact technique were compared with the ones obtained by coheren gradient sensing interferometry (CGS).

A new four-point bending experimental technique, based on a SHPB, was developed by (Weerasooriya et al., 2006) to determine the dynamic fracture toughness of ceramics at high rates under valid conditions, which was demonstrated through the determination of the dynamic fracture toughness as a function of loading rate for a silicon carbide ( $\mathrm{SiC}-\mathrm{N})$. 
(Jiang and Vecchio, 2007) performed pulse-shaped and unshaped pulse dynamic fracture tests using the experimental technique presented by (Weerasooriya et al., 2006). In such investigation, the authors affirmed that the time required for attaining stress equilibrium was reduced by pulse shaping. That is in pulse-shaped bending tests the specimen was more likely to attain stress-state equilibrium than in an unshaped incident pulse tests.

(Foster et al., 2011) adopted the four-point experimental technique of (Weerasooriya et al., 2006) for dynamic fracture tests of ceramic materials to measure the dynamic crack initiation toughness of 4340 high-strength steel. In this case, like in (Jiang and Vecchio, 2007), a pulse shaper was used to achieve constant loading rate at the crack tip and dynamic equilibrium across the specimen.

The dynamic response of fatigue damaged 6061-T6 aluminium alloy and AISI 4140-T steel to impact loading using a SHPB was obtained by (Rubio-González et al., 2008). The dynamic stress intensity factor history was determined using the finite element method based on the measured dynamic loads and the time of crack initiation was measured by a strain gauge.

The fracture behaviour, both in static and dynamic conditions, of high strength armour Steel Armox 500T three-point bending specimens was determined by (Gálvez et al., 2009). Displacements, velocities and rupture time measured by detection sensors attached to a SHPB were compared with 2D numerical simulations.

(Xu et al., 2012) proposed a novel approach to determine dynamic fracture toughness of high strength steel $40 \mathrm{Cr}$ using the SHTB technique and an hybrid experimental-numerical method. For such a purpose, curves of dynamic stress intensity factor history were obtained by full-scale 3D finite element simulation and dynamic fracture toughness was determined according to the fracture-initiation time measured by strain gauge method. In this investigation, the specimens were dog-bone shaped central fatigue-precracked plates.

A drop tower was used to obtained the dynamic fracture-initiation of 2024-T4 and 7075-T6 aluminium alloys three-point bending specimens at different loading rates 
by (Xing et al., 2013). In this case, authors considered the specimens to be in the state of dynamic equilibrium, that is, they considered the quasi-static equation as acceptable.

(Joudon et al., 2014) developed and validated a specific three point bending test associated with local measurements by strain gauge technique and high speed cinematography to determine de Mode-I dynamic stress intensity factor of advanced epoxy resins.

(Wang et al., 2015) proposed the use of an experimental-numerical-analytical method to determine the dynamic initiation and propagation toughness of rock, using cracked straight-through flattened Brazilian discs diametrically impacted by a SHPB. In this study, the crack initiation moment was measured with a crack propagation gauge and the dynamic stress intensity factor histories were obtained by finite element analysis with inputs of the dynamic histories recorded in the experiments.

(Henschel and Krüger, 2015) proposed a method for determining the crack initiation toughness of four-point bending precracked Charpy specimens by using a SHPB. From the wave analysis they observed an initial force disequilibrium at the onset of loading, but they concluded that the dynamic force equilibrium was achieved before the crack initiation took place.

Very recently, (Faye et al., 2016) reported a view to understanding the phenomenon of increase of fracture toughness with loading rate at very high rates in PMMA. In this investigation, the authors took advantage of the optical transparency of PMMA to try to detect fracture initiation at the midplane of the specimen.

As it has been demonstrated above, although several methods have been suggested and implemented and even it has long been studied, nowadays there is no standardised method for determining the dynamic fracture-initiation toughnes of materials. 


\subsection{Problem statement}

In view of the literature review, one can see that a combination of a wide spectrum of experimental techniques and diverse numerical procedures have been used, in the past and in recent years, to obtain the dynamic fracture-initiation toughness of quasi-brittle materials. What it has been understood as improvements in these two fronts, experimental and numerical, with respect to what has been reviewed are presented subsequently.

\subsubsection{Experimental method and procedures}

Often, different measurement techniques are employed to obtain such a property under different loading rates, which might lead to inconsistent results. This PhD thesis has tried to cope with this challenge by always employing the same technique for diffrerent loading rates. Pre-cracked three-point bending specimens loaded with increasing velocities have been tested trying to always mantain the same configuration. The load calculated from a strain gauge attached close to the crack tip has been the measuring technique selected to obtain the dynamic fracture-initiation toughness in every test, since it could be employed even in the open-air explosive tests.

\subsubsection{Numerical modelling of the constitutive and fracture behaviour}

In general, problems that deal with linear elastic fracture mechanics are modelled using elastic constitutive equations in finite element codes. Although one could think that it could be an appropriate way of approaching such a problem, sometimes small areas where plasticity is developed may arise. Further, often the comparison of experimentally-measured response and its numerical counterpart are not assessed. Here, without assuming in advance that the materials studied would remain in elastic regime, a complete set of experiments that allow for the constant identification of elastic-viscoplastic models has been carried out. Then, the models have been used to analyse the dynamic fracture behaviour of materials. 
Numerical methods are often employed to obtain the dynamic fracture toughness of materials. In this study, displacement and stress extrapolation methods computed from full three-dimensional finite element simulations, that take into account the transient dynamics of the problem, have been employed to estimate the dynamic fracture-initiation toughness and such results have been compared with the experimental values. Furthermore, ductile fracture criteria for uncracked solids have been implemented in order to check their prediction capabilities in a problem that is dominated by brittle fracture. A numerical study with two stressbased failure criteria of the finite element simulations conducted on the three-pointbending tests with variying loading rates has been performed. Although unorthodox, this approach has been proven to give very reasonable results if the adecuate failure criterion is chosen.

\subsection{Materials Description}

Two already-known armour metals were selected in order to carry out this study. The first material was selected because of its very mild rate effects (Rodríguez et al., 1994). Such found-aspect was considered an adequate characteristic to validate the experimental procedures described in this document. Once the developed experimental techniques were validated, they were brought into play in order to obtain the dynamic fracture-initiation toughness of a rate-dependent material at different loading rates. A more detailed description of both materials is described below.

\subsubsection{Aluminium 7017-T73 alloy}

Although a regular AA7017 alloy is considered a medium-strength aluminium alloy, because of the T73 heat-treatment the AA7017-T73 alloy is considered one of the highest-strength commercial aluminium alloys. This is the reason for being mainly used in armoured vehicles, light weight bridges and blast barricades for mines, as well as in various automotive and general engineering applications. It contains zinc as the primary alloying element, magnesium and chromium in a lesser proportion. Magnesium produces a marked improvement in precipitation hardening 
characteristics, whereas chromium provides an increase of the stress corrosion cracking resistance. The detailed chemical composition in weight percentage is presented in Table 2.1. The alloy is solution heat-treated with an artificial aging. This T73 heat-treatment leaves the alloy beyond the point of maximum strength and achieves the best stress corrosion resistance. Its typical mechanical properties are summarised in Table 2.2.

Initially, the material was selected because its mechanical behaviour was found to be nearly independent from the strain rate (Rodríguez et al., 1994). This noteworthy aspect makes such a material be the perfect candidate in validating an experimental procedure at different loading-rates.

Table 2.1. Certified chemical composition of AA7017-T73 alloy (weight \%) (The Aluminum Association, 2001).

\begin{tabular}{cccccccc}
\hline $\mathrm{Zn}$ & $\mathrm{Mg}$ & $\mathrm{Fe}$ & $\mathrm{Si}$ & $\mathrm{Cu}$ & $\mathrm{Mn}$ & $\mathrm{Cr}$ & $\mathrm{Zr}$ \\
\hline 5.1 & 2.4 & 0.3 & 0.16 & 0.12 & 0.22 & 0.16 & 0.12 \\
\hline
\end{tabular}

Table 2.2. Mechanical properties of AA7017-T73 alloy (The Aluminum Association, 2001).

\begin{tabular}{cccc}
\hline $\mathrm{E}(\mathrm{GPa})$ & $\sigma_{0.2}(\mathrm{MPa})$ & $\sigma_{\text {UTS }}(\mathrm{MPa})$ & $\varepsilon_{f}(\%)$ \\
\hline 71 & 450 & 499 & 12 \\
\hline
\end{tabular}

\subsection{2. $\operatorname{Mars} \otimes 240$ armour steel}

The steels called Mars ${ }^{\circledR}$ (Creusot-Loire) belong to the well-known armour steels for light armoured vehicles, such as APCs (armoured personnel carriers) or IFVs (infantry fighting vehicles). Such steels should resist without cracking hits of largecalibre small arms bullets (survivability requirement) and meet the welding requirements (in case of welds tempering).

The most typical armour steel of this grade is Mars $® 240$ (France). This alloy is a high-hardness steel with optimal compromise ballistic resistance properties and workability. Typical values of the chemical composition in weight percentage are presented in Table 2.3. The heat treatment consists of austenisation, quenching 
and finally tempering at low temperature. Its mechanical properties are shown in Table 2.4. In contrast to the AA7017-T73 alloy, the Mars ${ }^{\circledR} 240$ steel is a ratedependent material (Nahme and Lach, 1997).

Table 2.3 Chemical composition of Mars ${ }^{\circledR} 240$ steel (weight \%) (ASMInternational, 2012).

\begin{tabular}{cccccccc}
\hline $\mathrm{C}$ & $\mathrm{Cr}$ & $\mathrm{Ni}$ & $\mathrm{Mo}$ & $\mathrm{Mn}$ & $\mathrm{S}$ & $\mathrm{P}$ & $\mathrm{Si}$ \\
\hline 0.30 & 1.6 & 1.8 & 0.6 & 1.00 & 0.002 & 0.010 & 0.4 \\
\hline
\end{tabular}

Table 2.4. Mechanical properties of Mars $® 240$ steel (ASM-International, 2012).

\begin{tabular}{c|cccc}
\hline As supplied & $\mathrm{H}(\mathrm{HB})$ & $\sigma_{0.2}(\mathrm{MPa})$ & $\sigma_{U T S}(\mathrm{MPa})$ & $\varepsilon_{f}(\%)$ \\
\hline Minimum values & $477-534$ & $\geq 1100$ & $\geq 1600$ & $\geq 9$ \\
\hline
\end{tabular}





\section{CHAPTER 3}

\section{EXPERIMENTAL CHARACTERISATION OF THE MATERIALS}

An experimental program was designed to characterise the rate-dependent plasticity and fracture response, as well as to study the effect of anisotropy of the armour materials. For such a purpose, uniaxial tensile (UT) tests were performed at low, intermediate and high strain rates and at different temperatures. In order to study the anisotropy of the materials, UT specimens extracted at $0^{\circ}, 45^{\circ}$ and $90^{\circ}$ with respect to the rolling direction were tested at low strain rates. For each experiment, at least three repetitions were performed. Prior to testing, a random speckle pattern with black speckles on a white background were painted on the specimens in order to use a DIC-based extensometer. All the experiments were carried out at the Laboratoire de Mécanique des Solides (LMS) at l'École Polytechnique of the Université Paris-Saclay in France. 


\subsection{Uniaxial tension specimens}

The experimental program included the tensile testing of sheet specimens under uniaxial loading at three different strain rates and temperatures. Uniaxial Tension (UT) specimens with a $20 \mathrm{~mm}$ gauge length were obtained from a rolled plate by Electro Discharge Machining (EDM). Specimens as shown in Figure 3.1, were extracted from three different directions: $0^{\circ}, 45^{\circ}$ and $90^{\circ}$; being $0^{\circ}$ the rolling direction and $90^{\circ}$ the transverse direction. Please note that the gauge section width of the Al7017-T73 alloy specimens was larger than that in the Mars $® 240$ steel specimens. The intention was to use the same Hopkinson bar set up for both materials. However, this came at a downside. The resolution of the data to be collected in the case of the Al7017-T73 alloy was going to be less of that of the Mars $₫ 240$ steel. In order to improve such a resolution, larger loads were needed, thus the width increased (see Figure 3.1).

A random black speckle pattern on a thin layer of white matt paint was applied to the specimen surface in order to measure the surface displacements through Vic2D (Correlated Solutions) digital image correlation (DIC).

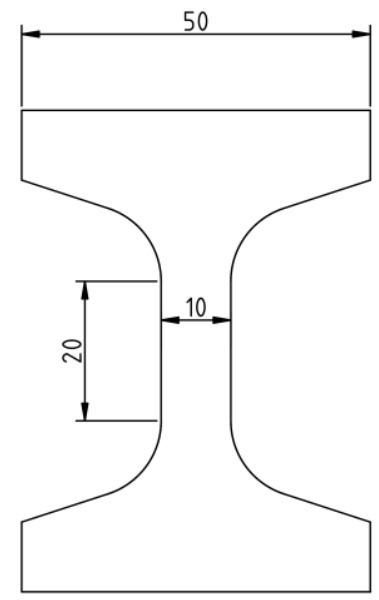

(a)

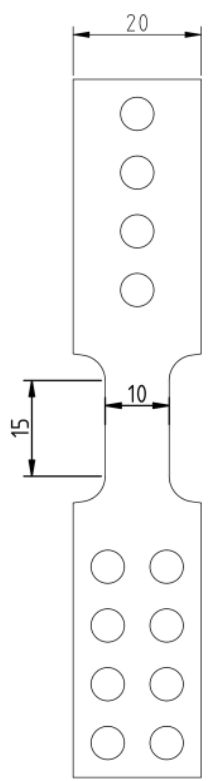

(b)

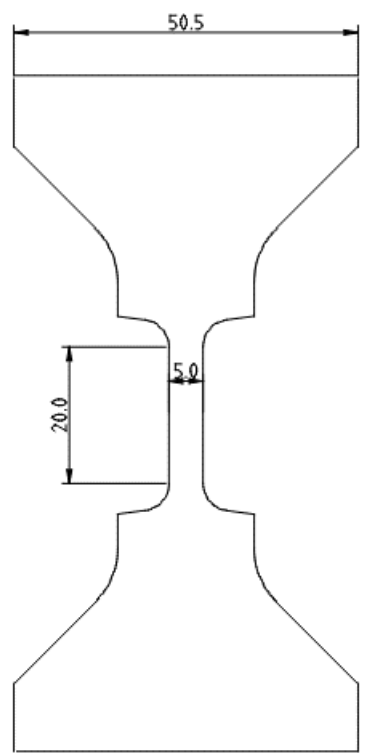

(c)

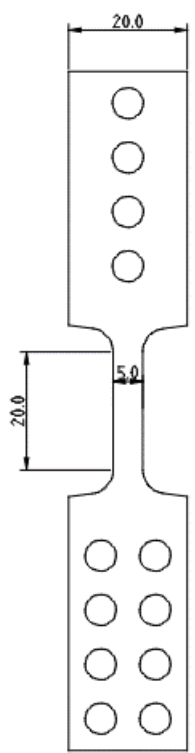

(d)

Figure 3.1. AA7017-T73 alloy (a, b) and Mars ${ }^{\circledR} 240$ (c, d) UT specimens for the (a, c) quasi-static, $(a, c)$ intermediate and $(b, d)$ dynamic testing. 


\subsection{Experimental set-up for low strain rates}

The experiments at low strain rates were carried out on a MTS hydraulic testing machine with a $250 \mathrm{kN}$ load cell (Figure 3.2). Two custom-made high pressure clamps were used to ensure the specimen alignment with respect to the loading frame (see Figure 3.3a). The experiments were run under displacement-control at an actuator velocity of $1 \cdot 10^{-5} \mathrm{~m} / \mathrm{s}$, which resulted in an average strain rate of about $5 \cdot 10^{-4} \mathrm{~s}^{-1}$ in the gauge section of the specimens. To observe the displacement field, the software VicSnap (Correlated Solutions) was employed to acquire $2 \mathrm{fps}$ by a AVT Pike F-505B/C camera with a resolution of $2452 \times 2054$ pixels.

In order to obtain the thermal softening of the material model, additionally, an environmental chamber (Figure 3.3b) was used to perform high temperature experiments of the AA7017-T73. These experiments were carried out at room temperature, $75^{\circ} \mathrm{C}$ and $150^{\circ} \mathrm{C}$. The maximum temperature this environmental chamber could operate was $200^{\circ} \mathrm{C}$. That is why in the case of the experiments of the Mars ${ }^{\circledR} 240$ steel, the thermal softening part was extracted from the experiments at high strain rate.

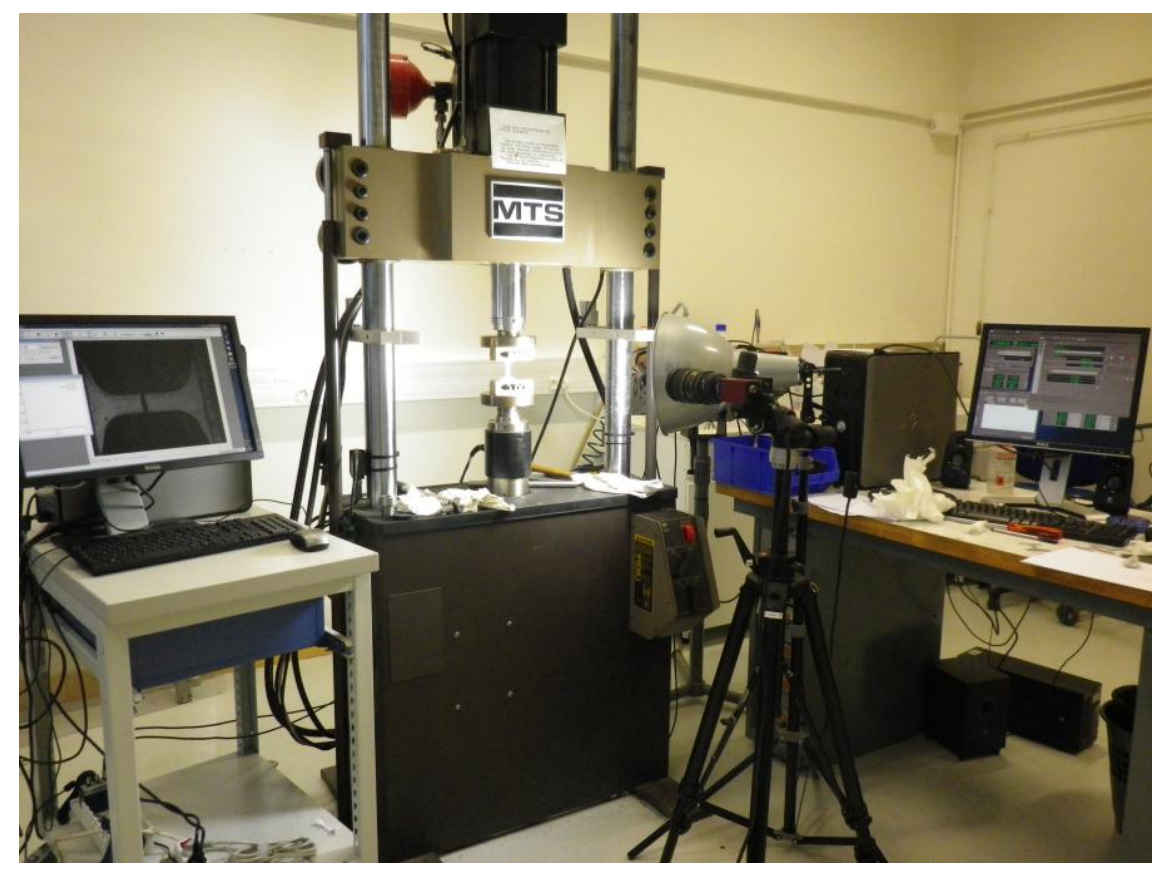

Figure 3.2. Experimental set-up for UT tests at low strain rates. 
(a)

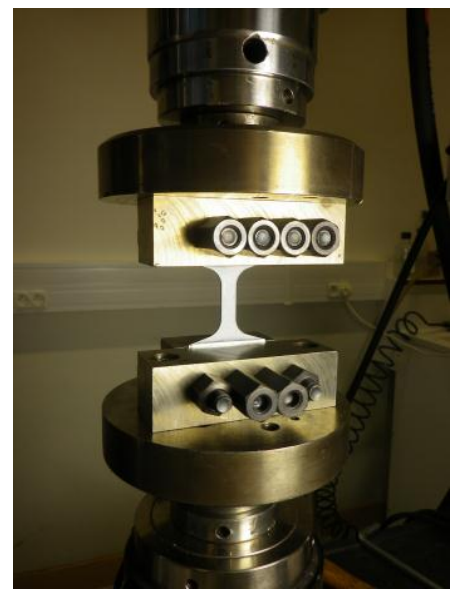

Figure 3.3. (a) Custom-made high pressure chamber for high temperature experiments. (b)

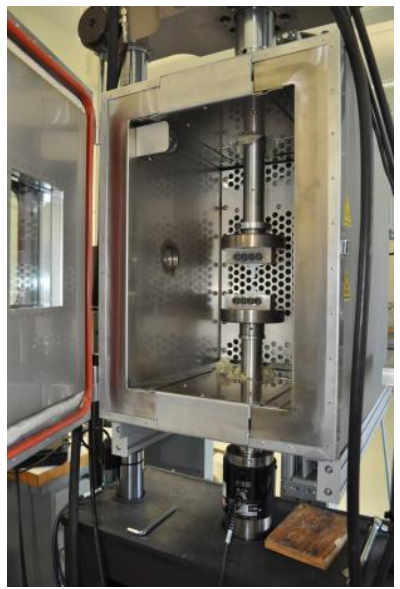

clamps. (b) The environmental

\subsection{Experimental set-up for intermediate strain rates}

The intermediate strain rate experiments were conducted on the same hydraulic testing machine as the low strain rate experiments were. The UT specimens were loaded at a cross-head velocity of $0.01 \mathrm{~m} / \mathrm{s}$, resulting in an average strain rate of $0.5 \mathrm{~s}^{-1}$. A high speed camera (Vision Research, Phantom v7.3., Figure 3.4a) was used to record $1000 \mathrm{fps}$ with a resolution of $800 \times 600$ pixels. The image acquisition was triggered by the rise in the force signal measured by the load cell. The equipment included high-powered lamps that were focussed on the specimen (Figure 3.4b).

(a)

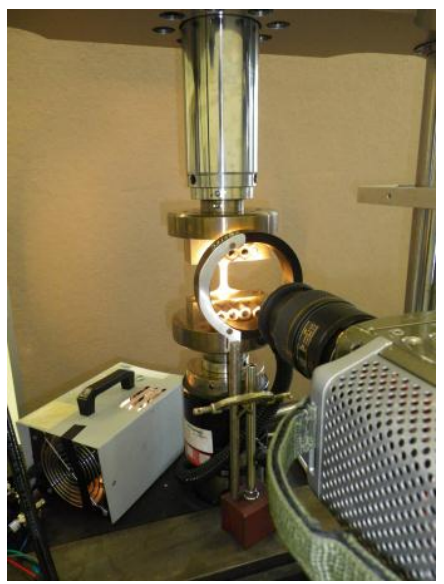

(b)

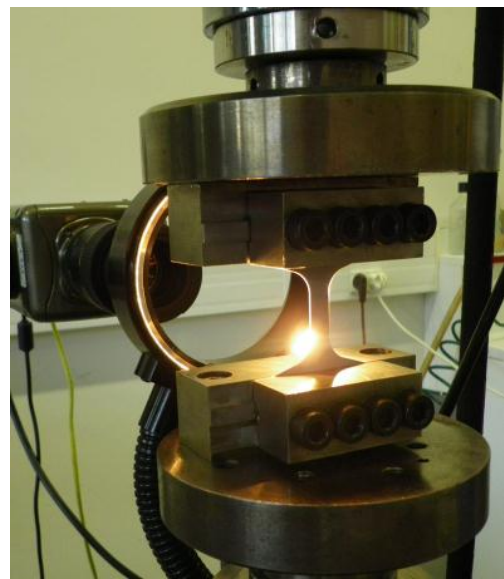

Figure 3.4. The high speed camera and the high-powered lamps used for recording intermediate and high strain rate experiments. 


\subsection{Experimental set-up for high strain rates}

The experiments at high strain rates were carried out on a split Hopkinson bar (SHPB) system (Kolsky, 1949) equipped with a load inversion device (LID) for tensile testing, designed by (Dunand et al., 2013) and presented in (Roth et al., 2015) as well. The system (see Figure 3.5) consisted of:

- A $20 \mathrm{~mm}$ diameter steel striker bar of length $L_{s t r}=3.80 \mathrm{~m}$. It matched the input bar impedance and generated a $1.61 \mathrm{~ms}$ long loading pulse (measured wave speed of $\mathrm{c}=4725 \mathrm{~m} / \mathrm{s}$ ).

- A steel input bar of length $L_{\text {in }}=4.49 \mathrm{~m}$ and $20 \mathrm{~mm}$ diameter, for transmitting the loading pulse from the striker to the pusher, matching the impedance of the striker bar.

- A load inversion device, as shown in Figure 3.6., made from tool steel. It consisted of a pusher being held by two lubricated aluminium bearings. The right side of the specimen was clamped to the pusher with M5 screws. The compressive pulse from the input bar was transmitted into the pusher which in turn applied tensile loading to the attached sheet specimen. The opposite shoulder of the specimen was fitted into a slot machined in the output bar and clamped to it wiht M5 screws. All screw heads were counter-sunk to maintain a symmetric mass distribution with respect to the centre axis of the bar, thereby minimising the generation of bending waves through the specimen clamping. The assembly was guided through bearings with lubricated contact surfaces. The load inversion device also featured a base plate with guide blocks that prevented the out-of-plane motion of the pusher.

- A steel output bar of length $\mathrm{L}_{\text {out }}=4.35$ and $20 \mathrm{~mm}$ diameter, positioned on top of the input bar and equipped with a strain gauge located at a distance $a_{\text {out }}=320 \mathrm{~mm}$ from the specimen interface. That strain gauge was used for recording the output bar strain history. For the measured longitudinal wave speed of $c=5175 \mathrm{~m} / \mathrm{s}$, the valid theoretical duration of the testing systems was about $2 \mathrm{~L}_{\text {out }} / \mathrm{c}=1.557 \mathrm{~ms}$. 
The history of the forces acting on the output bar / specimen interface was determined based on the recordings of the output bar strain gauge, measured at an acquisition frequency of $1 \mathrm{MHz}$. Post-processing of the recorded signal was performed using the software package DAVID (Gary, 2005), which involved removing electrical noise and accounting for geometric dispersion when reconstructing the strain history $\varepsilon_{t}(t)$ at the output bar / specimen interface. Then, the history of the axial forces $F(t)$ acting on the specimen was calculated from

$$
F(t)=A_{\text {out }} E_{\text {out }} \varepsilon_{t}(t)
$$

where $E_{\text {out }}$ and $A_{\text {out }}$ denoted the output bar elastic modulus and cross sectional area, respectively.

For the displacement measurements, a high speed camera (Vision Research, Phantom v7.3.) was used for acquiring $160000 \mathrm{fps}$ with a resolution of $432 \times 32$ pixels, being the interval between images $6.25 \mu \mathrm{s}$. Two cold light sources with halogen bulbs were used to provide the required lighting. The camera was triggered when the input bar strain gauge detected the rising edge of the incident wave. The image correlation was performed with the commercial software Vic2D (Correlated Solutions). A virtual extensometer was used to determine the relative axial displacement $u(t)$ of two lines located on the specimen surface (Figure 3.7 and Figure 3.8). These experiments were carried out at an average strain rate of $250 \mathrm{~s}^{-1}$.

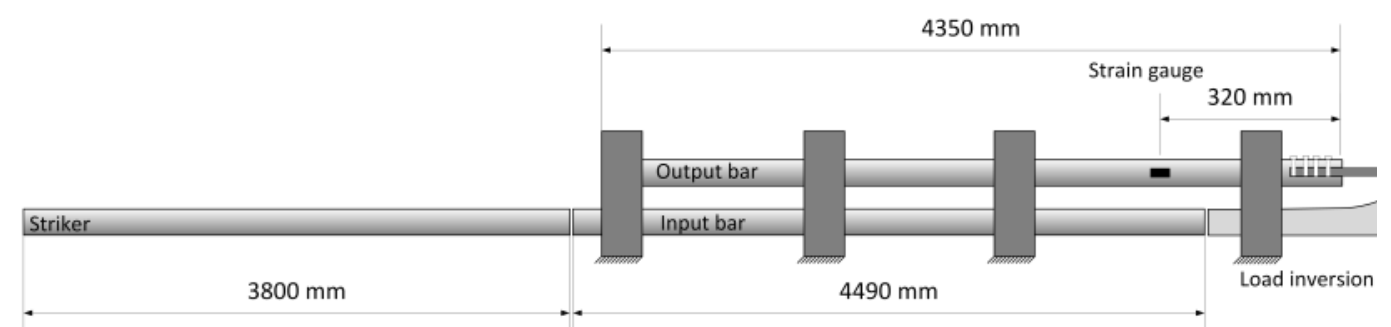

Figure 3.5. Scheme with the geometry and dimensions of the modified Split Hopkinson Pressure Bar. 


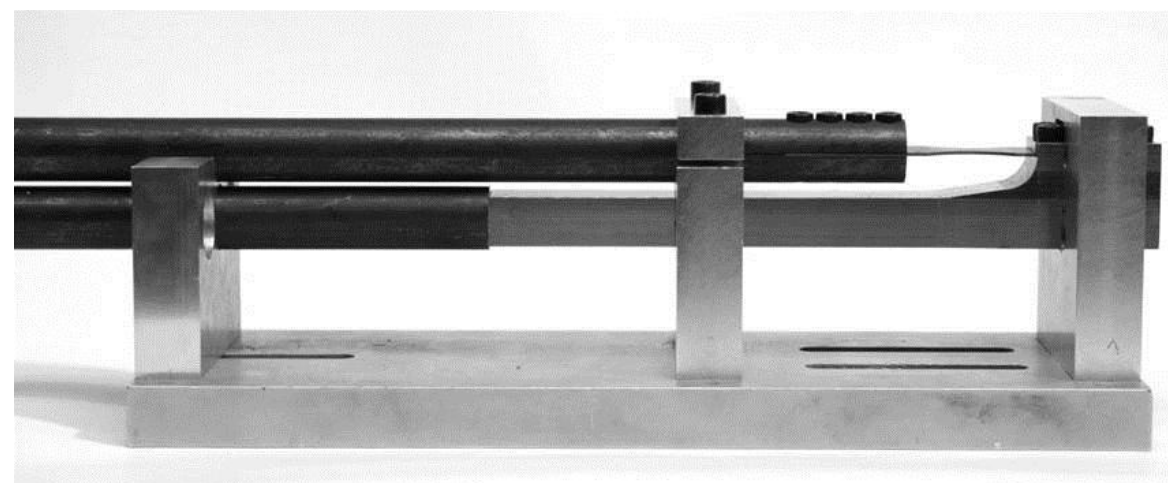

Figure 3.6. The load inversion device mounted on an independent bearing system for high strain rate tensile testing.

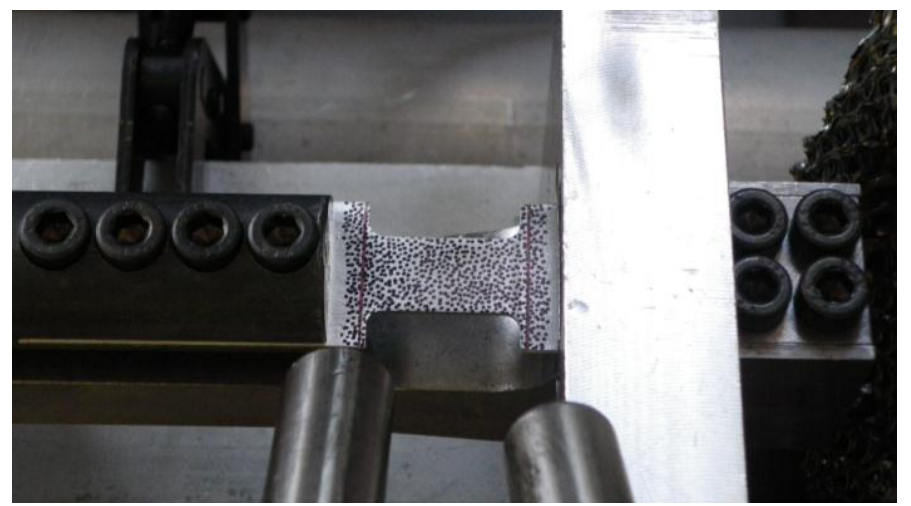

Figure 3.7. The UT specimen mounted on the set-up with two red solid lines highlighting the position of the virtual extensometer for measuring the relative displacement

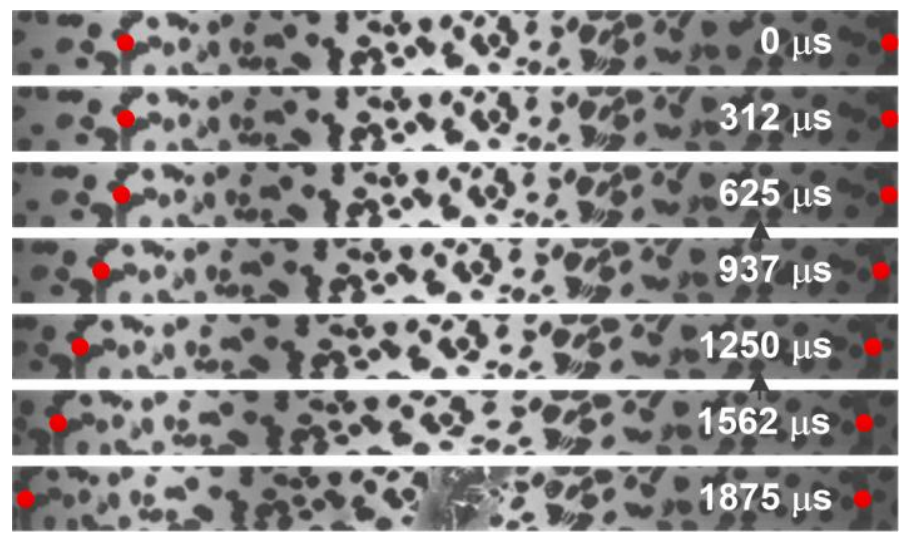

Figure 3.8. Sequence of images of an experiment at high strain rate taken with the high speed camera. 


\subsection{Results}

The presentation of the experimental results is divided into two subsections. The first describes the results obtained from the uniaxial tensile experiments for the AA7017-T73, while the second focuses on the results obtained for the Mars $₫ 240$ steel.

\subsubsection{AA7017-T73}

The engineering stress-strain curves corresponding to the uniaxial tensile quasistatic tests at $0^{\circ}$ (in black), $45^{\circ}$ (in blue) and $90^{\circ}$ (in green), as well as the fracture strain (in red dots), are shown in Figure 3.9. The results evidenced the distinctly anisotropy of the material. Such anisotropy could be described quantitatively by the Lankford coefficients ( $r$-values) and the yield stresses corresponding to the $0^{\circ}$, $45^{\circ}$ and $90^{\circ}$ orientations. Based on the assumption of plastic incompressibility, the $r$-values were then determined from the ratios of the in-plane over the throughthickness logarithmic plastic strains,

$$
r_{\theta}=\frac{\varepsilon_{p}^{w}}{\varepsilon_{p}^{t}}
$$

where $\theta$ is the direction of a vector aligned with the loading axis with respect to the rolling direction. The obtained uniaxial yield stresses $Y_{0}, Y_{45}, Y_{90}$, and Lankford coefficients $r_{0}, r_{45}, r_{90}$, are summarized in Table 3.1.

Table 3.1. Uniaxial yield stresses and Lankford coefficients of AA7017-T73 alloy.

\begin{tabular}{cccccc}
\hline$Y_{0}(\mathrm{MPa})$ & $Y_{45}(\mathrm{MPa})$ & $Y_{90}(\mathrm{MPa})$ & $r_{0}$ & $r_{45}$ & $r_{90}$ \\
\hline 434 & 400 & 413 & 0.5 & 0.84 & 0.61 \\
\hline
\end{tabular}

The obtained yield stress at $0.01 \%$ as well as the Lannkford coefficients for the three directions were different, proving the high degree of anisotropy existing in the material. Therefore, the results showed that the AA7017-T73 alloy was not only anisotropic in its yield strength but also in its plastic flow. 
Figure 3.10 shows the experimental engineering stress-strain response of the specimens oriented at $0^{\circ}$ with increasing loading rates. The quasi-static experiments at $5 \cdot 10^{-4} \mathrm{~s}^{-1}$ are plotted in black, the intermediate strain rate test performed at $0.5 \mathrm{~s}^{-1}$ are shown in blue, and the dynamic stress-strain response of the material at $250 \mathrm{~s}^{-1}$ is depicted in green. The fracture strain for all tests is identified in the plots as a red dot. As expected, since all of the curves were almost coincident, there was no significant strain-rate sensitivity.

In Figure 3.11, the experimental engineering stress-strain curves corresponding to the uniaxial tensile tests of the specimens oriented at $0^{\circ}$ at three different temperatures (at $25^{\circ} \mathrm{C}$ in black, $75^{\circ} \mathrm{C}$ in blue and $150^{\circ} \mathrm{C}$ in green) are plotted. As it can be seen, at $150^{\circ} \mathrm{C}$ the AA7017-T73 strength was largely affected by the temperature.

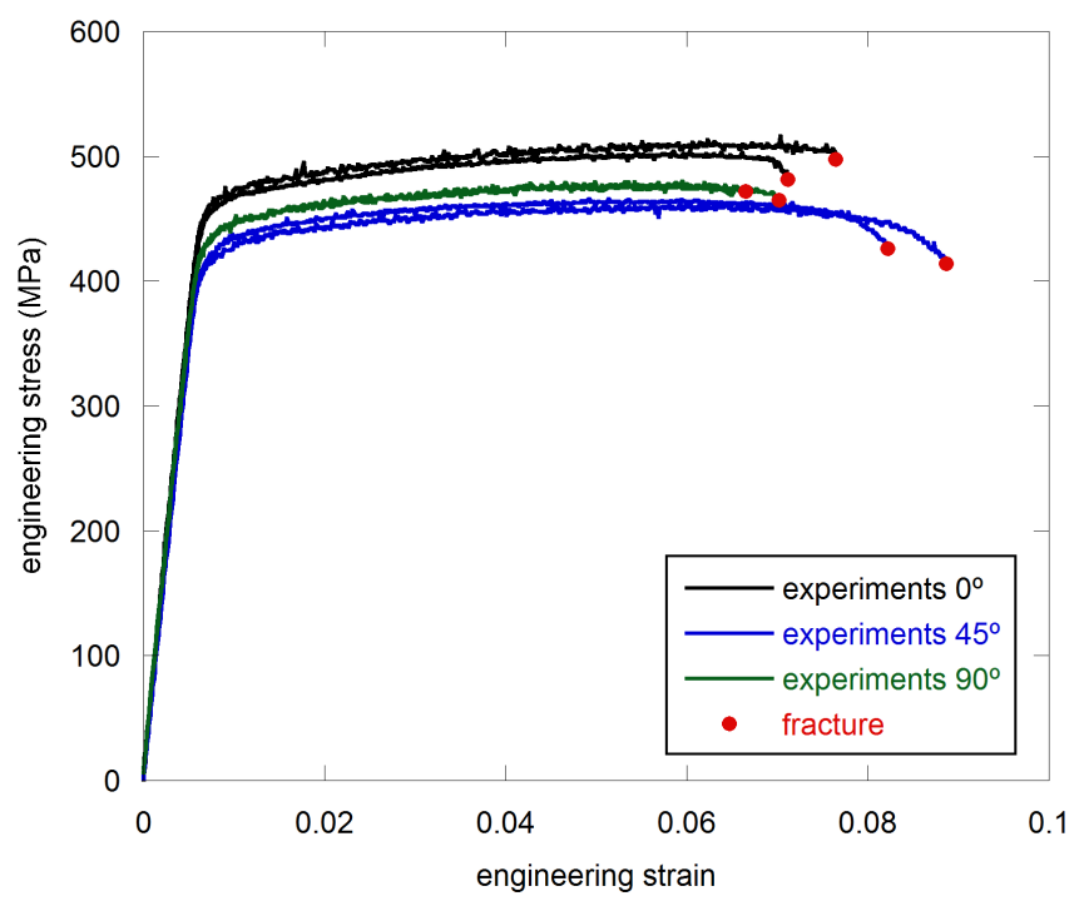

Figure 3.9. Engineering stress-strain curves of AA7017-T73 alloy obtained from uniaxial tensile quasi-static experiments along three different directions $\left(0^{\circ}, 45^{\circ}\right.$ and $\left.90^{\circ}\right)$. 


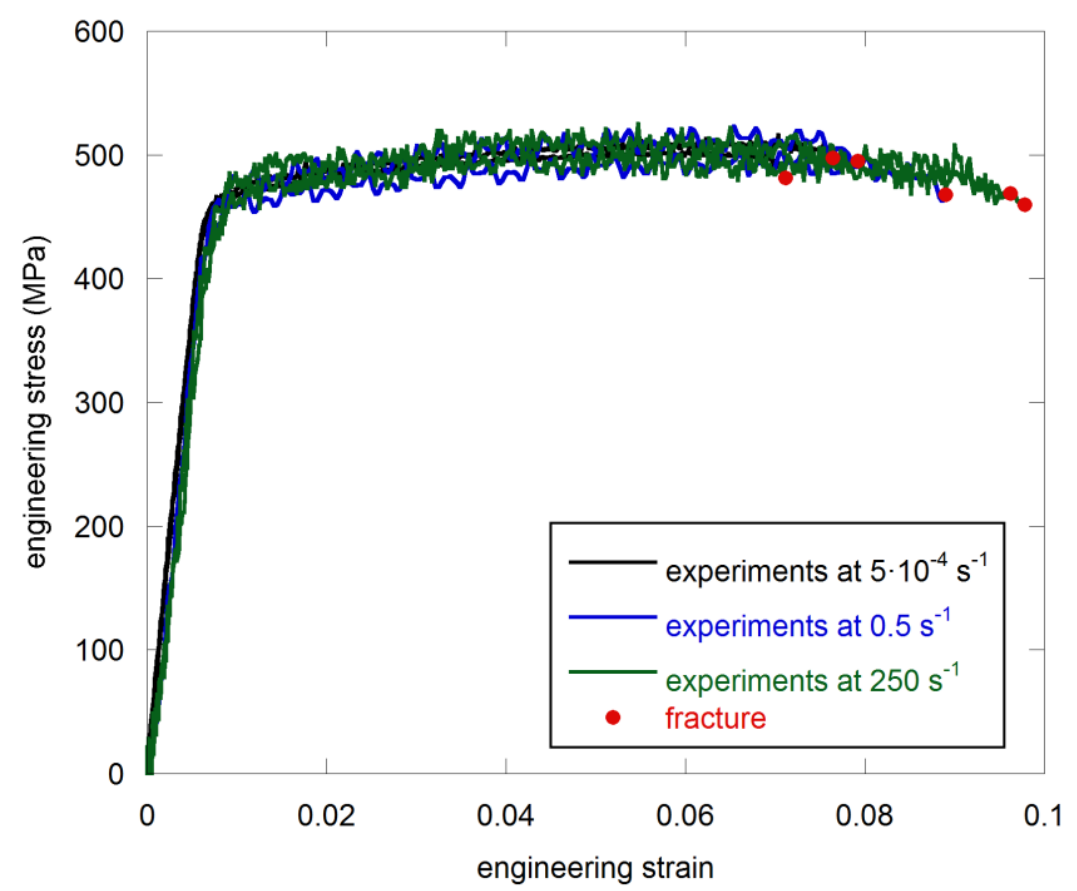

Figure 3.10. Engineering stress-strain curves of AA7017-T73 alloy obtained from uniaxial tensile experiments at three different strain rates $\left(5 \cdot 10^{-4} \mathrm{~s}^{-1}, 0.5 \mathrm{~s}^{-1}\right.$ and $\left.250 \mathrm{~s}^{-1}\right)$.

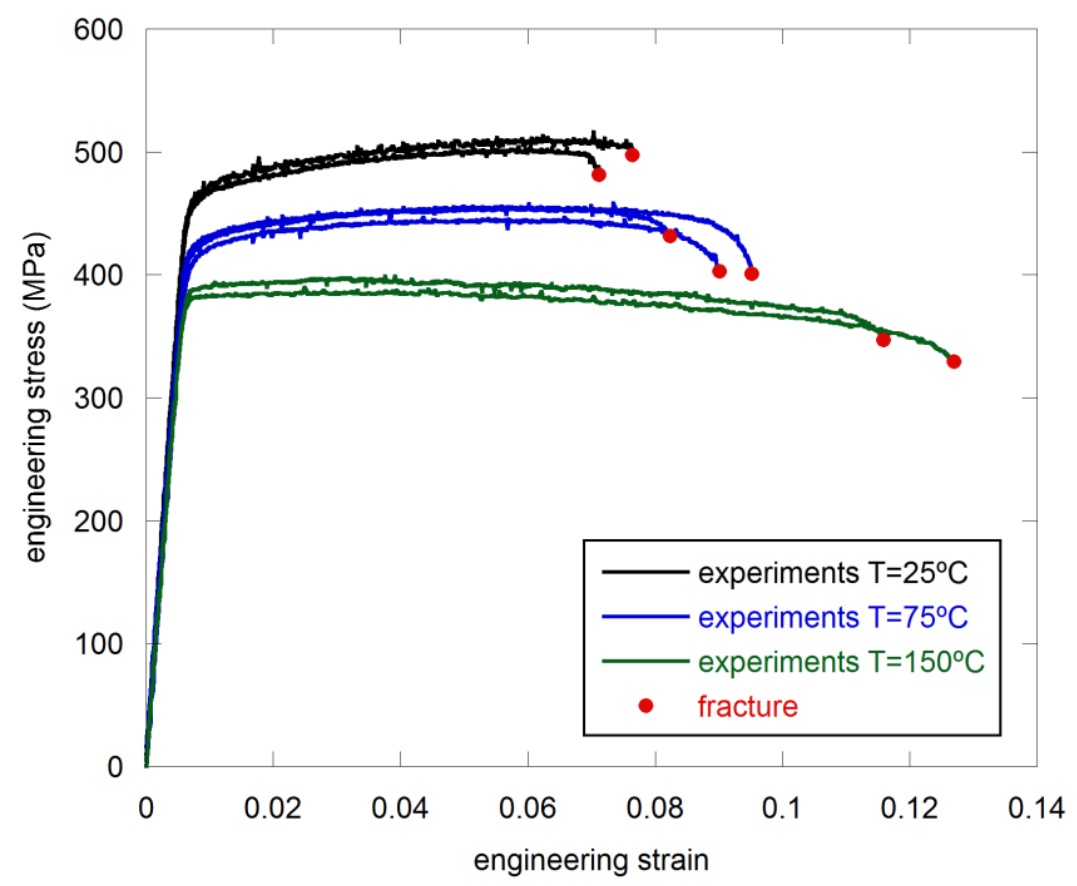

Figure 3.11. Engineering stress-strain curves of AA7017-T73 alloy obtained from uniaxial tensile experiments at $75^{\circ} \mathrm{C}, 150^{\circ} \mathrm{C}$ and room temperature. 


\subsubsection{Mars $® 240$ steel}

The engineering stress-strain curves corresponding to the uniaxial tensile quasistatic tests at $0^{\circ}$ (in black), $45^{\circ}$ (in blue) and $90^{\circ}$ (in green), as well as the fracture strain (in red dots), are shown in Figure 3.12.

As it was done with the AA7017-T73, the anisotropy of the material was quantitatively identified by the Lankford coefficients (eq. (3.2)), as well as by the yield stresses corresponding to the $0^{\circ}, 45^{\circ}$ and $90^{\circ}$ orientations. The obtained uniaxial yield stresses $Y_{0}, Y_{45}, Y_{90}$ at $0.01 \%$ of engineering strain, and Lankford coefficients $r_{0}, r_{45}, r_{90}$, are summarised in Table 3.2.

Table 3.2. Uniaxial yield stresses and Lankford coefficients of Mars $® 240$ steel.

\begin{tabular}{cccccc}
\hline$Y_{0}(\mathrm{MPa})$ & $Y_{45}(\mathrm{MPa})$ & $Y_{90}(\mathrm{MPa})$ & $r_{0}$ & $r_{45}$ & $r_{90}$ \\
\hline 1300 & 1300 & 1300 & 0.99 & 0.99 & 0.99 \\
\hline
\end{tabular}

The measured yield stresses were the same in all three orientations. The Lankford coeffients were also identical and very close to unity for all orientations. Contrary to the AA7017-T73 alloy, in this case the results manifested the isotropy of the Mars $® 240$ steel.

Figure 3.13 shows the experimental engineering stress-strain response of the specimens oriented at $0^{\circ}$ with increasing loading rates. The quasi-static experiments at $5 \cdot 10^{-4} \mathrm{~s}^{-1}$ are plotted in black, the intermediate strain rate test performed at $0.5 \mathrm{~s}^{-1}$ are shown in blue, and the dynamic stress-strain response of the material at $250 \mathrm{~s}^{-1}$ is depicted in green, as well as the fracture strains (in red dots). From those curves, a strain rate dependency can be observed. Please note that due to the scale of the plot such dependency cannot be fully appreciated. However, the increase in the yield stress was around $12.5 \%$ for the intermediate tests, while for the fast was close to $35 \%$.

As it was mentioned before (section 3.2), the environmental chamber could only operate up to $200^{\circ} \mathrm{C}$. Thus, no experiments on Mars $\AA 240$ steel at high temperature were performed since the temperature range did not provide enough information of the material behaviour at different temperatures. 


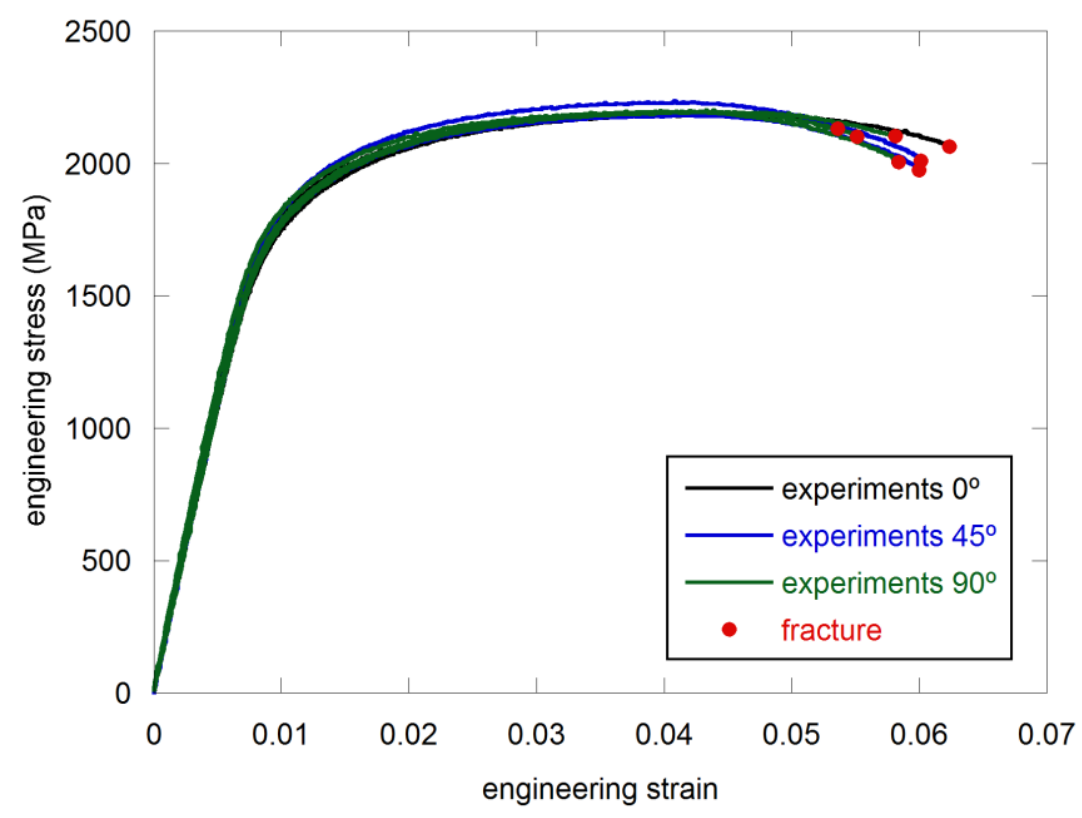

Figure 3.12. Engineering stress-strain curves of Mars $₫ 240$ steel obtained from uniaxial tensile quasi-static experiments along three different directions $\left(0^{\circ}, 45^{\circ}\right.$ and $\left.90^{\circ}\right)$.

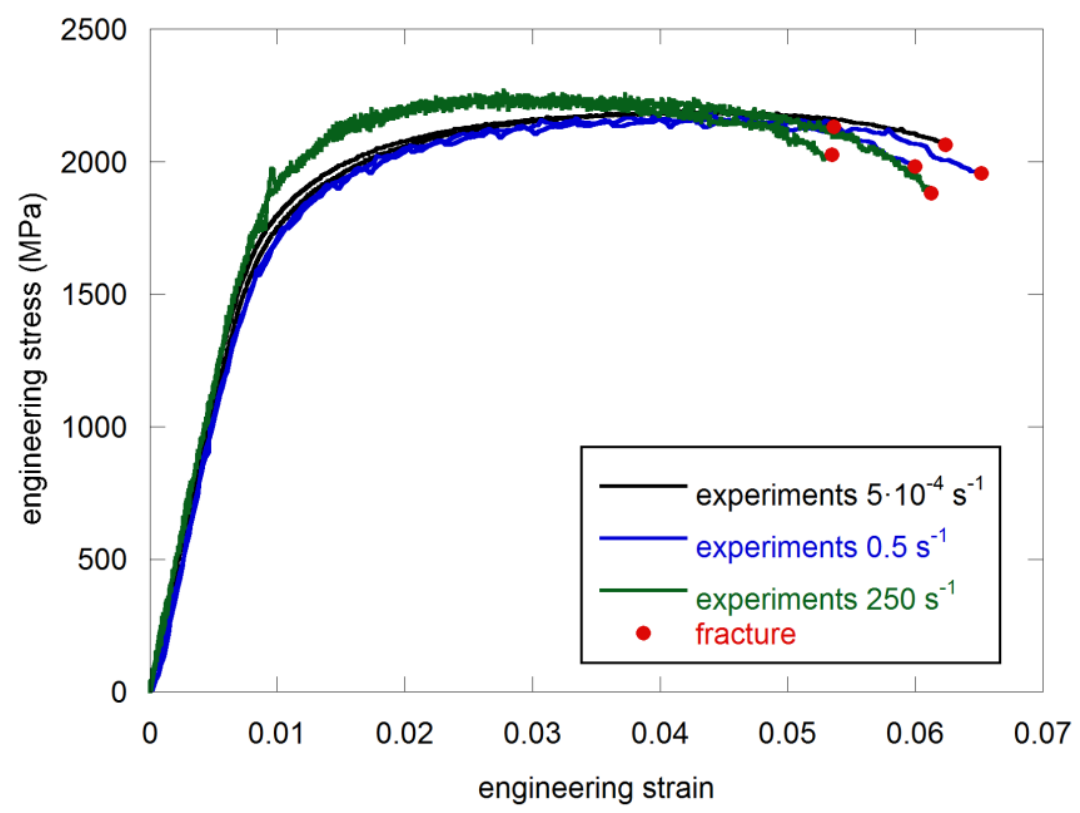

Figure 3.13. Engineering stress-strain curves of Mars ${ }^{\circledR} 240$ steel obtained from uniaxial tensile quasi-static experiments at three different strain rates $\left(5 \cdot 10^{-4} \mathrm{~s}^{-1}\right.$, $0.5 \mathrm{~s}^{-1}$ and $\left.250 \mathrm{~s}^{-1}\right)$. 


\subsection{Concluding remarks}

An experimental campaign was designed to characterise the rate-dependent plasticity and fracture response of the two high-strength materials, AA7017-T73 and Mars 240 steel.

Two series of uniaxial tensile tests on AA7017-T73 alloy and Mars $\AA 240$ steel sheet specimens machined from different orientations $\left(0^{\circ}, 45^{\circ}\right.$ and $\left.90^{\circ}\right)$ with respect to the rolling direction were carried out at three different loading rates. In addition, in the case of AA7017-T73, tests at different temperatures were performed.

The experimental results of the AA7017-T73 alloy revealed a high degree of anisotropy on both yield stress and plastic flow. Additionally, the material revealed a very mild strain-rate dependency.

As it was done with the aluminium alloy, the anisotropy of the Mars $\otimes 240$ steel was quantitatively identified by the Lankford coefficients, as well as by the yield stresses corresponding to the $0^{\circ}, 45^{\circ}$ and $90^{\circ}$ orientations. In this case, the experimental results of the Mars $\circledast 240$ steel showed the isotropic behaviour of the material. Also, the strain-rate dependency of the material was experimentally observed. 



\section{CHAPTER 4}

\section{CONSTITUTIVE MODELLING}

Sheet metals, and particularly aluminium alloys, are prone to exhibit anisotropic mechanical behaviour. Because of the manufacturing processes the material obtains a highly textured microstructure which is translated into a directiondependent mechanical behaviour. Various yield functions have been proposed over the years to describe the anisotropy of metallic sheets. Moreover, this choice typically depends on the material type; being Hill's anisotropic plasticity model family the classical choice for steel, and Barlat's yield function family the most extended when dealing with aluminium alloys.

The Yld2000-2D yield criterion (Barlat et al., 2003) has been widely employed to describe the yield surface of different aluminium alloys. However, in most mechanical problems full 3D analysis is needed.

Different yield surfaces can be found to model advanced high strength steels.Traditionally, the Hill ' 48 yield criterion (Hill, 1948) has been extensively utilised to model the anisotropy exihibited by such material due to ts mathematical simplicity and substantial improvement over the "classical" isotropic von Mises plasticity. 
In the present work, an extension of the Yld2000-2D yield function for general three-dimensional stress states (Dunand et al., 2012) and the quadratic Hill '48 yield criterion, along with a Voce hardening model (Voce, 1948), are used to describe the anisotropic plastic yielding of AA7017-T73 alloy and Mars $® 240$ steel, respectively.

\subsection{Elasticity}

All equations will be from now on expressed in matrix notation to be able to easily follow the implementation of such equations in any finite element code.

We asume the additive decomposition of the strain vector in its of the elastic and plastic parts, $\boldsymbol{\varepsilon}^{e}$ and $\boldsymbol{\varepsilon}^{p}$ respectively as:

$$
\boldsymbol{\varepsilon}=\boldsymbol{\varepsilon}^{e}+\boldsymbol{\varepsilon}^{p}
$$

being

$$
\boldsymbol{\varepsilon}=\left\{\begin{array}{llllll}
\varepsilon_{x x} & \varepsilon_{y y} & \varepsilon_{z z} & 2 \varepsilon_{x y} & 2 \varepsilon_{y z} & 2 \varepsilon_{x z}
\end{array}\right\}^{T}
$$

Then, its elastic part and the vector form of the Cauchy stress tensor

$$
\boldsymbol{\sigma}=\left\{\begin{array}{llllll}
\sigma_{x x} & \sigma_{y y} & \sigma_{z z} & \sigma_{x y} & \sigma_{y z} & \sigma_{x z}
\end{array}\right\}^{T}
$$

are related by the Hooke's law as follows:

$$
\boldsymbol{\sigma}=\mathbf{C} \varepsilon^{\mathrm{e}}=\mathbf{C}\left(\boldsymbol{\varepsilon}-\boldsymbol{\varepsilon}^{\mathrm{p}}\right)
$$

where $\mathbf{C}$ can be expressed as a $6 \times 6$ matrix that contains the elastic modus $E$ and Poisson's ratio $v$,

$$
\mathbf{C}=\frac{E}{(1+v)(1-2 v)}\left[\begin{array}{cccccc}
1-v & v & v & 0 & 0 & 0 \\
v & 1-v & v & 0 & 0 & 0 \\
v & v & 1-v & 0 & 0 & 0 \\
0 & 0 & 0 & \frac{1-2 v}{2} & 0 & 0 \\
0 & 0 & 0 & 0 & \frac{1-2 v}{2} & 0 \\
0 & 0 & 0 & 0 & 0 & \frac{1-2 v}{2}
\end{array}\right]
$$




\subsection{Plasticity}

\subsubsection{YId2000-3D yield criterion}

The Yld2000-3D yield function is defined as (Dunand et al., 2012):

$$
\phi\left[\boldsymbol{\sigma}, \bar{\varepsilon}_{p}, \dot{\bar{\varepsilon}}_{p}, T\right]=\bar{\sigma}[\boldsymbol{\sigma}]-k\left[\bar{\varepsilon}_{p}, \dot{\bar{\varepsilon}}_{p}, T\right]=0
$$

where $k$ is the hardening and $\bar{\sigma}$ is the equivalent stress that is defined as a sum of two functions,

$$
\bar{\sigma}=\frac{1}{2^{1 / a}}\left(\phi^{\prime}\left(\mathbf{s}^{\prime}\right)+\phi^{\prime \prime}\left(\mathbf{s}^{\prime \prime}\right)\right)^{\frac{1}{a}}
$$

where

$$
\begin{gathered}
\phi^{\prime}\left(\mathbf{s}^{\prime}\right)=\left|s_{I}^{\prime}-s_{I I}^{\prime}\right|^{a} \\
\phi^{\prime \prime}\left(\mathbf{s}^{\prime \prime}\right)=\left|2 s_{I I}^{\prime \prime}+s_{I}^{\prime \prime}\right|^{a}+\left|2 s_{I}^{\prime \prime}+s_{I I}^{\prime \prime}\right|^{a}
\end{gathered}
$$

and $s_{I}^{\prime}, s_{I I}^{\prime}$ and $s_{I}^{\prime \prime}, s_{I I}^{\prime \prime}$ denote the principal values of the modified deviatoric stress vectors $\mathbf{s}^{\prime}$ and $\mathbf{s}^{\prime \prime}$ given by the following linear transformations:

$$
\begin{aligned}
& \mathbf{s}^{\prime}=\mathbf{L}^{\prime} \boldsymbol{\sigma} \\
& \mathbf{s}^{\prime \prime}=\mathbf{L}^{\prime \prime} \boldsymbol{\sigma}
\end{aligned}
$$

These traceless vectors are expressed as,

$$
\begin{aligned}
& \mathbf{s}^{\prime}=\left\{\begin{array}{llllll}
s_{x x}^{\prime} & s_{y y}^{\prime} & s_{z z}^{\prime} & s_{x y}^{\prime} & s_{y z}^{\prime} & s_{z x}^{\prime}
\end{array}\right\}^{T} \\
& \mathbf{s}^{\prime \prime}=\left\{\begin{array}{llllll}
s_{x x}^{\prime \prime} & s_{y y}^{\prime \prime} & s_{z z}^{\prime \prime} & s_{x y}^{\prime \prime} & s_{y z}^{\prime \prime} & s_{z x}^{\prime \prime}
\end{array}\right\}^{T}
\end{aligned}
$$

while their $z z$ components $\left(s_{x x}+s_{y y}+s_{z z}=0\right)$ are independently defined through

$$
\begin{aligned}
& s_{z z}^{\prime}=-\left(s_{x x}^{\prime}+s_{y y}^{\prime}\right) \\
& s_{z z}^{\prime}=-\left(s_{x x}^{\prime \prime}+s_{y y}^{\prime \prime}\right)
\end{aligned}
$$

The linear transformations are specified through eight independent parameters $\alpha_{i}$ (for $i$ from 1 to 8 ) associated with plane stress state anisotropy, plus four parameters $\alpha_{k}$ (for $i$ from 9 to 12) that are associated with out-of-plane shear stresses, 
and

$$
\begin{aligned}
\mathbf{L}^{\prime} & =\frac{1}{3}\left[\begin{array}{cccccc}
2 \alpha_{1} & -\alpha_{1} & -\alpha_{1} & 0 & 0 & 0 \\
-\alpha_{2} & 2 \alpha_{2} & -\alpha_{2} & 0 & 0 & 0 \\
0 & 0 & 0 & 3 \alpha_{7} & 0 & 0 \\
0 & 0 & 0 & 0 & 3 \alpha_{9} & 0 \\
0 & 0 & 0 & 0 & 0 & 3 \alpha_{10}
\end{array}\right] \\
\mathbf{L}^{\prime \prime} & =\frac{1}{9}\left[\begin{array}{cccccc}
L_{11}^{\prime \prime} & L_{12}^{\prime \prime} & L_{13}^{\prime \prime} & 0 & 0 & 0 \\
L_{21}^{\prime \prime} & L_{22}^{\prime \prime} & L_{23}^{\prime \prime} & 0 & 0 & 0 \\
0 & 0 & 0 & 9 \alpha_{8} & 0 & 0 \\
0 & 0 & 0 & 0 & 9 \alpha_{11} & 0 \\
0 & 0 & 0 & 0 & 0 & 9 \alpha_{12}
\end{array}\right]
\end{aligned}
$$

$$
\begin{aligned}
& L_{11}^{\prime \prime}=-2 \alpha_{3}+2 \alpha_{4}+8 \alpha_{5}-2 \alpha_{6} \\
& L_{12}^{\prime \prime}=-4 \alpha_{4}+4 \alpha_{6}+\alpha_{3}-4 \alpha_{5} \\
& L_{13}^{\prime \prime}=\alpha_{3}+2 \alpha_{4}-4 \alpha_{5}-2 \alpha_{6} \\
& L_{21}^{\prime \prime}=4 \alpha_{3}-4 \alpha_{4}-4 \alpha_{5}+\alpha_{6} \\
& L_{22}^{\prime \prime}=-2 \alpha_{3}+8 \alpha_{4}+2 \alpha_{5}-2 \alpha_{6} \\
& L_{23}^{\prime \prime}=-2 \alpha_{3}-4 \alpha_{4}+2 \alpha_{5}+\alpha_{6}
\end{aligned}
$$

Imposing $\alpha_{9}=\alpha_{10}=\alpha_{11}=\alpha_{12}=1$ provides satisfactory results in applications where the sheet material accommodates most deformation under plane stress conditions (Luo et al., 2012).

The direction of the plastic strains is given by an associated flow rule as,

$$
\dot{\boldsymbol{\varepsilon}}^{p}=\dot{\lambda} \mathbf{n}=\dot{\lambda} \frac{\partial \phi}{\partial \boldsymbol{\sigma}}
$$

where $\dot{\lambda}$ is the plastic multiplier. Due to the complexity when deriving the yield function, an equally effective procedure was used to compute the plastic flow vector $\mathbf{n}$ (Aretz, 2005). It was numerically computed using a forward difference scheme:

$$
\mathbf{n}=\frac{\partial \phi}{\partial \boldsymbol{\sigma}} \approx \frac{\phi[\boldsymbol{\sigma}+\Delta \boldsymbol{\sigma}]-\phi[\boldsymbol{\sigma}]}{\Delta \boldsymbol{\sigma}}
$$


Employing a $\Delta \boldsymbol{\sigma}$ of the order of $10^{-5}$ has given good results in many other studies found in the literature (Aretz, 2005; Dunand et al., 2012).

Please recall that $\bar{\sigma}[\boldsymbol{\sigma}]$ is a first order homogeneus function of the stress tensor and therefore:

$$
\boldsymbol{\sigma}^{T} \frac{\partial \bar{\sigma}}{\partial \boldsymbol{\sigma}}=\bar{\sigma}
$$

Now using the work conjugation,

$$
\boldsymbol{\sigma}^{T} \dot{\boldsymbol{\varepsilon}}^{p}=\bar{\sigma} \dot{\bar{\varepsilon}}_{p}
$$

one can combine eqs. (4.18) and (4.19) to get the evolution equation of the equivalent plastic strain,

$$
\bar{\sigma} \dot{\bar{\varepsilon}}_{p}=\boldsymbol{\sigma}^{T} \dot{\lambda} \mathbf{n}=\dot{\lambda} \boldsymbol{\sigma}^{T} \frac{\partial \bar{\sigma}}{\partial \boldsymbol{\sigma}} \Rightarrow \dot{\bar{\varepsilon}}_{p}=\dot{\lambda}
$$

\subsubsection{Non-associated Hill 48' plasticity}

The Hill 48' yield function is given by (Hill, 1948):

$$
\phi\left[\boldsymbol{\sigma}, \bar{\varepsilon}_{p}, \dot{\bar{\varepsilon}}_{p}, T\right]=\bar{\sigma}[\boldsymbol{\sigma}]-k\left[\bar{\varepsilon}_{p}, \dot{\bar{\varepsilon}}_{p}, T\right]=0
$$

where $k$ is the isotropic hardening and $\bar{\sigma}$ is the equivalent stress that is expressed as a linear transformation of the stress tensor (Crisfield, 1997),

$$
\bar{\sigma}[\boldsymbol{\sigma}]=\sqrt{\boldsymbol{\sigma}^{T} \mathbf{P \sigma}}
$$

where $\mathbf{P}$ is symmetric matrix that contains Hill's constants for anisotropic plasticity

$$
\mathbf{P}=\left[\begin{array}{cccccc}
1 & P_{12} & -\left(1+P_{12}\right) & 0 & 0 & 0 \\
P_{12} & P_{22} & -\left(P_{12}+P_{22}\right) & 0 & 0 & 0 \\
-\left(1+P_{12}\right) & -\left(P_{12}+P_{22}\right) & 1+2 P_{12}+P_{22} & 0 & 0 & 0 \\
0 & 0 & 0 & P_{33} & 0 & 0 \\
0 & 0 & 0 & 0 & 3 & 0 \\
0 & 0 & 0 & 0 & 0 & 3
\end{array}\right]
$$


The rolling direction is considered as a reference being aligned to the direction of the unit vector $\mathbf{e}_{1}$ in the local material coordinate system $\left\{\mathbf{e}_{1}, \mathbf{e}_{2}, \mathbf{e}_{3}\right\}$. Therefore, $P_{11}=1$ is imposed. $P_{12}, P_{22}$ and $P_{33}$ are the constants that define the $\mathbf{P}$ matrix, weighing the ratios among the uniaxial yield stresses in three directions with respect to the rolling direction, typically at $0^{\circ}, 45^{\circ}$ and $90^{\circ}\left(Y_{0}, Y_{45}\right.$ and $\left.Y_{90}\right)$. In the case of isotropic yielding, the yield function collapses to a von Mises yield surface, i.e. $Y_{0}=Y_{45}=Y_{90}$; therefore $P_{12}=-0.5, P_{22}=1.0$ and $P_{33}=3.0$, being $\mathbf{P}=\mathbf{P}_{\mathrm{vm}}$. The direction of the plastic flow vector $\mathbf{m}$ is given by a non-associated flow rule, where the flow potential is expressed as

$$
\psi[\boldsymbol{\sigma}]=\sqrt{\boldsymbol{\sigma}^{T} \mathbf{G \sigma}}
$$

being $\mathbf{G}$ a symmetric matrix expressed as,

$$
\mathbf{G}=\left[\begin{array}{cccccc}
1 & G_{12} & -\left(1+G_{12}\right) & 0 & 0 & 0 \\
G_{12} & G_{22} & -\left(G_{12}+G_{22}\right) & 0 & 0 & 0 \\
-\left(1+G_{12}\right) & -\left(G_{12}+G_{22}\right) & 1+2 G_{12}+G_{22} & 0 & 0 & 0 \\
0 & 0 & 0 & G_{33} & 0 & 0 \\
0 & 0 & 0 & 0 & 3 & 0 \\
0 & 0 & 0 & 0 & 0 & 3
\end{array}\right]
$$

where as in close analogy to $\mathbf{P}, G_{11}=1$ is imposed and the independent components, and $G_{12}, G_{22}$ and $G_{33}$, contain the Lankford ratios (eq. (3.2)):

$$
G_{12}=-\frac{r_{0}}{1+r_{0}} \quad G_{22}=\frac{r_{0}}{r_{90}} \frac{1+r_{90}}{1+r_{0}} \quad G_{33}=\frac{1+2 r_{45}}{r_{90}} \frac{r_{0}+r_{90}}{1+r_{0}}
$$

The non-associated flow rule is defined as

$$
\dot{\boldsymbol{\varepsilon}}^{p}=\dot{\lambda} \mathbf{m}=\dot{\lambda} \frac{\partial \psi[\boldsymbol{\sigma}]}{\partial \boldsymbol{\sigma}}=\dot{\lambda} \frac{\mathbf{G} \boldsymbol{\sigma}}{\psi}
$$

where $\dot{\lambda}$ is the plastic multiplier.

Operating, from the work conjugation (eq. (4.19)), we get the evolution equations of the equivalent plastic strain:

$$
\dot{\bar{\varepsilon}}_{p}=\dot{\lambda} \frac{\psi}{\bar{\sigma}}
$$




\subsubsection{Isotropic hardening}

The strain, strain rate and temperature dependent response of the materials is modelled using purely isotropic hardening. It should be noted that for the sake of simplicity neither kinematic or distorsional hardening were considered in the present study. The hardening is defined as a combination of three terms that include Voce strain hardening (Voce, 1948), Johnson-Cook-based (Johnson and Cook, 1983) strain rate hardening and thermal softening as,

$$
k\left[\bar{\varepsilon}_{p}, \dot{\bar{\varepsilon}}_{p}, T\right]=k_{v}\left[\bar{\varepsilon}_{p}\right]\left\{1+C \ln \left[\frac{\dot{\bar{\varepsilon}}_{p}}{\dot{\varepsilon}_{0}}\right]\right\}\left\{1-\left(\frac{T-T_{r}}{T_{m}-T_{r}}\right)^{m}\right\}
$$

where $C$ and $m$ are material constants, $\dot{\varepsilon}_{0}$ is the reference strain rate, and $T_{r}$ and $T_{m}$ are the reference and melting temperatures respectively. The strain hardening is defined as a Voce law,

$$
k_{v}\left[\bar{\varepsilon}_{p}\right]=\sigma_{0}+Q_{1}\left(1-\exp \left[-C_{1} \bar{\varepsilon}_{p}\right]\right)+Q_{2}\left(1-\exp \left[-C_{2} \bar{\varepsilon}_{p}\right]\right)
$$

where $\sigma_{0}, Q_{1}, C_{1}, Q_{2}, C_{2}$ are material constants.

The evolution equation of the temperature is given by:

$$
\dot{T}=\frac{\chi\left[\dot{\bar{\varepsilon}}_{p}\right]}{\rho c_{p}} \bar{\sigma} \dot{\bar{\varepsilon}}_{p}
$$

where $\chi$ is the Taylor-Quiney coefficient that evolves according to the strain rate

$$
\chi\left[\dot{\bar{\varepsilon}}_{p}\right]=\left\{\begin{array}{ccc}
0 & \text { for } & \dot{\bar{\varepsilon}}_{p} \leq \dot{\varepsilon}_{0} \\
\chi_{0} \frac{\left(\dot{\bar{\varepsilon}}_{p}-\dot{\varepsilon}_{0}\right)^{2}\left(3 \dot{\varepsilon}_{a}-2 \dot{\bar{\varepsilon}}_{p}-\dot{\varepsilon}_{0}\right)}{\left(\dot{\varepsilon}_{a}-\dot{\varepsilon}_{0}\right)^{3}} & \text { for } & \dot{\varepsilon}_{0}<\dot{\bar{\varepsilon}}_{p}<\dot{\varepsilon}_{a} \\
\chi_{0} & \text { for } & \dot{\varepsilon}_{a} \leq \dot{\bar{\varepsilon}}_{p}
\end{array}\right.
$$

being $\dot{\varepsilon}_{0}$ and $\dot{\varepsilon}_{a}$ the limit strain rates for the isothermal and adiabatic domains, respectively. 


\subsection{Numerical simulations of the uniaxial tension experiments}

\subsubsection{Numerical set-up}

Numerical simulations of uniaxial tension experiments, at different strain rates and temperatures, were performed in order to identify the corresponding plasticity model parameters through inverse modelling.

All the experiments were simulated using LS-DYNA (LSTC, 2014) non-linear finite element code. The dimensions and geometry of the specimens as well as the experimental data used to performed the simulations can be found in section 3.5. Due to the symmetry of the model, only one eighth of each specimen was modelled. An experimentally measured prescribed velocity in the y axis was applied to all nodes on the upper face of the finite element mesh (see Figure 4.1), while a zero displacement constraint was applied to the nodes placed on the three symmetry planes of the specimen in the normal direction to such planes. The specimens were discretised using eight-node solid elements with one integration point and stiffness-based hourglass control. The approximate size of the elements was $0.1 \times 0.1 \times 0.1 \mathrm{~mm}^{3}$. Uniform mass scaling was applied in low and intermediate strain rate simulations assuming stable time increment of $t_{f} \cdot 0.65 \cdot 10^{-5}$, being $t_{f}$ the termination time corresponding to each one of the calculations.

Both materials were modelled using the command MAT_USER_DEFINED_MATERIAL_MODELS which called the user defined material subroutines programmed in FORTRAN language with appropriate input data formatting. Calibrated material parameters are reported in Table 4.2 for AA7017-T73 and Table 4.4 for Mars $₫ 240$ steel. 


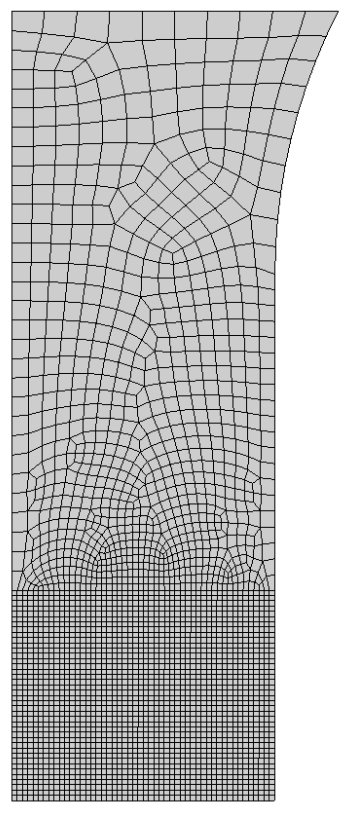

(a)

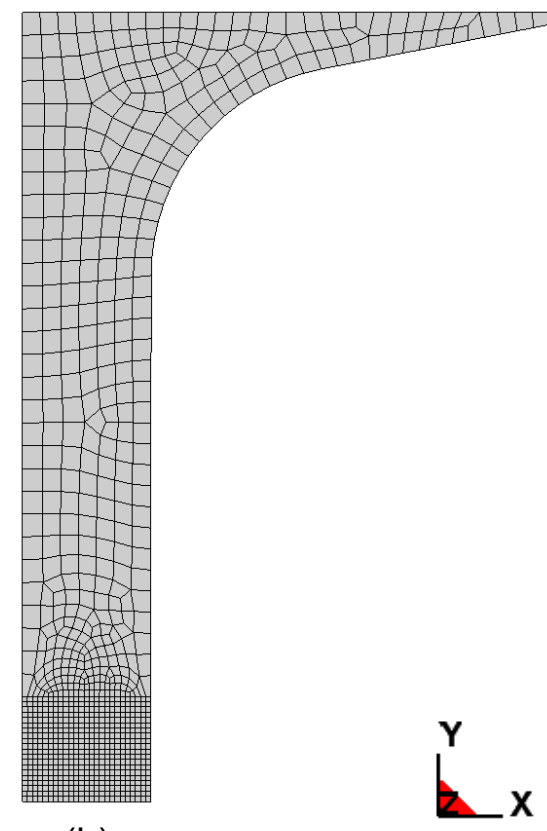

(b)

Figure 4.1. Finite element meshes used for the numerical simulations of the (a) AA7017-T73 and the Mars ${ }^{\circledR} 240$ steel.

\subsubsection{AA7017-T73 alloy}

\subsubsection{Constant identification}

To model the rate and temperature dependent anisotropic plastic yielding of the AA7017-T73 alloy, the Yld2000-3D yield criterion (Dunand et al., 2012) was modified as shown in in section 4.2. The uniaxial yield stresses $Y_{0}, Y_{45}, Y_{90}$, and Lankford coefficients $r_{0}, r_{45}, r_{90}$, were not enough to identify the eight independent model parameters $\alpha_{k}$ (for $\mathrm{k}$ from 1 to 8 ). Typically, additional equi-biaxial test data is used to identify such parameters. When these data are lacking, it is common practice (Hopperstad et al., 2007) to assume that the r-ratio in equi-biaxial tension $r_{b}$ is equal to unity and the yield stress is equal to that measured in the rolling direction $Y_{0}=Y_{b}$. The yield exponent was chosen to be $a=8$ since it is well established choice for materials with FCC crystal structures (Logan and Hosford, 1980). 
The seven constants of the hardening function (eq. (4.29)), $\left\{\sigma_{0}, Q_{1}, C_{1}, Q_{2}, C_{2}, C, m\right\}$ were identified through inverse modelling using LSOPT (LSTC, 2015) optimisation software package by LSTC. For such an optimisation, all tests shown in the previous section were simulated. For the sake of simplicity, the reference strain rate was set to $\dot{\varepsilon}_{0}=5 \cdot 10^{-4} \mathrm{~s}^{-1}$, making it coincide with the average quasi-static strain rate. The uniaxial yield stresses $Y_{0}, Y_{45}, Y_{90}$, and Lankford coefficients $r_{0}, r_{45}, r_{90}$, used for model calibration are summarized in Table 4.1.

\subsubsection{Results}

The obtained material constants are summarised in Table 4.2. As expected, (see section 2.4.1) the material model followed the experimental trend and showed practically a rate-independent strain rate hardening behaviour. This can be seen in Figure 4.2, where the model prediction for constant strain rates of $5 \cdot 10^{-4} \mathrm{~s}^{-1}, 10$ $\mathrm{s}^{-1}$ and $1000 \mathrm{~s}^{-1}$ are depicted. However, the thermal softening of the material, as it can be observed in the very same figure, was significant.

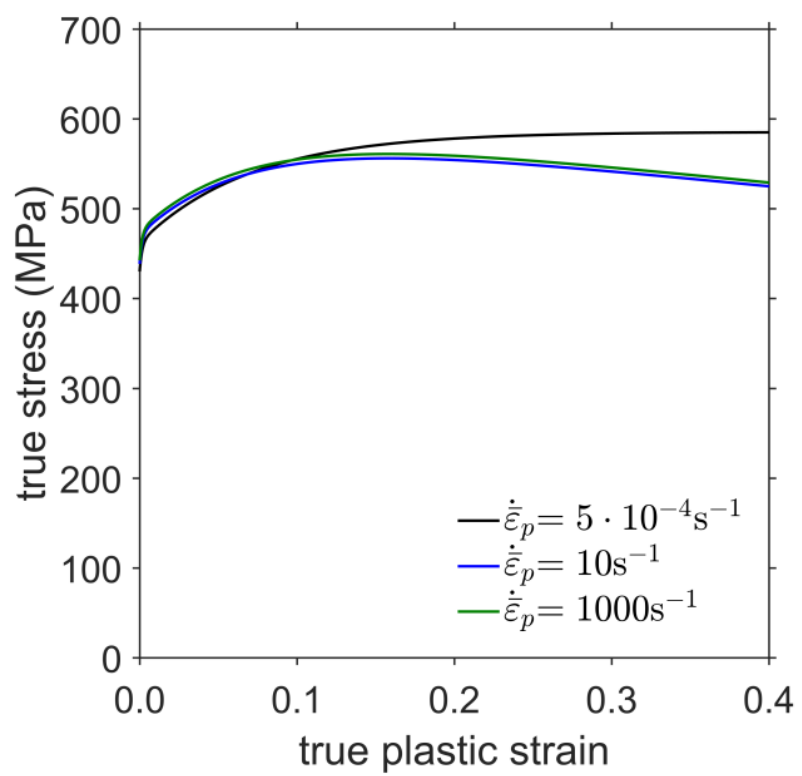

Figure 4.2. Hardening for $0^{\circ}$ orientation with parameters reported in Table 4.2 for constant strain rates of $5 \cdot 10^{-4} \mathrm{~s}^{-1}, 10 \mathrm{~s}^{-1}$ and $1000 \mathrm{~s}^{-1}$. 
Table 4.1. Uniaxial yield stresses and Lankford coefficients of AA7017-T73 alloy.

\begin{tabular}{ccccccccc}
\hline \multicolumn{7}{l}{ Experimental data used for model calibration } \\
\hline$Y_{0}(\mathrm{MPa})$ & $Y_{45}(\mathrm{MPa})$ & $Y_{90}(\mathrm{MPa})$ & $Y_{b}(\mathrm{MPa})$ & $r_{0}$ & $r_{45}$ & $r_{45}$ & $r_{b}$ \\
\hline 434 & 400 & 413 & 434 & 0.5 & 0.84 & 0.61 & 1 \\
\hline
\end{tabular}

In Figure 4.3, Figure 4.4 and Figure 4.5, where the stress-strain curves are shown for different orientations under quasi-static regime, for increasing loading rates and temperatures respectively, the excellent agreement between the experimental and numerical engineering responses can be observed. In order to show the results more clearly, in Figure 4.3 and Figure 4.4 the different stress-strain curves are plotted with a $+100 \mathrm{MPa}$ offset. Note that, in order to obtain the thermal softening exponent of the material model, the tests conducted at $150^{\circ} \mathrm{C}$ (please recall Figure 3.11) were not taken into account. Since the selected material model does not consider microstructural changes that might occur at that temperature on the material, the experiments at $150^{\circ} \mathrm{C}$ were considered non-representative of the material behaviour. It should be pointed out that the yield stress was accurately predicted, but the model was not able to predict properly the strain hardening.

Table 4.2. Material constants for the AA7017-T73 alloy

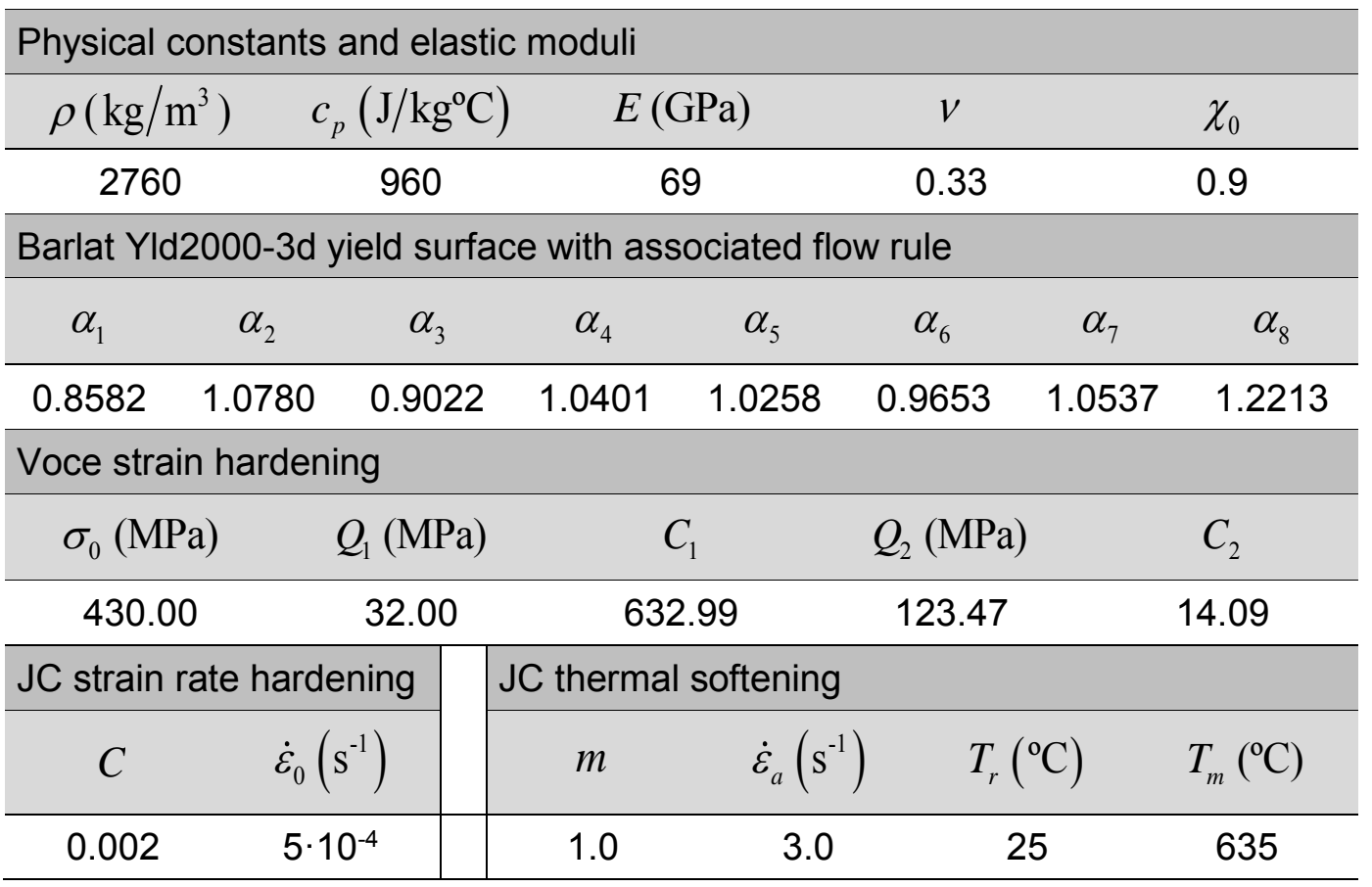




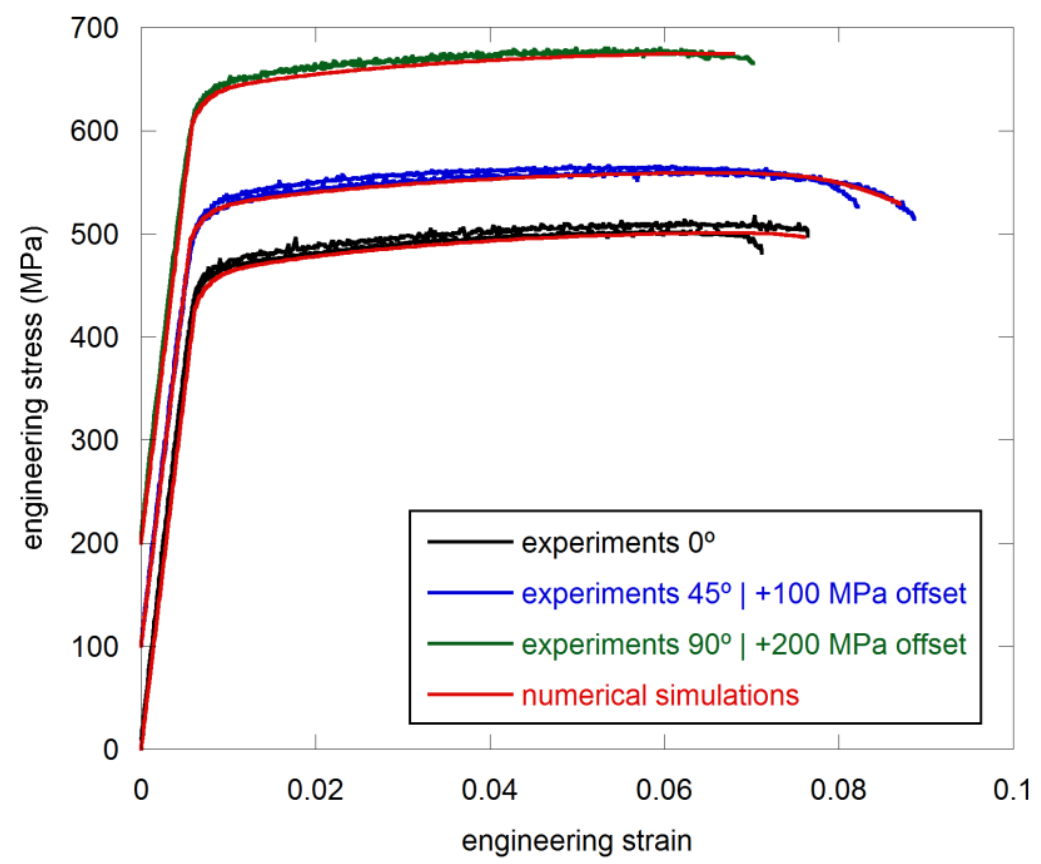

Figure 4.3. Engineering stress-strain curves of AA7017-T73 alloy obtained from UT quasi-static experiments along three different directions $\left(0^{\circ}, 45^{\circ}\right.$ and $\left.90^{\circ}\right)$ compared with the corresponding numerical simulations.

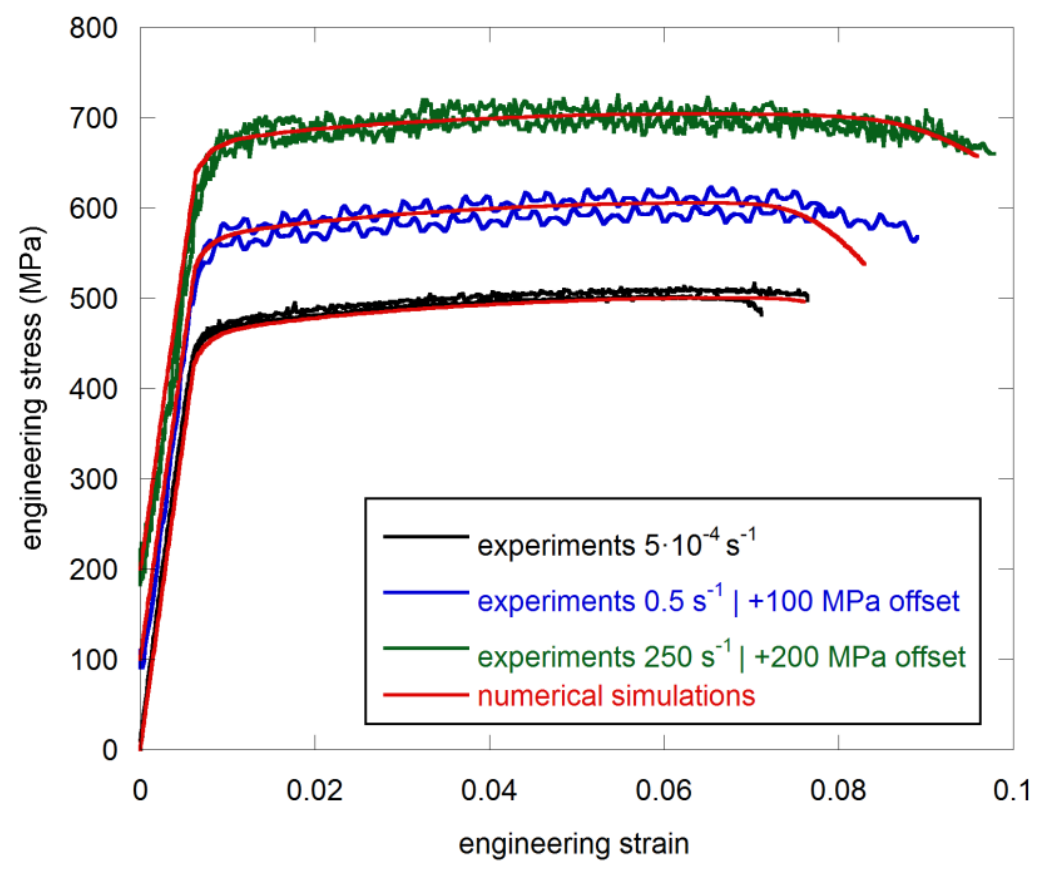

Figure 4.4. Engineering stress-strain curves of AA7017-T73 alloy obtained from UT experiments at three different strain rates $\left(5 \cdot 10^{-4} \mathrm{~s}^{-1}, 0.5 \mathrm{~s}^{-1}\right.$ and $\left.250 \mathrm{~s}^{-1}\right)$ compared with the corresponding numerical simulations. 


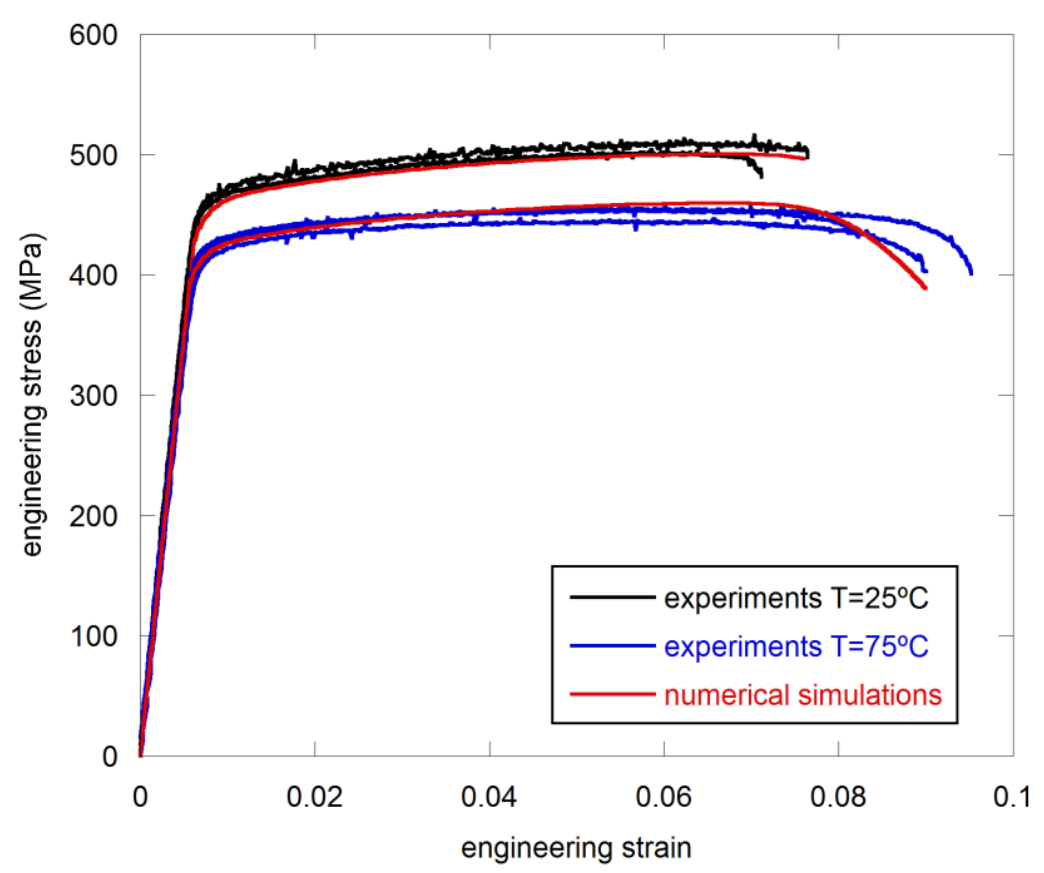

Figure 4.5. Engineering stress-strain curves of AA7017-T73 alloy obtained from UT experiments at $75^{\circ} \mathrm{C}$ and room temperature compared with the corresponding numerical simulations.

\subsubsection{Mars $® 240$ steel}

In order to model the plastic yielding of the Mars $® 240$ steel, the rate and temperature dependent (Erice et al., 2017) quadratic non-associated Hill 48' yield criterion (Hill, 1948) was chosen.

\subsubsection{Constant identification}

The uniaxial yield stresses $Y_{0}, Y_{45}, Y_{90}$, and Lankford coefficients $r_{0}, r_{45}, r_{90}$, were enough to identify the independent model parameters $P_{12}, P_{22}, P_{33}, G_{12}, G_{22}$ and $G_{33}$. All tests shown in the previous section were simulated to identify the seven constants of the hardening function (eq. (4.19)), $\left\{\sigma_{0}, Q_{1}, C_{1}, Q_{2}, C_{2}, C, m\right\}$ through inverse modelling using LS-OPT optimisation software package by LSTC. As in the case of the aluminium alloy, the reference strain rate was set to 
$\dot{\varepsilon}_{0}=5 \cdot 10^{-4} \mathrm{~s}^{-1}$. The uniaxial yield stresses $Y_{0}, Y_{45}, Y_{90}$, and Lankford coefficients $r_{0}, r_{45}, r_{90}$, used for model calibration are summarized in Table 4.3.

Table 4.3. Uniaxial yield stresses and Lankford coefficients of Mars $® 240$ steel.

\begin{tabular}{cccccc}
\hline \multicolumn{7}{l}{ Experimental data used for model calibration } \\
\hline$Y_{0}(\mathrm{MPa})$ & $Y_{45}(\mathrm{MPa})$ & $Y_{90}(\mathrm{MPa})$ & $r_{0}$ & $r_{45}$ & $r_{90}$ \\
\hline 1300 & 1300 & 1300 & 0.99 & 0.99 & 0.99 \\
\hline
\end{tabular}

Table 4.4. Material constants of Mars $® 240$ steel.

\begin{tabular}{|c|c|c|c|c|c|}
\hline \multicolumn{6}{|c|}{ Physical constants and elastic moduli } \\
\hline$\rho\left(\mathrm{kg} / \mathrm{m}^{3}\right)$ & \multicolumn{2}{|c|}{$c_{p}\left(\mathrm{~J} / \mathrm{kg}^{\circ} \mathrm{C}\right)$} & & $v$ & $\chi_{0}$ \\
\hline 8100 & \multicolumn{2}{|l|}{450} & & 0.3 & 0.862 \\
\hline \multicolumn{6}{|c|}{ Hill yield surface with non-associated flow rule } \\
\hline$P_{12}$ & $P_{22}$ & $P_{33}$ & $G_{12}$ & $G_{22}$ & $G_{33}$ \\
\hline-0.5 & 1.0 & 3.0 & -0.5 & 1.0 & 3.0 \\
\hline \multicolumn{6}{|c|}{ Voce strain hardening } \\
\hline$\sigma_{0}(\mathrm{MPa})$ & \multicolumn{2}{|c|}{$Q_{1}(\mathrm{MPa})$} & & $Q_{2}(\mathrm{MPa})$ & $C_{2}$ \\
\hline 1300 & 570 & & & 550 & 40 \\
\hline \multicolumn{2}{|c|}{ JC strain rate hardening } & \multicolumn{3}{|c|}{ JC thermal softening } & \\
\hline$C$ & $\dot{\varepsilon}_{0}\left(\mathrm{~s}^{-1}\right)$ & $m$ & $\dot{\varepsilon}_{a}\left(\mathrm{~s}^{-1}\right)$ & $T_{r}\left({ }^{\circ} \mathrm{C}\right)$ & $T_{m}\left({ }^{\circ} \mathrm{C}\right)$ \\
\hline 0.009 & $5 \cdot 10^{-4}$ & 0.6 & 7.0 & 25 & 1600 \\
\hline
\end{tabular}




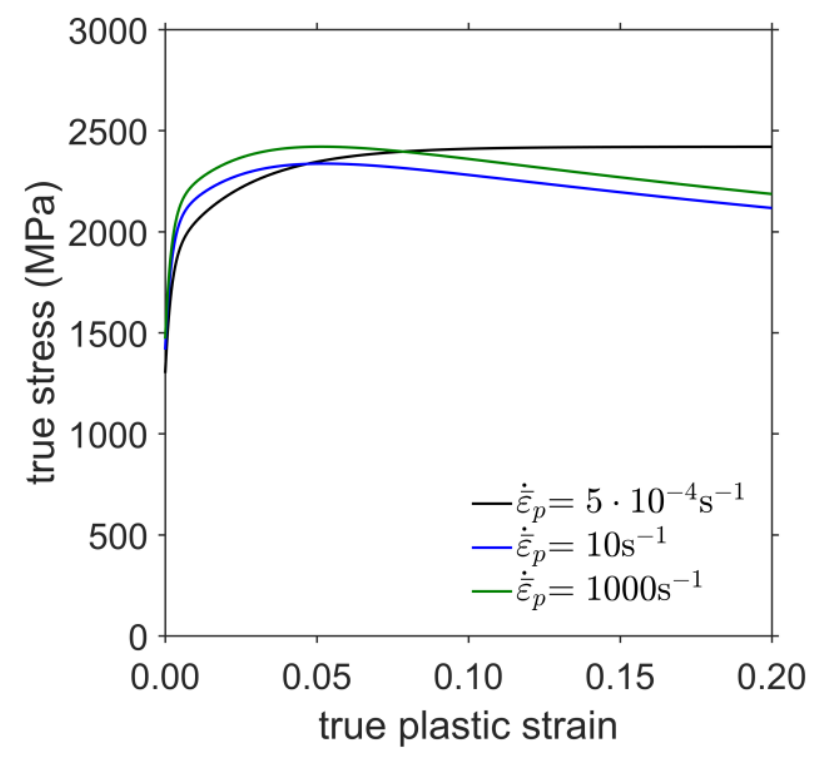

Figure 4.6. Hardening with parameters reported in Table 4.4 for constant strain rates of of $5 \cdot 10^{-4} \mathrm{~s}^{-1}, 10 \mathrm{~s}^{-1}$ and $1000 \mathrm{~s}^{-1}$.

\subsubsection{Results}

The obtained material constants are summarised in Table 4.4. The hardening predicted by the model for constant strain rates, $10 \mathrm{~s}^{-1}$ and $1000 \mathrm{~s}^{-1}$ is presented in Figure 4.6, where the rate-dependent behaviour of the material can be observed.

Figure 4.7 shows the quite remarkable agreement between the experimental and numerical engineering stress-strain response of the quasi-static tests performed at different orientations. As it can be observed in Figure 4.8, the model is overpredicting the stress-strain response in the case of the experiments at an average strain rate of $0.5 \mathrm{~s}^{-1}$. Nevertheless, the agreement was more than reasonable for the quasi-static and fast cases with average strain rates of $5 \cdot 10^{-4} \mathrm{~s}^{-}$ ${ }^{1}$ and $250 \mathrm{~s}^{-1}$ respectively. For the sake of clarity, in Figure 4.7 and Figure 4.8 the different stress-strain curves are plotted with a +500 MPa offset. 


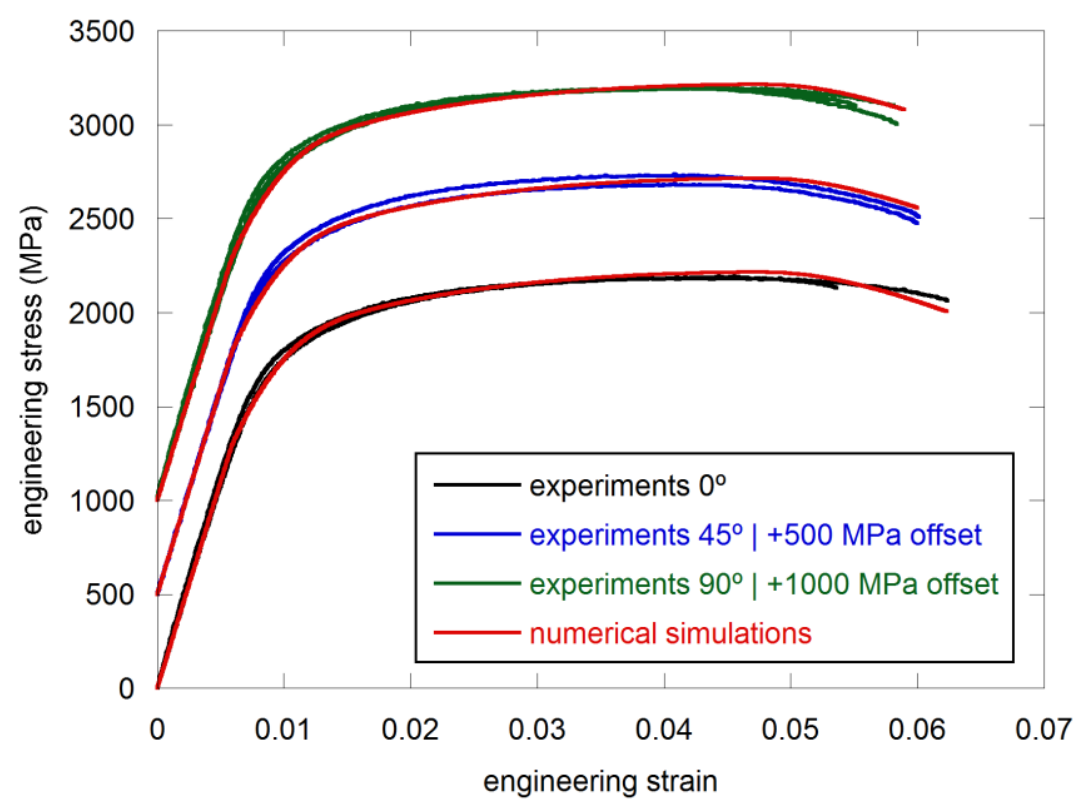

Figure 4.7. Engineering stress-strain curves of Mars ${ }^{\circledR} 240$ steel obtained from UT quasi-static experiments along three different directions $\left(0^{\circ}, 45^{\circ}\right.$ and $\left.90^{\circ}\right)$ compared with the corresponding numerical simulations.

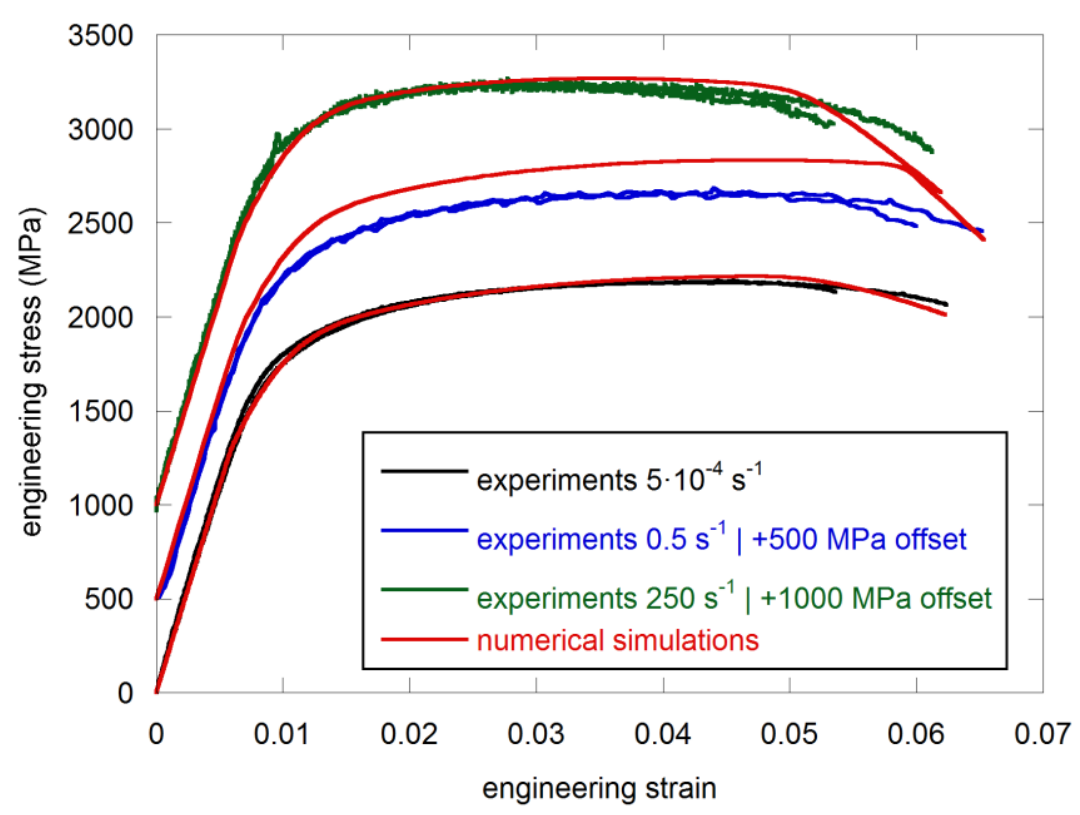

Figure 4.8. Engineering stress-strain curves of Mars 2240 steel obtained from UT experiments at three different strain rates $\left(5 \cdot 10^{-4} \mathrm{~s}^{-1}, 0.5 \mathrm{~s}^{-1}\right.$ and $\left.250 \mathrm{~s}^{-1}\right)$ compared with the corresponding numerical simulations. 


\subsection{Concluding remarks}

The experimental results of the AA7017-T73 alloy revealed a high degree of anisotropy on both yield stress and plastic flow. In order to describe the anisotropy of the material, the rate and temperature dependent Yld2000-3D yield criterion combined with an isotropic Voce hardening model were used. Finite element simulations of the uniaxial tensile tests showed that the plasticity model implemented as a user material subroutine provided accurate predictions.

The experimental results of the Mars $\AA 240$ steel showed the quasi-isotropic behaviour of the material. In order to model its plastic yielding the quadratic rate and temperature dependent Hill 48' yield criterion was chosen, combined with an isotropic Voce hardening model. Finite element simulations of the experiments showed that the plasticity model implemented as a user material subroutine was able to give more than reasonable predictions. 



\section{CHAPTER 5}

\section{EXPERIMENTAL DETERMINATION OF THE DYNAMIC FRACTURE-INITIATION TOUGHNESS}

In order to determine the evolution of the dynamic fracture-initiation toughness with the loading rate of the studied materials, fracture toughness experiments were performed. For such a purpose, four experimental devices were designed and developed. Three-point bending tests of pre-fatigued specimens at different loading rates were carried out employing the following apparatus: a servo-hydraulic universal testing machine, a free-drop tower, a modified split Hopkinson pressure bar (SHPB) and an explosive load testing device. All specimens were tested in asshipped conditions. Dynamic fracture-initiation toughness of AA7017-T73 and Mars $® 240$ at broad range of loading rates was determined. 


\subsection{Standard test method for linear-elastic plane- strain fracture toughness $\mathrm{K}_{\mathrm{IC}}$ of metallic materials}

E 399 standard (E399-12e3, 2012) covers the determination of fracture toughness, $K_{I C}$, of metallic materials under predominantly linear-elastic, plane-strain conditions using fatigue precracked specimens subjected to slowly increasing crack-displacement force. Force is applied either in tension or three-point bending.

The property $K_{I C}$ determined by this test method characterises the resistance of a material to fracture in a neutral environment in the presence of a sharp crack under essentially linear-elastic stress and severe tensile constraint; such that the state of stress near the crack front approaches tritensile plane strain and the cracktip plastic zone is small compared to the crack size, specimen thickness and ligament ahead of the crack.

\subsubsection{Standard bend specimens}

There are several recommended specimen configurations (E399-12e3, 2012). In this $\mathrm{PhD}$ thesis, all the experiments were performed by employing the standard bend geometry $\mathrm{SE}(\mathrm{B})$. A standard bend specimen is a single edge-notched and fatigue precracked beam loaded in three-point bending configuration. In order for a result to be considered valid according to E 399 standard, the specimen ligament size should fulfil

$$
(W-a) \geq 2.5\left(\frac{K_{I C}}{\sigma_{0.2}}\right)^{2}
$$

being $W$ the specimen width, $a$ the specimen crack size and $\sigma_{0.2}$ the $0.2 \%$ offset yield strength of the material at the temperature and loading rate of the test. The bend specimen must also meet the following requirements: 
- Be of sufficient thickness, $B$, to satisfy the width to thickness ratio of $1 \leq W / B \leq 4$ and the nominal crack size (total size of crack starter plus fatigue crack) of $0.45 \mathrm{~W} \leq a \leq 0.55 \mathrm{~W}$.

- The specimen crack size, $a$, should be measured after fracture at midthickness and the two quarter-thickness points. The average of these three measurements should be taken as the crack size, $a$. The difference between any two of the three crack size measurements should not exceed $10 \%$ of the average.

- The plane of the fatigue precrack should be parallel to the plane of the starter notch to $\pm 10^{\circ}$.

- There should be no evidence of multiple cracking.

- The support span, $S$, is nominally equal to four times the specimen width, $W$.

Bend specimen $K_{Q}$ is calculated as follows

$$
K_{Q}=\frac{P_{Q} S}{B W^{3 / 2}} f\left(\frac{a}{W}\right)
$$

being

$$
f\left(\frac{a}{W}\right)=3 \sqrt{\frac{a}{W}} \frac{1.99-\left(\frac{a}{W}\right)\left(1-\frac{a}{W}\right)\left[2.15-3.93 \frac{a}{W}+2.7\left(\frac{a}{W}\right)^{2}\right]}{2\left(1+2 \frac{a}{W}\right)\left(1-\frac{a}{W}\right)^{3 / 2}}
$$

where $P_{Q}$ is the force determine by drawing the secant line through the origin of the force-displacement test record (Figure 5.1) with slope $(P / u)$ equal to $0.95(P / u)_{0}$, where $(P / u)_{0}$ is the slope of the tangent to the initial linear portion of the record. If the force at every point on the record which precedes $P$ is lower than $P$ (Figure 5.1, Type I), then $P$ is $P_{Q}$. However, if there is a maximum force 
preceding $P$ which exceeds it (Figure 5.1, Type II and III), then this maximum force is $P_{Q}$. When $P_{Q}$ is determined, then $K_{Q}$ should be calculated. If the following expression is fulfilled

$$
2.5\left(\frac{K_{I C}}{\sigma_{0.2}}\right)^{2} \leq(W-a)
$$

then

$$
K_{Q}=K_{I C}
$$

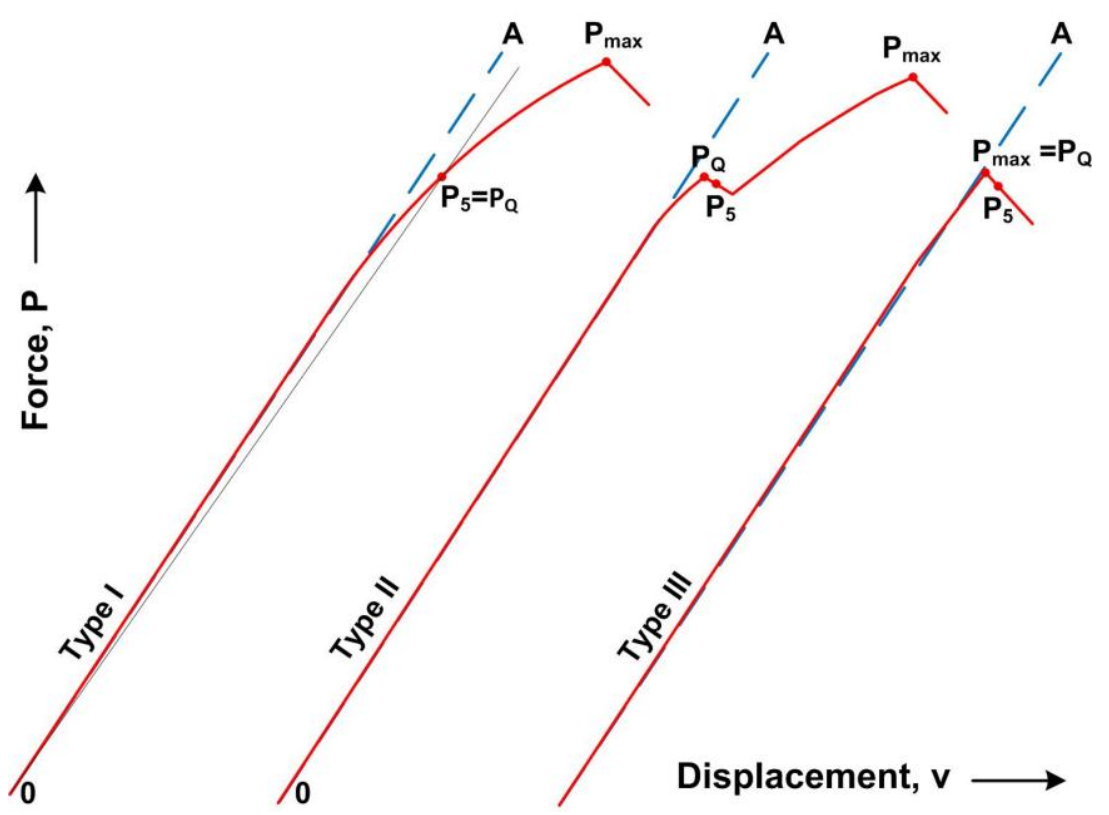

Figure 5.1. Principal types of force-displacement (CMOD) records.

Testing bend specimens are fatigue precracked. The objective of fatigue precracking is to produce a sharp crack which is unaffected by the precracking procedure. A fatigue precrack is produced by cyclically loading the notched specimen at a ratio of minimum-to-maximum stress. Fatigue cycling usually begins with a sinusoidal waveform and near to the highest practical frequency. The maximum stress-intensity factor, $K_{\max }$, during any stage of fatigue crack growth should not exceed $80 \%$ of the $K_{I C}$ value of the material. For the terminal stage of 
fatigue precracking $K_{\max }$ should not exceed $60 \%$ of $K_{I C}$. The fatigue cracking setup should be such that the stress distribution is uniform through the specimen thickness; otherwise the crack will not grow uniformly. The stress distribution should also be symmetrical about the plane of the prospective crack. The procedure should be done at room temperature with the specimen in the finally heat-treated or mechanically-worked state in which it is to be tested. The specimen should be carefully monitored until crack initiation is observed on one side of the specimen (Figure 5.2). If crack initiation is not observed on the other side before appreciable growth is observed on the first one, then fatigue cycling should be stopped to try to determine the cause and remedy for the unsymmetrical behaviour.
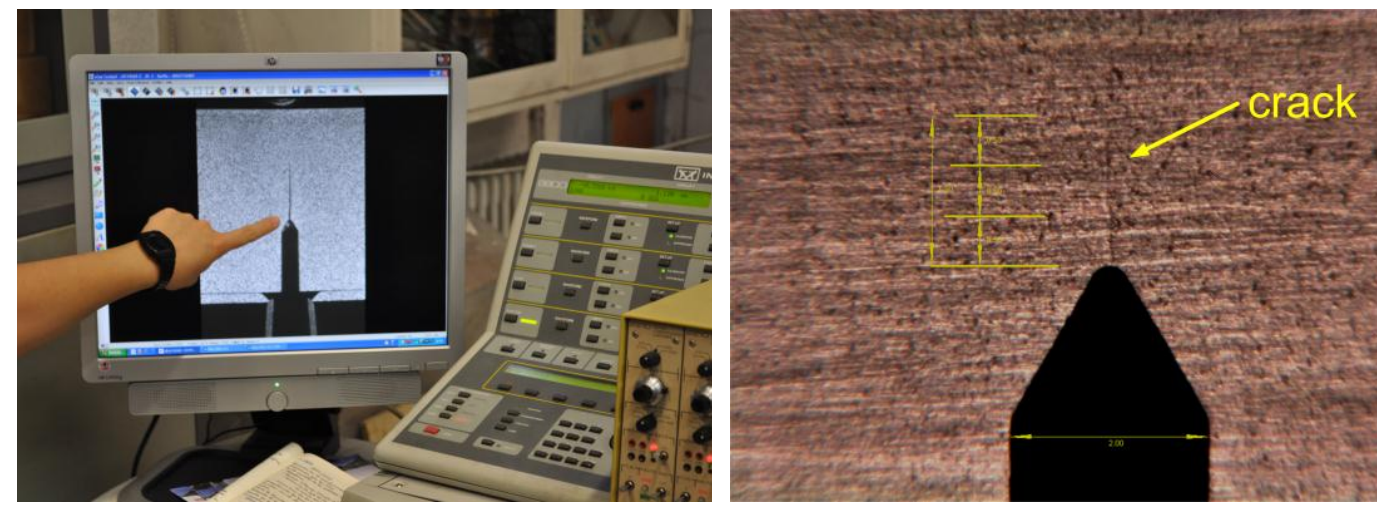

Figure 5.2. Crack growth monitored while fatigue pre-cracking.

As stated before, in this thesis all of the experiments were performed by employing the standard bend geometry SE(B). The specimens were machined with EDM from a rolled plate as the one shown in Figure 5.3, following the requirements of the standards (Figure 5.4). The reference directions were identified as $\mathrm{L}$ or direction of principal deformation (maximum grain flow), $\mathrm{T}$ or direction of least deformation and $\mathrm{S}$ or third orthogonal direction. L-S specimens were extracted from the rolled plate, in which the fracture plane normal was in the direction of maximum grain flow or longitudinal direction of the plate and the expected direction of crack propagation was coincident with the thickness direction of the plate (Figure 5.3). The final dimensions of the AA7017-T73 alloy and Mars $₫ 240$ steel specimens are specified in Table 5.1. 


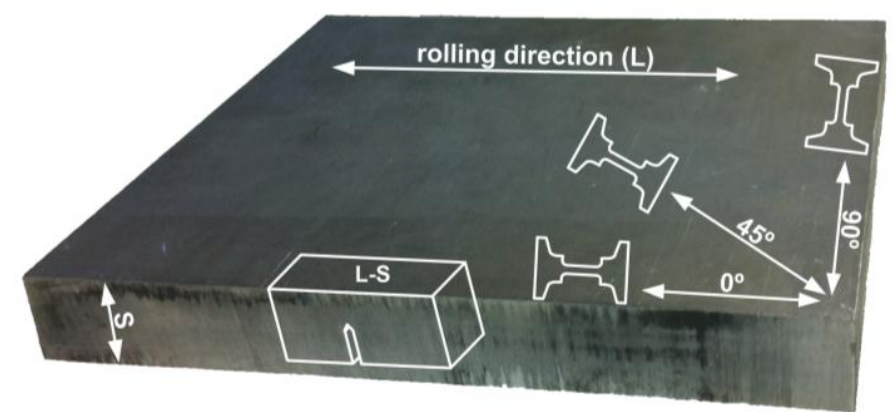

Figure 5.3. Specimens extracted from the original plate.

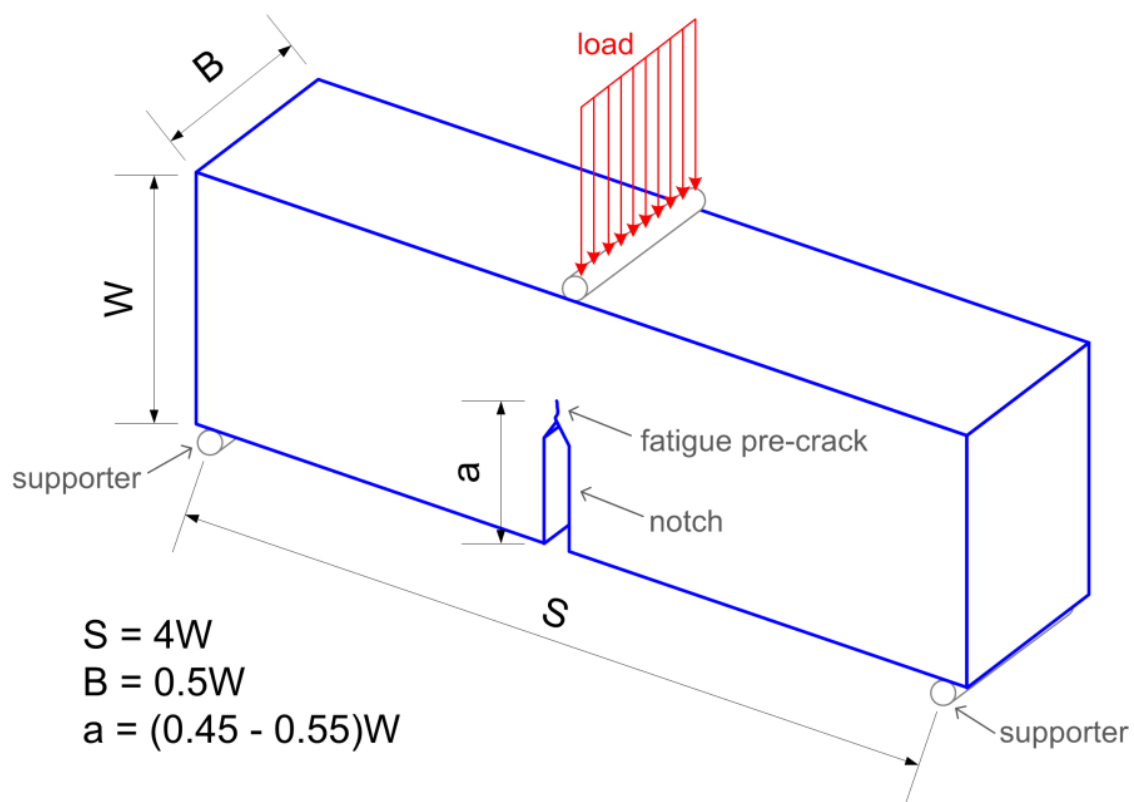

Figure 5.4. Geometry and dimensions requirements of the standard bend specimen.

Table 5.1. Dimensions of the specimens

\begin{tabular}{|c|c|c|c|c|}
\hline & $\begin{array}{c}\text { width, } W \\
(\mathrm{~mm})\end{array}$ & $\begin{array}{c}\text { thickness, } B \\
(\mathrm{~mm})\end{array}$ & $\begin{array}{c}\text { crack length, } a \\
(\mathrm{~mm})\end{array}$ & $\begin{array}{c}\text { span, } S \\
(\mathrm{~mm})\end{array}$ \\
\cline { 1 - 4 } AA7017-T73 & 30 & 15 & 16 & 120 \\
\cline { 1 - 4 } Mars ${ }^{2} 240$ & 25 & 12.5 & 13 & 100 \\
\hline
\end{tabular}


After testing, all of the specimens were carefully examined (Figure 5.5), the specimen crack size $a$ was measured and when all of the requirements were fulfilled, then the $K_{I C}$ of the material was obtained for each sample.

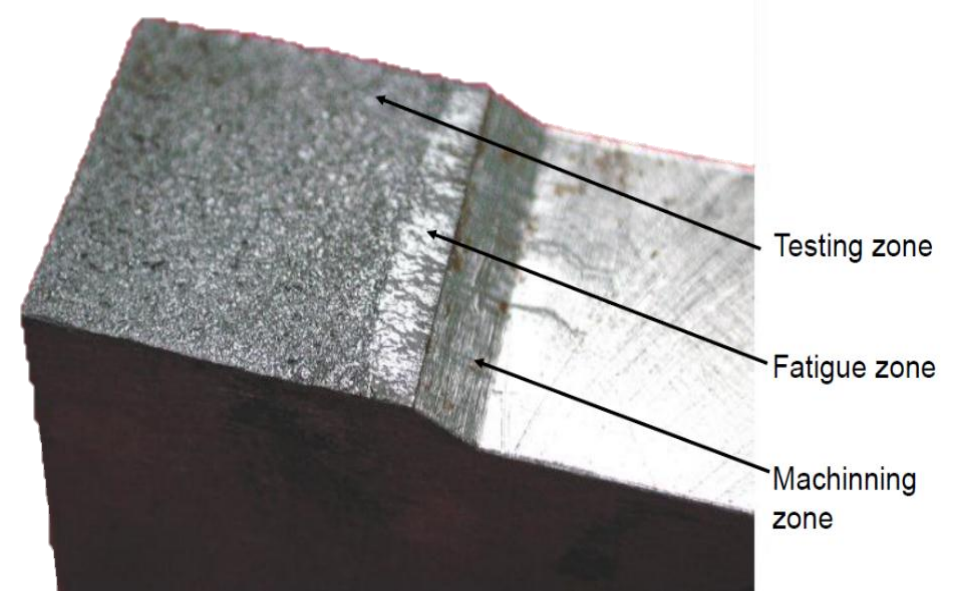

Figure 5.5. Fracture crack zones.

A strain gauge was bonded close to the tip of the fatigue crack of each sample (Figure 5.6a), enabling the measured strain to be associated with the load applied to each specimen. This was considered as an indirect method of load measurement that was particularly important in the dynamic tests, given that they lacked a load cell. Note that the measured strain component was normal to the crack plane; in other words, it was perpendicular to the load applying axis. In order to obtain the relationship between the applied load and measured strain, all the pre-cracked samples were subjected previously to a loading and unloading cycle without any crack propagation. Such a relation was found to be linear and different for every sample (Figure 5.6b). The strain gauges were model CEA-13-062UW350 for the AA7017-T73 specimens and model CEA-06-062UW-350 for the Mars $®$ 240 steel samples, from Micro-Measurements. The signal obtained from the strain gauges was treated with a 2210 signal conditioning amplifier system also from Micro-Measurements. 


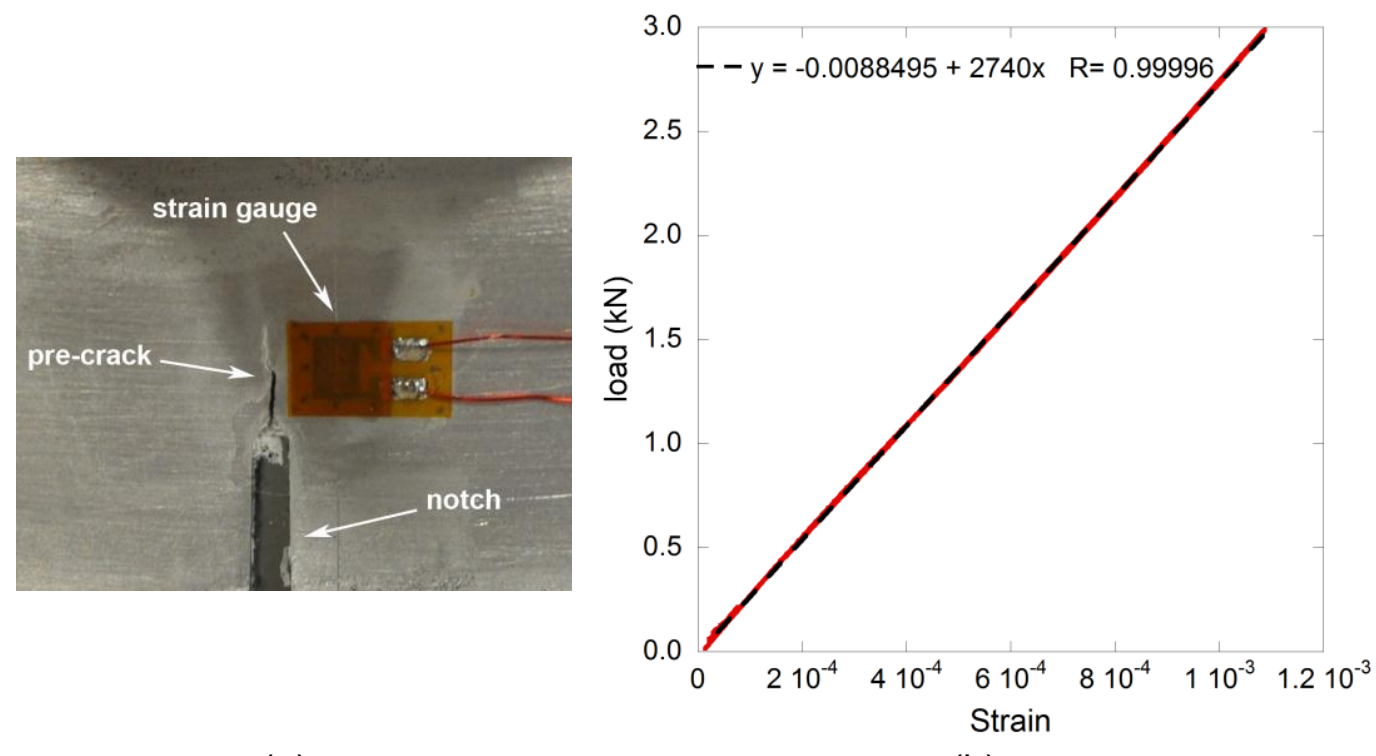

(a)

(b)

Figure 5.6. Crack growth monitored while fatigue pre-cracking.

\subsection{Experimental set-up for low strain rates}

Quasi-static fracture toughness tests were conducted in a Instron 8803 servohydraulic universal testing machine under displacement control following the recommendations of the standards $(E 399-12 e 3,2012)$. The bend test fixture is shown in Figure 5.7, designed to minimise friction effects. The specimen was positioned on two cylindrical support rollers that could rotate and translate slightly as the specimen was loaded, thereby achieving rolling contact. While free to roll and translate during test, the rollers were initially positioned against stoppers that set the span length and were held in place by low-tension rubber bands Another cylinder, supported on top of the specimen was the responsible of applying the load. The bend fixture was positioned such that the line of action of the applied force was allined with the midpoint line between the support rollers and was perpendicular to the roller axes. Additionally, an extensometer with a range of $+7 /$ $1 \mathrm{~mm}$ was attached to the specimen in order to measure the crack-mouth opening displacement (CMOD). The tests were recorded with a IDS uEye 1490SE video camera configured to achieve $1 \mathrm{fps}$ with a resolution of $2448 \times 2048$ pixels. A 
speckle pattern was painted on the specimens in order to perform DIC analysis of the images taken during the tests. The applied load was obtained by a $25 \mathrm{kN}$ load cell and by the strain gauge measurement, that is, from the linear relation for each specimen (see section 5.1.1, Figure 5.6b). The signal obtained from the strain gauge was treated with a 2210 signal conditioning amplifier system from MicroMeasurements.

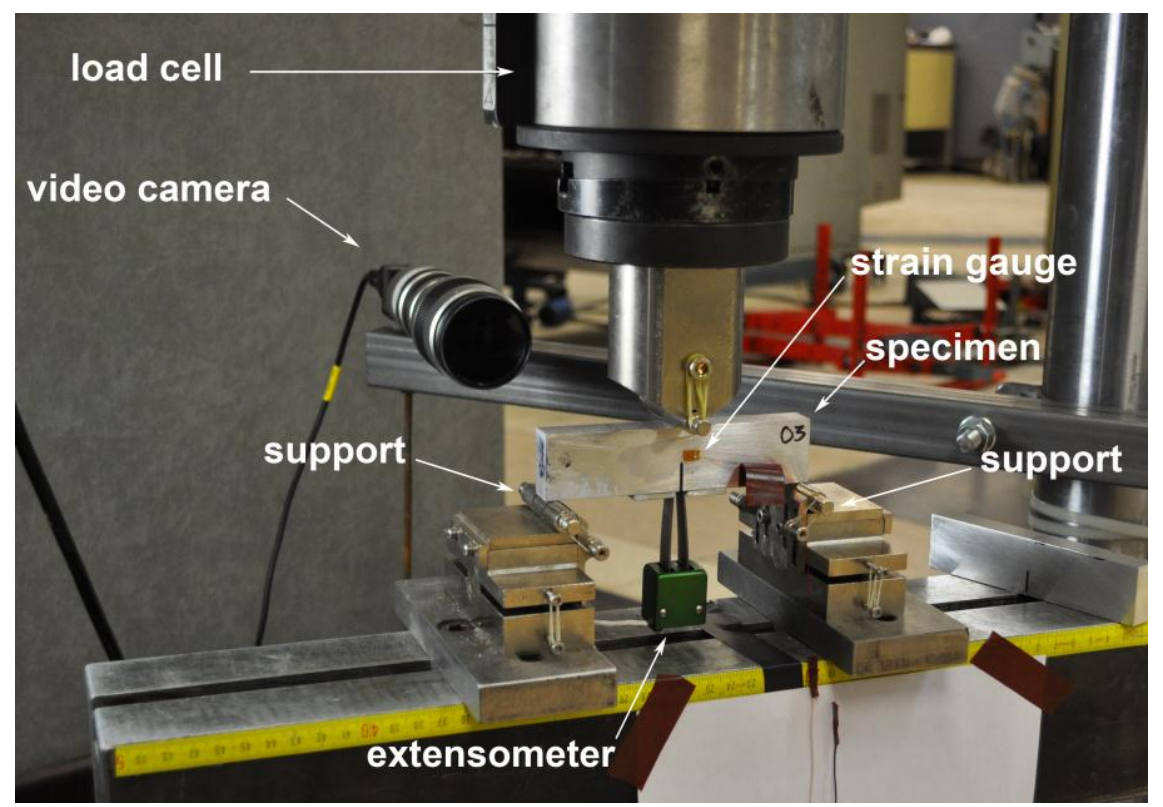

Figure 5.7. Experimental set-up of the quasi-static fracture toughness tests.

\subsection{Experimental set-up for drop weight impact tests}

The tests were conducted in a Dynatup 8250 drop weight tower. These tests were carried out by following the same configuration as that employed in the quasi-static experiments. The experimental device used is shown in Figure 5.8. The test consisted of dropping a $6 \mathrm{~kg}$ weight located $2 \mathrm{~m}$ above the specimen. A cylinder was attached to the bottom of the weight in order to apply the load. The specimen was positioned on two cylindrical roller bearings. The tests were recorded with a Phantom v12 high speed camera which was set up to record $180064 \mathrm{fps}$, taking $128 \times 128$ pixels resolution images with $5.55 \mu$ s spacing between each one. The DIC software was used to post-process the images. The equipment included highpowered lamps that were focussed on the specimen. The applied load was 
obtained by the strain gauge measurement, that is, from the linear relation for each specimen. The signal obtained from the strain gauge was treated with a 2210 signal conditioning amplifier system from Micro-Measurements and recorded by a Tektronix TDS714L oscilloscope.

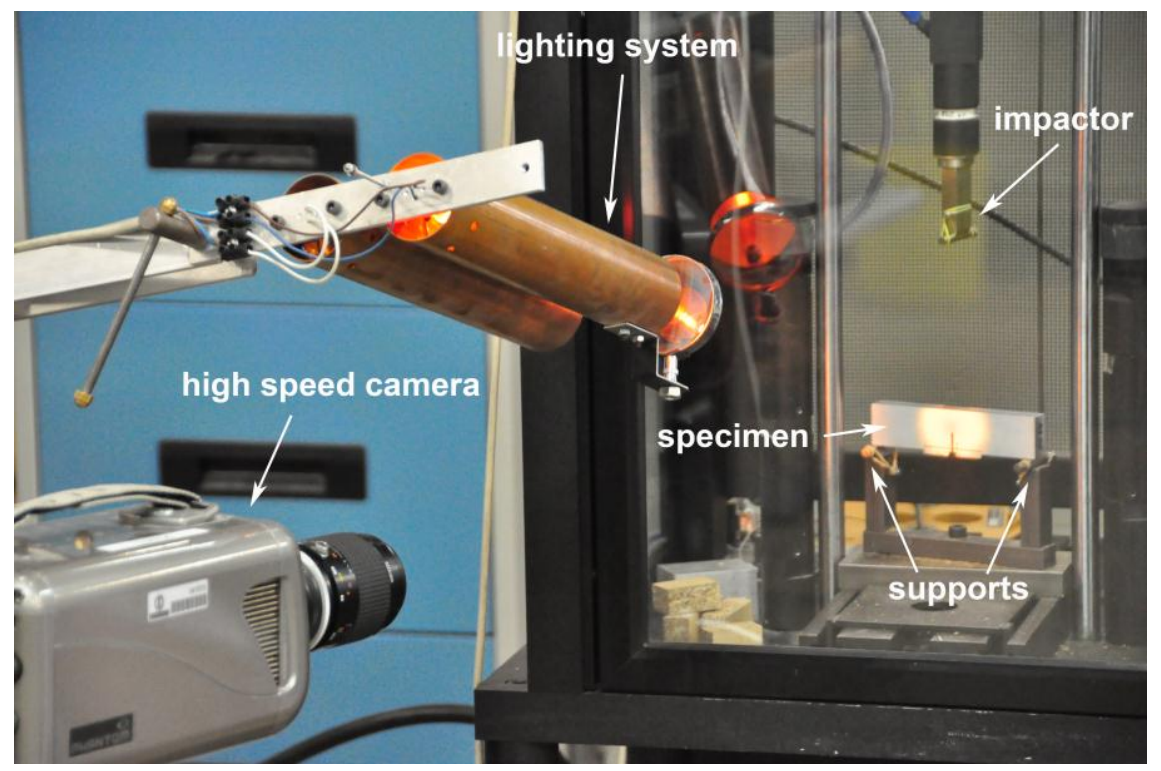

Figure 5.8. Experimental set-up of the drop weight fracture toughness impact tests.

\subsection{Experimental set-up for modified split Hopkinson pressure bar tests}

A classical split Hopkinson pressure bar (SHPB) (Kolsky, 1949) was modified in order to test the same specimen geometry as in the cases above. The test consisted of impacting the sample with an input bar. The experimental set-up, schematically illustrated in Figure 5.9, was composed of a striker bar launched inside a tubular cannon and two input bars. The striker bar, made of steel, was 510 $\mathrm{mm}$ in length and $22 \mathrm{~mm}$ in diameter. The input bars, both of steel, were $1000 \mathrm{~mm}$ in length and $22 \mathrm{~mm}$ in diameter and had strain gauges attached in order to measure the incident and the reflected waves. In this case, the end of the second input bar initially in contact with the specimen was rounded off to simulate the action of the load applying rollers used in the rest of the test configurations. The tests were recorded with a Phantom v12 high speed camera set up to record 
$120171 \mathrm{fps}$, leading to a time increment of $8.32 \mu \mathrm{s}$ between consecutive images, and with a resolution of $208 \times 128$ pixels. The images were post-processed using the DIC software. The equipment included high-powered lamps focussed on the specimen. The load was obtained through applying the linear relationship calculated previously for each sample to the measured strain from the strain gauge attached to the specimen. The signal obtained from the strain gauges attached to the specimen and to the bars were treated with a 2210 signal conditioning amplifier system from Micro-Measurements and recorded by a Tektronix TDS714L oscilloscope.

The striker bar, launched with compressed air, impacted the first input bar. Such impact caused a compressive incident wave which travelled along the first and second input bars until it reached the specimen. This wave could be measured by the strain gauges attached to the bars that were wired in a full Wheatstone bridge circuit.

According to (Guo et al., 2011), during the initial loading phase there might be a loss of contact between the specimen and such supports. If the loss of contact time is greater than the time that the specimen takes to fracture, then there is no influence of the support conditions. This loss of contact was reported previously in other studies, such as those by (Böhme and Kalthoff, 1982; Kalthoff, 1985; Yokoyama, 1993) and (Rubio-González et al., 2008). In order to verify that the support conditions were not affecting the results when performing these particular three-point bending tests, two experimental set-ups were tested:

- A first batch of tests was performed with no cylindrical supports (see Figure 5.11a).

- A second batch of tests where two output bars were added to the experimental device (Figure 5.10 and Figure 5.11b) was carried out. These bars, both of steel, were $800 \mathrm{~mm}$ in length and $12 \mathrm{~mm}$ in diameter. The full experimental set-up is shown in Figure 5.12. 


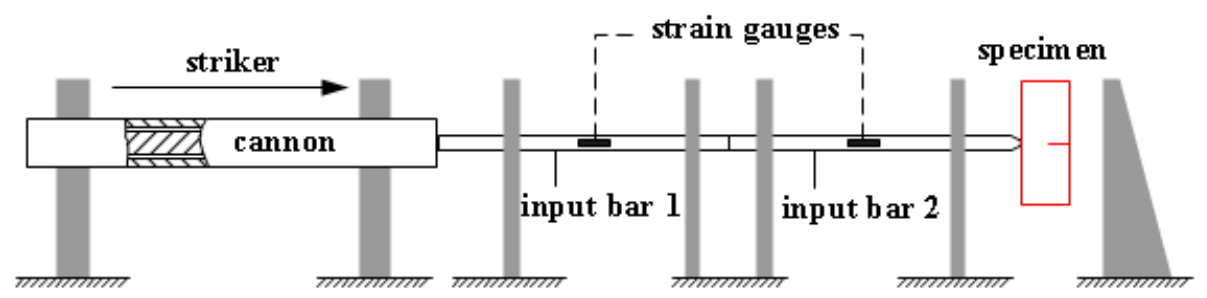

Figure 5.9. Schematic view of the modified SHPB used to carry out the fracture toughness tests on TPB specimen without supports.

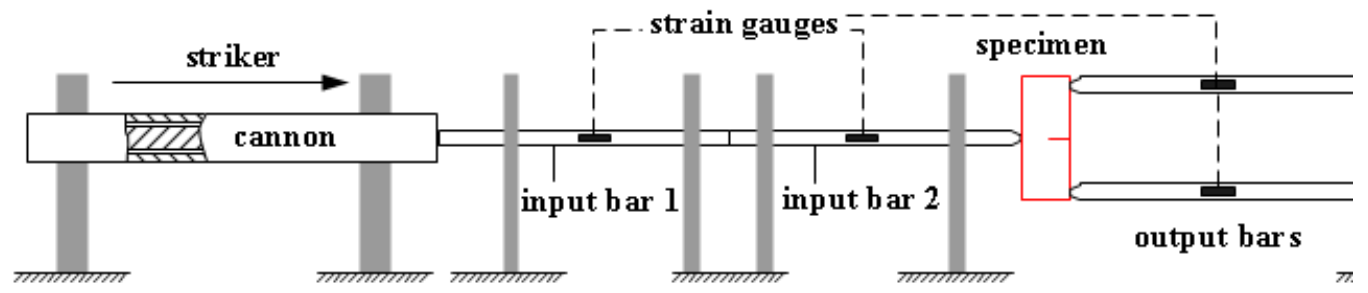

Figure 5.10. Schematic view of the modified SHPB used to carry out the fracture toughness tests on TPB specimen with two output bars as supports.

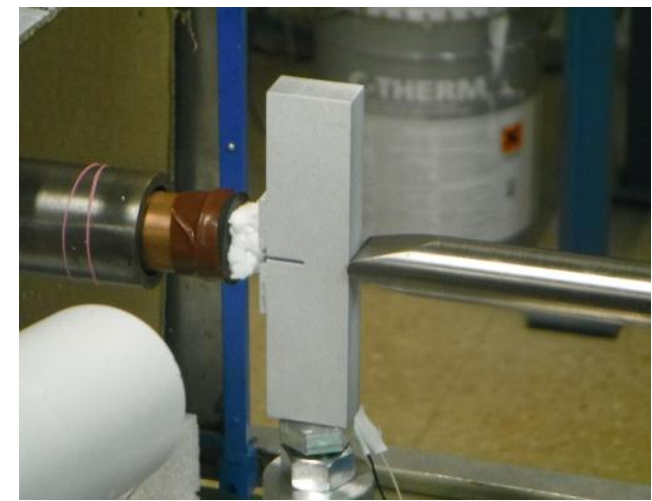

(a)

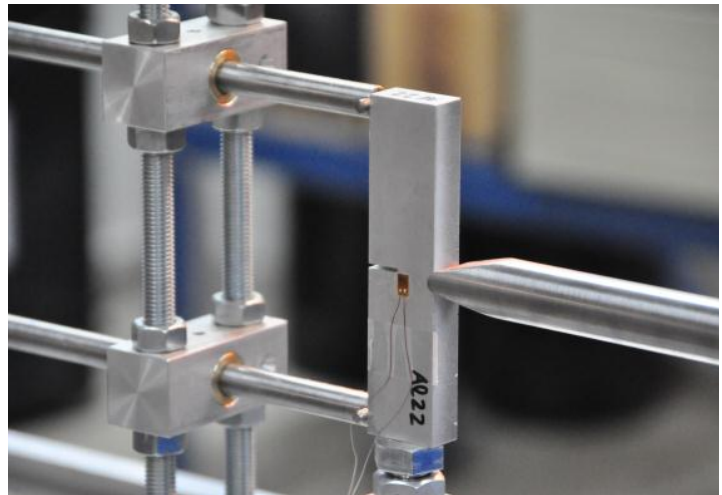

(b)

Figure 5.11. Images of the modified SHPB used to carry out TPB tests without (a) and with two output bars (b). 


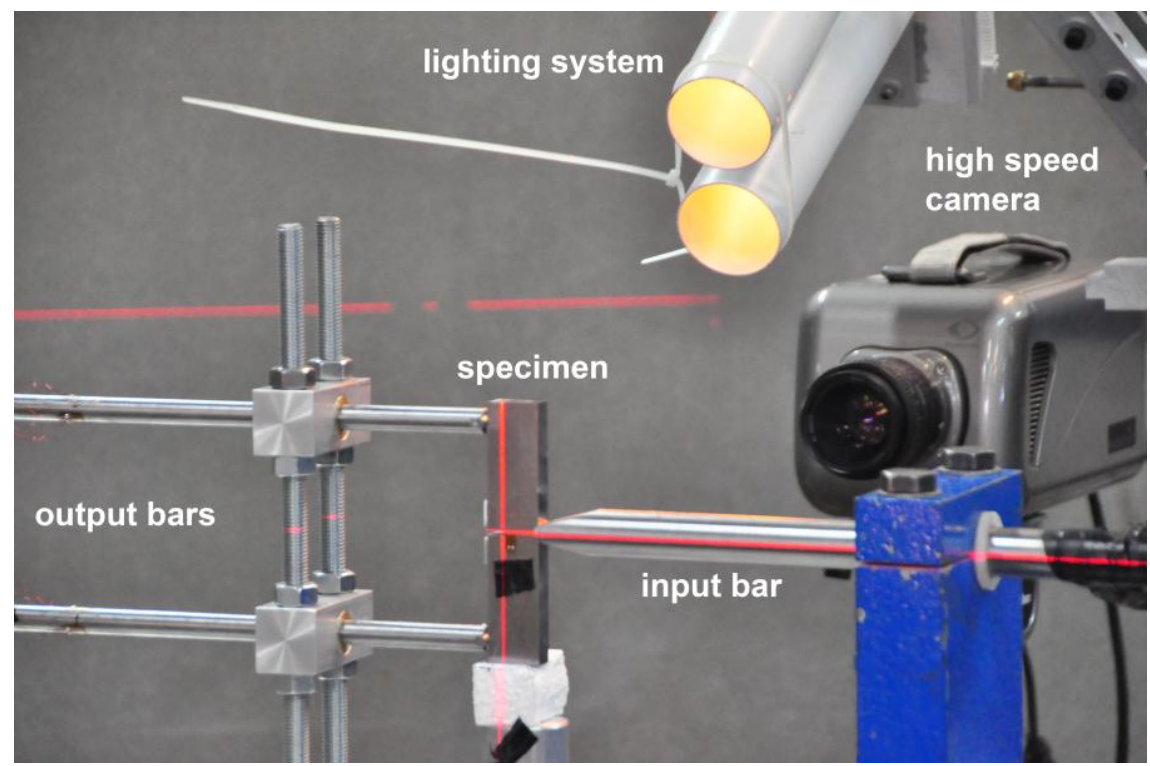

Figure 5.12. Experimental set-up of the modified SHPB used to carry out fracture toughness tests.

\subsection{Experimental set-up for explosive tests}

An explosion may be defined as an event that occurs due to a sudden release of energy within a limited space. However, an explosion in which the chemical energy of a certain explosive compound is liberated should be called detonation. In such a detonation, a blast wave is formed by a difference in the air pressure on both sides of the shock front and moves away at high speed from the detonation point. Unconfined explosions are those that take place in the open air. Particularly, open air explosions are those where the shock wave reaches the structure with no intermediate disturbances. It should be noted that an open air detonation depends on the atmospheric conditions and landscape configuration.

A series of fracture toughness tests were conducted under blast loadings by using explosives. A new device was designed and developed to perform three-point bending tests under explosive loadings. For the sake of consistency and as in the rest of the tests, the design was based on the ASTM E 399 standard (E399-12e3, 2012). Nevertheless, substantial modifications were made in order to adapt it to conduct tests under impulsive loadings. 
A steel frame, designed in (Morales-Alonso, 2013; Morales-Alonso et al., 2011a; Morales-Alonso et al., 2011b), for testing concrete samples under blast loading, was simultaneously used to test the new device and the afore-mentioned samples. The frame consisted of four vertical steel columns joined horizontally by I steel beams, with it being square in plan view (see Figure 5.13). These horizontal beams acted as a support for the devices. The steel frame was a symmetric structure in which the explosive was hung at its geometrical centre. It was considered a braced structure when subjected to the blast wave. The new device and the explosive were placed on a horizontal plane above the ground, with its height being greater than the distance from the explosive to the device (Figure 5.14). By doing this, the blast shock wave reached the device directly without any rebound that could have been created by interacting with the floor.

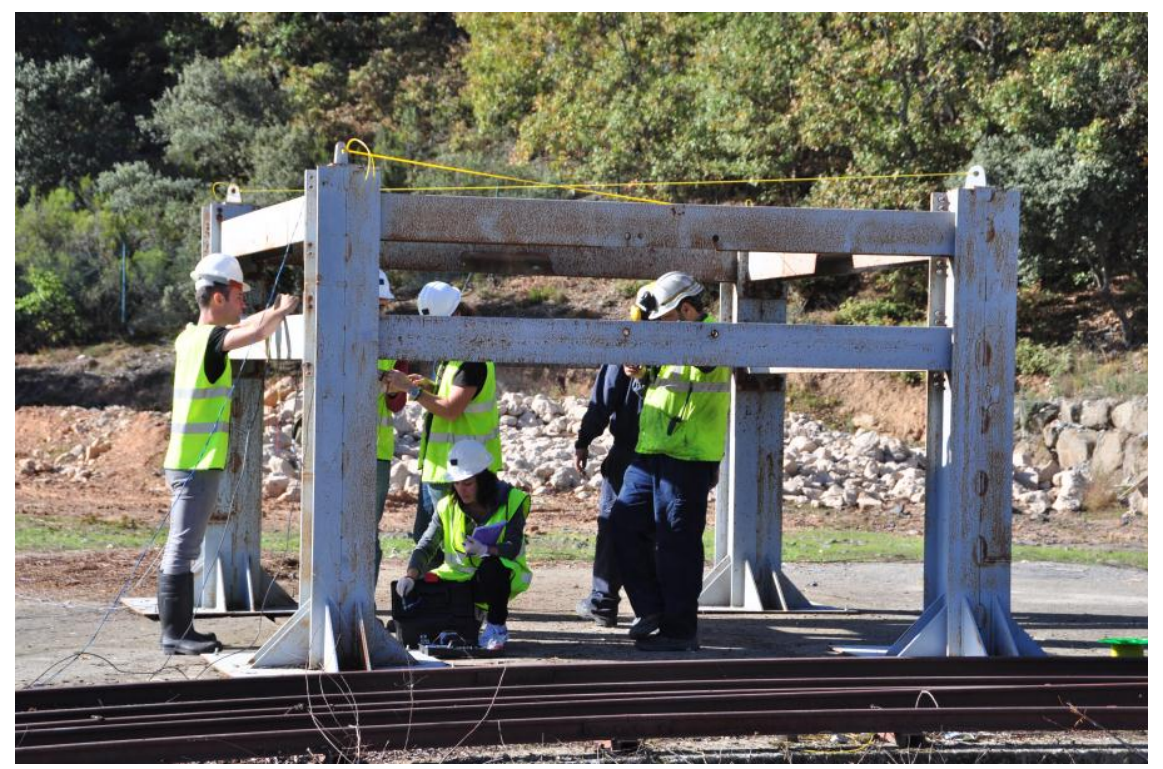

Figure 5.13. Steel frame used to bear the device for the fracture toughness explosive tests. 


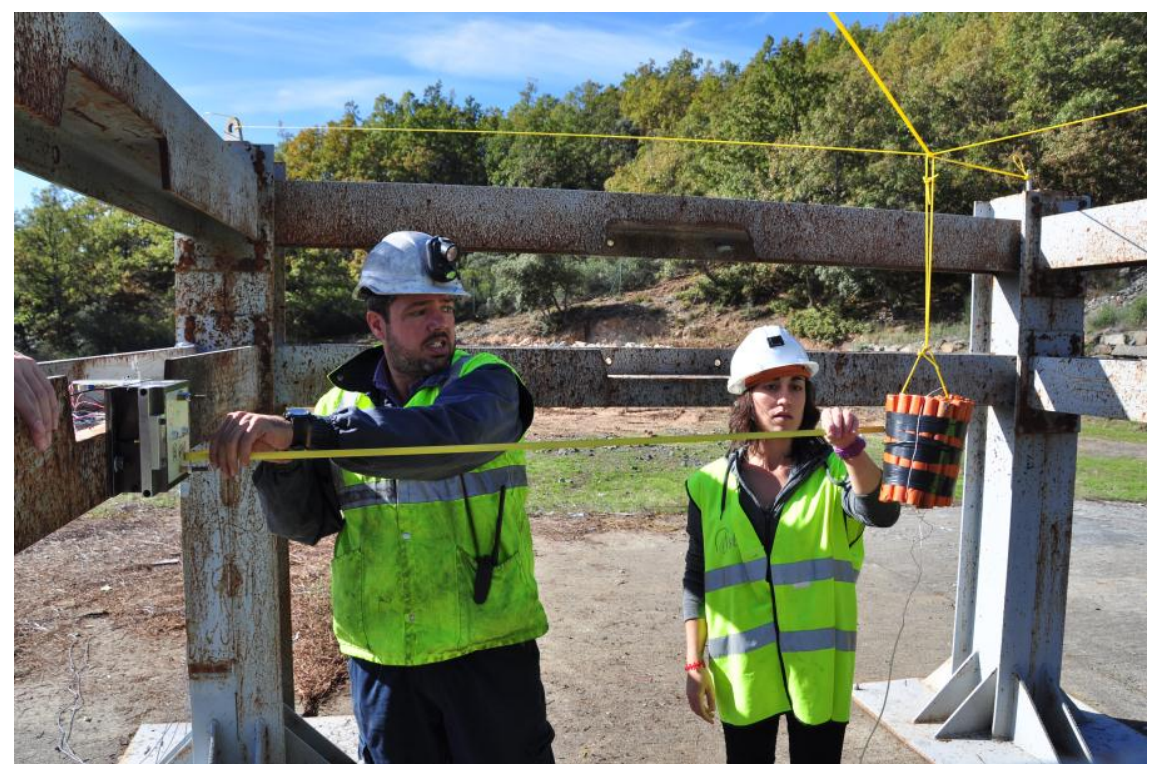

Figure 5.14. The new device used for the fracture toughness explosive tests and the explosive placed on a horizontal plane above the ground.

Another key point that needed to be fulfilled in oder to conduct successful experiments was that the shock wave generated in the explosion had to strike at the same time and in a uniform manner the exposed surface of the device. In other words, the shock wave shape had to be as planar as possible. This requirement did not match with the spherical shaped shock waves generated in an open air explosion. As the device was small enough and was far enough from the explosive, the curvature of the blast wave could be neglected and it could be assumed to be planar (Morales-Alonso et al., 2011a). The dimensions of the steel frame were set to $2 d=3.00 \mathrm{~m}$ between columns, stand-off from explosive to the device to $d=1.50$ $\mathrm{m}$, and height of the centre to the device to $\mathrm{H}=1.60 \mathrm{~m}$ (see Figure 5.15).

The newly developed device was mounted on the steel frame, as can be seen in Figure 5.16. It consisted of a $146 \times 146 \times 90 \mathrm{~mm}$ steel box with its cover made of a composite laminate and facing directly to the explosive (Figure 5.17). The specimen was positioned on two cylindrical roller bearings, as it can be seen in Figure 5.18. A steel cylinder attached to the composite laminate was the load applier. When the shock wave reached the laminate it was moved into the box loading the specimen. The laminate was composed of several carbon and glassfibre plies. Due to the low weight of such a component, close to $0.4 \mathrm{~kg}$, higher load 
application velocities could be achieved. Two coil springs were installed in order to guarantee that the load applier was initially in contact with the specimen (Figure 5.18). In addition, the device allowed the simultaneous testing of up to two threepoint bending samples (see Figure 5.19 and Figure 5.20), thus making experimental scatter more controlable.

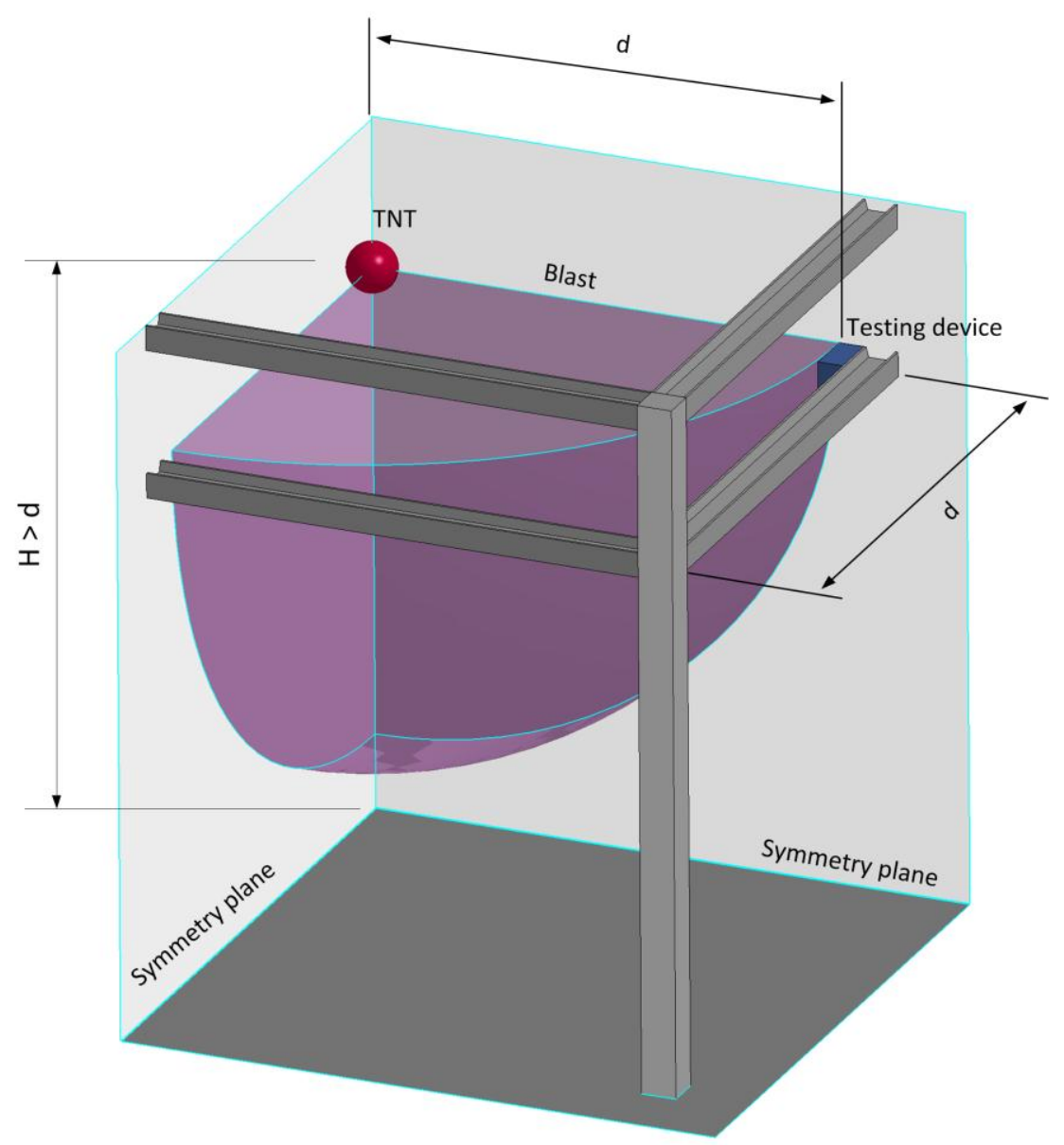

Figure 5.15. A sketch of the set-up used in the fracture toughness explosive tests. 


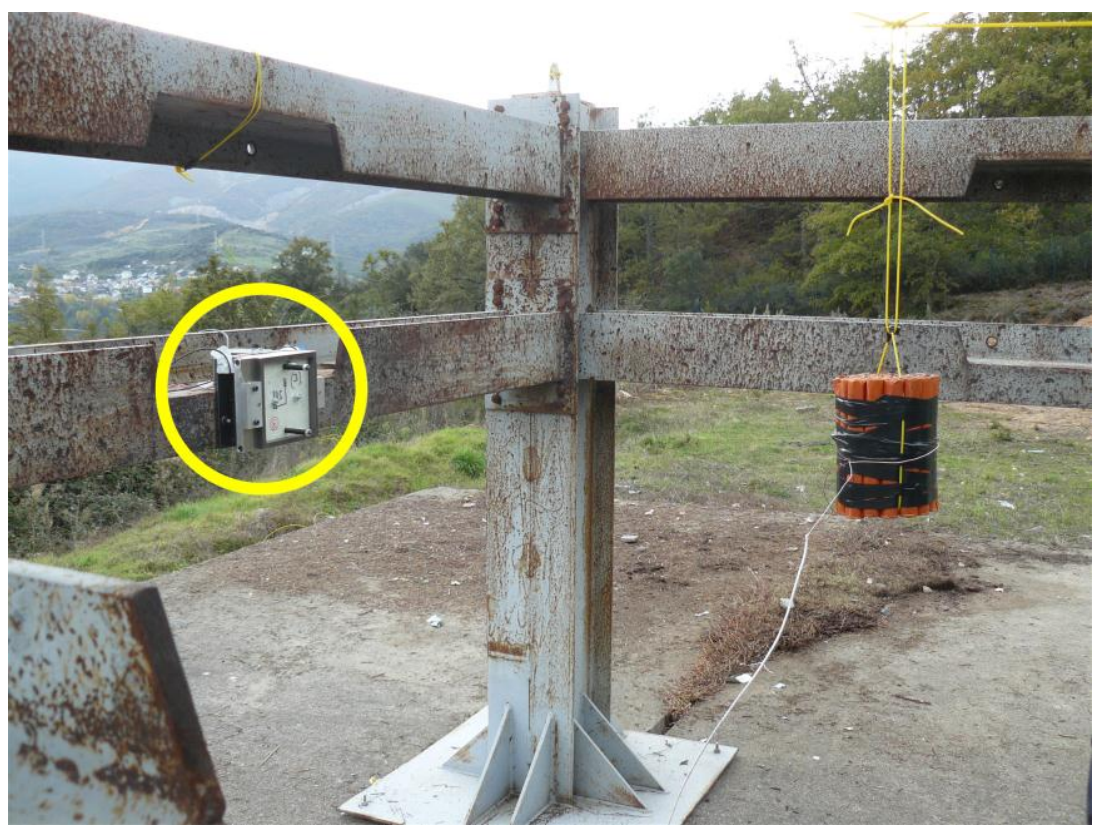

Figure 5.16. The developed new deviced for fracture toughness explosive tests mounted on the steel frame.

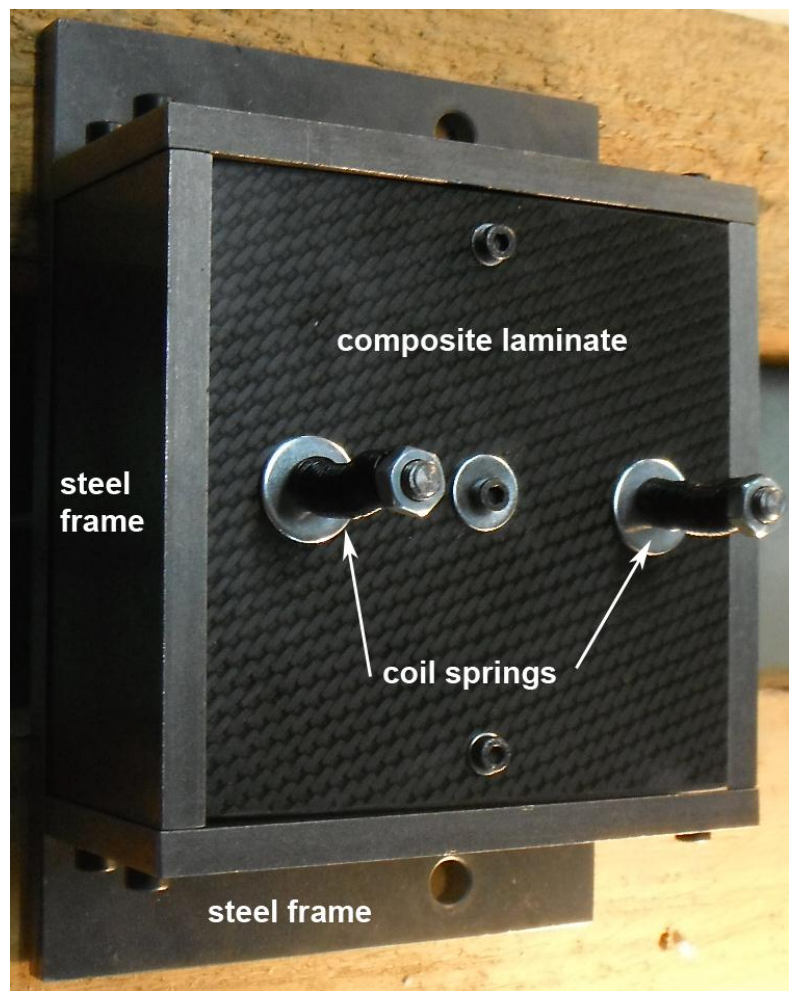

Figure 5.17. The device for fracture toughness explosive tests consisted of a steel box with a composite laminate cover. 


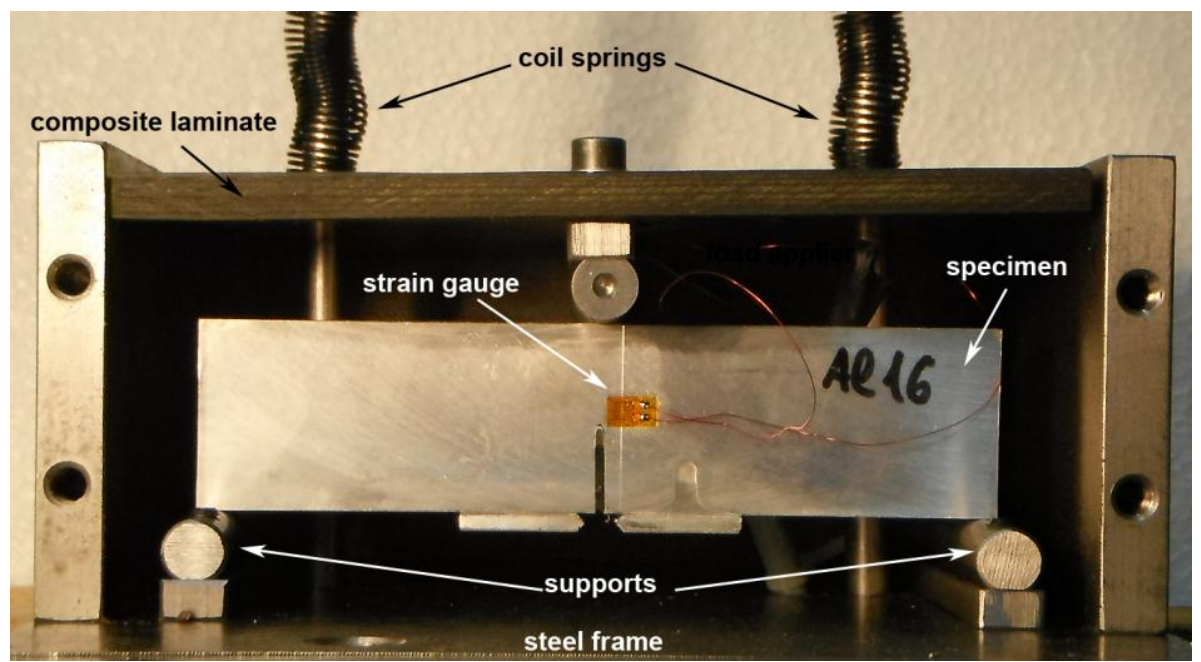

Figure 5.18. Interior layout of the device for fracture toughness explosive tests: two cylindrical supports, the load applier attached to the composite laminate and the specimen with an attached strain gauge.

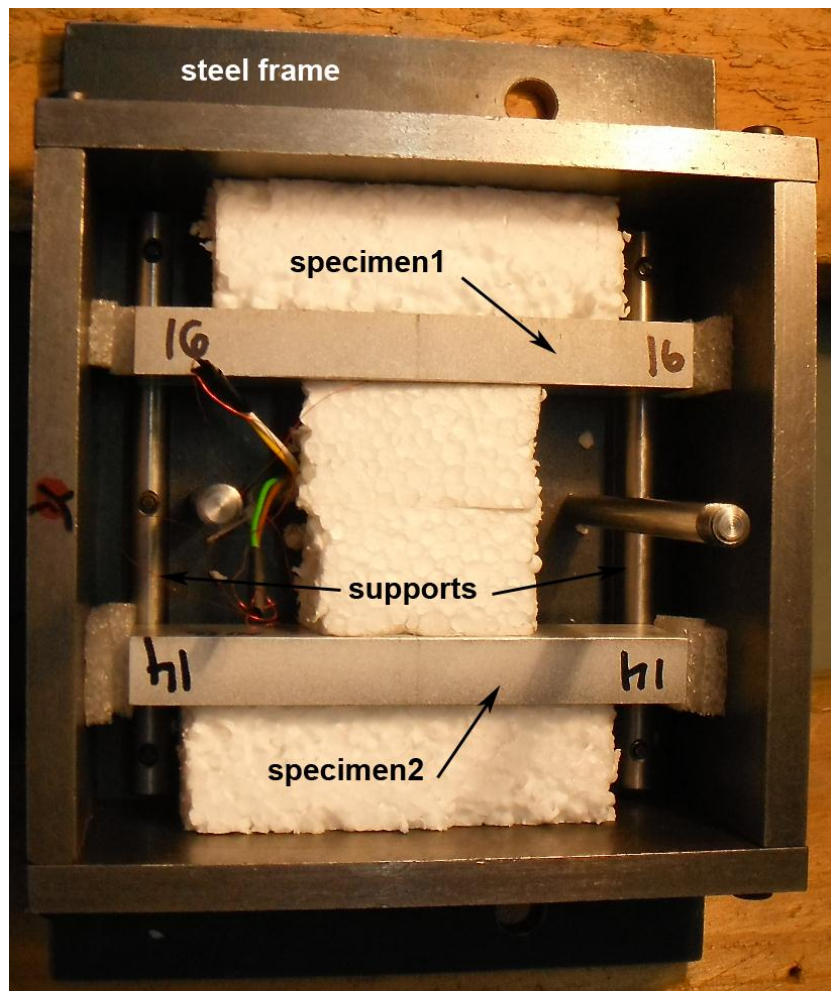

Figure 5.19. Two specimens mounted on the cylindrical supports in the device for fracture toughness explosive tests. 


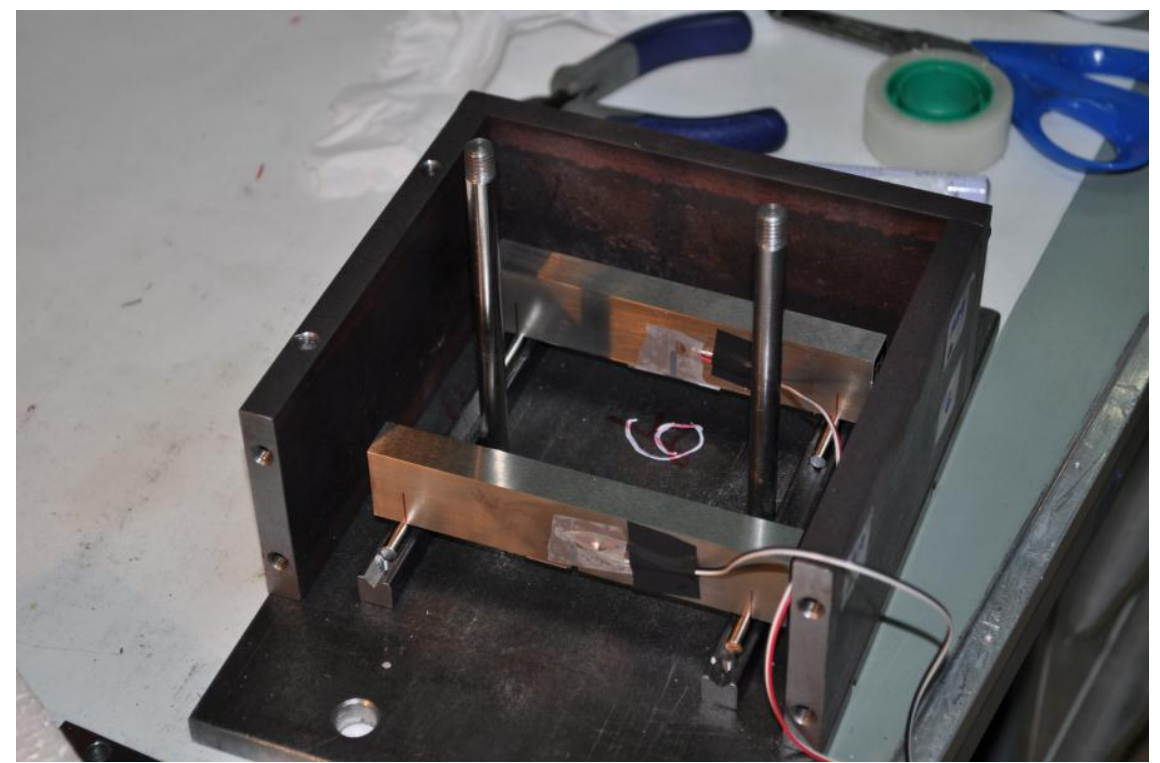

Figure 5.20. The device for fracture toughness explosive tests allowed the simultaneous testing of up to two TPB samples.

The explosive used for the detonations was the commercial compound Goma-2 ECO (NordNorsk, 2003) or dynamite, with a density of $1.48 \mathrm{~g} / \mathrm{cm}^{3}$ and a combustion heat of $89 \%$ of the energy release of $1 \mathrm{~kg}$ of TNT. This kind of explosives generate a blast wave when exploding, which propagation speed is higher than the speed of sound in the air, generating very high pressures. The explosive was available in bar form (see Figure 5.21a). The bars were $200 \mathrm{~mm}$ in length and $8 \mathrm{~mm}$ in diameter and were tied together forming a cylindrical bunch. In order to preserve the blast wave symmetry as much as possible, the explosive pack was vertically hung (see Figure 5.21b). It should be taken into account that the maximum amount of explosive was limited to $5 \mathrm{~kg}$ of equivalent TNT due to restrictions of noise pollution legislation (BOE-A-2003-20976, 2003). Although employing explosives allowed to achieve really high loading rates comparing to other experimental techniques, note that special permits and qualified personnel were required to manipulate explosives. So the experiments had to be done in specialised institutions. In this research, all of the experiments under impulsive loadings were performed in Fundación Santa Bárbara in León, Spain. 


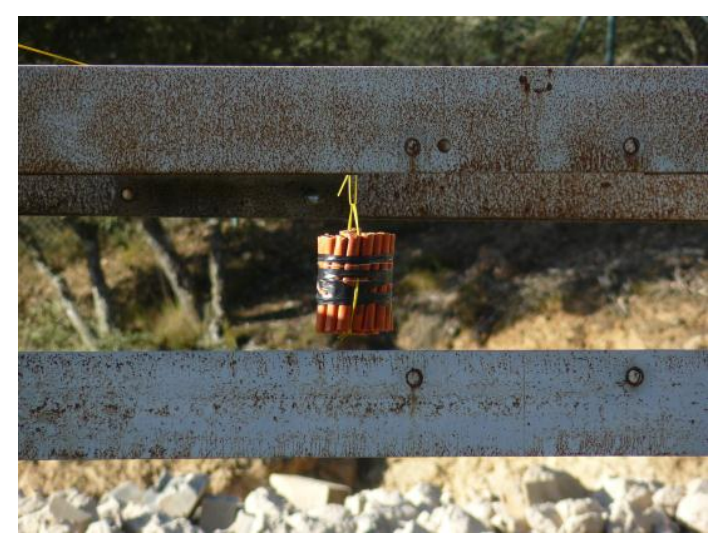

(a)

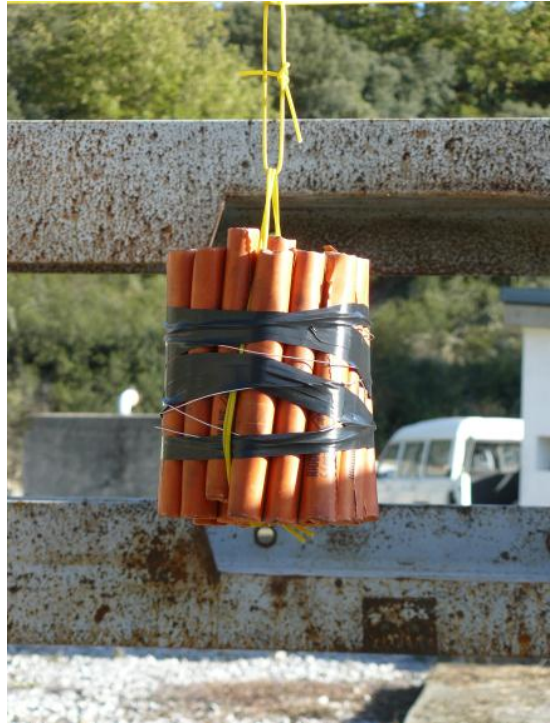

(b)

Figure 5.21. The explosive was presented in bars, tied together forming a cylindrical bunch.

The data acquisition systems were set on a bunker located at a stand-off distance of $20 \mathrm{~m}$ from the detonation point (see Figure 5.22). A Phantom v12 high speed camera was set up to record $18000 \mathrm{fps}$, leading a time period of $55.55 \mu \mathrm{s}$ among images, and with a resolution of $640 \times 480$ pixels. It was used to verify that all the bars exploded at the same time and an appropriate blast shock front was formed (Figure 5.23a).
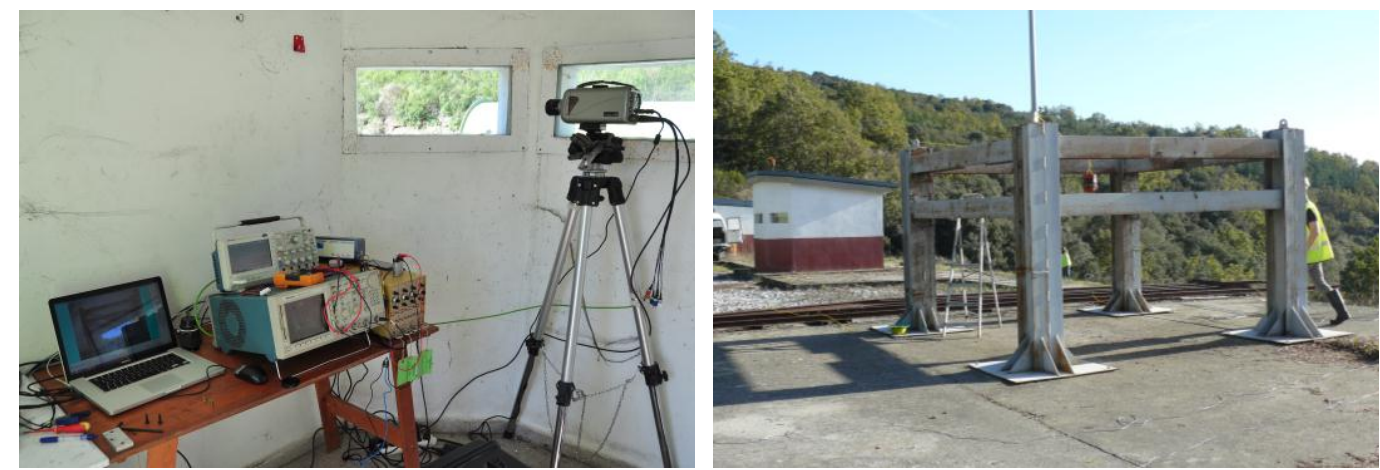

Figure 5.22. Data acquisition systems set on a bunker located at a strand-off distance of $20 \mathrm{~m}$ from the detonation point. 
In order to measure the pressure history of each detonation, a piezoelectric pressure sensor (Figure 5.23b) from PCB Piezotronics, model 102B, was located on the same vertical plane as the device and at the same distance from the explosive (yellow arrow of Figure 5.24 points at the pressure sensor). Occasionally two piezoelectric pressure sensors were used at the same time just to double check the pressure measurement. The pressure history depended mainly on the amount of explosive and the distance between the device and the explosive. But it should be noted that it was also markedly influenced by the atmospheric conditions. Figure 5.25 shows the pressure histories of two detonations performed the same day with the same amount of explosive, $4 \mathrm{~kg}$ of TNT, but with different atmospheric conditions. In black the one performed at 10 am at $10^{\circ} \mathrm{C}$ and the sky was overcast; while the one in red represents the one performed at $2 \mathrm{pm}$ at $21^{\circ} \mathrm{C}$ and the sky was totally clear.

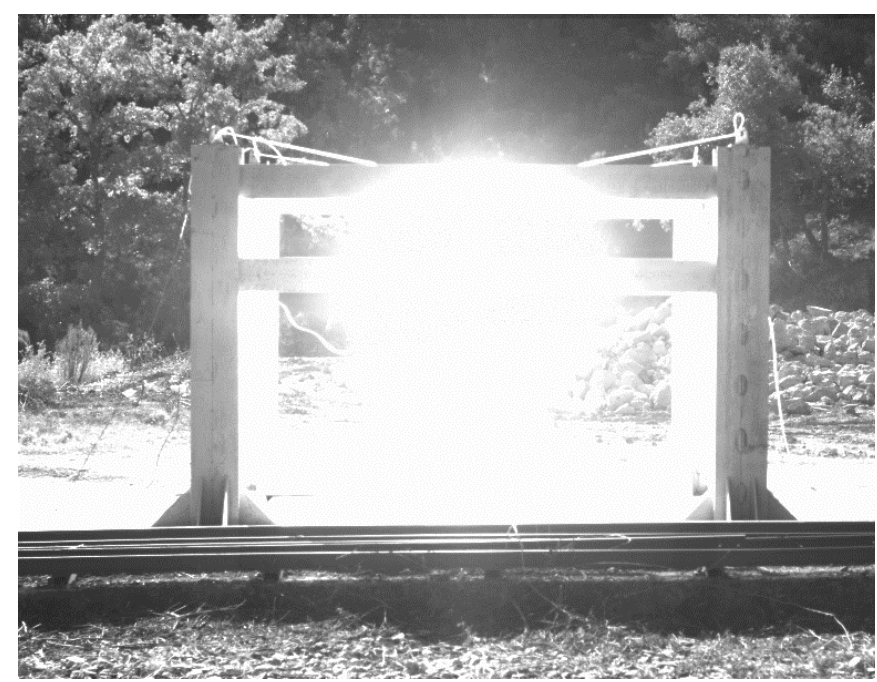

(a)

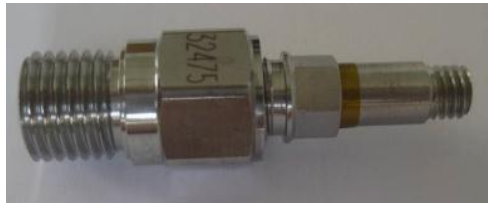

(b)

Figure 5.23. (a) An image captured when the detonation occurred. (b) A piezoelectric pressure sensor for measuring the reflected pressure history of each detonation. 


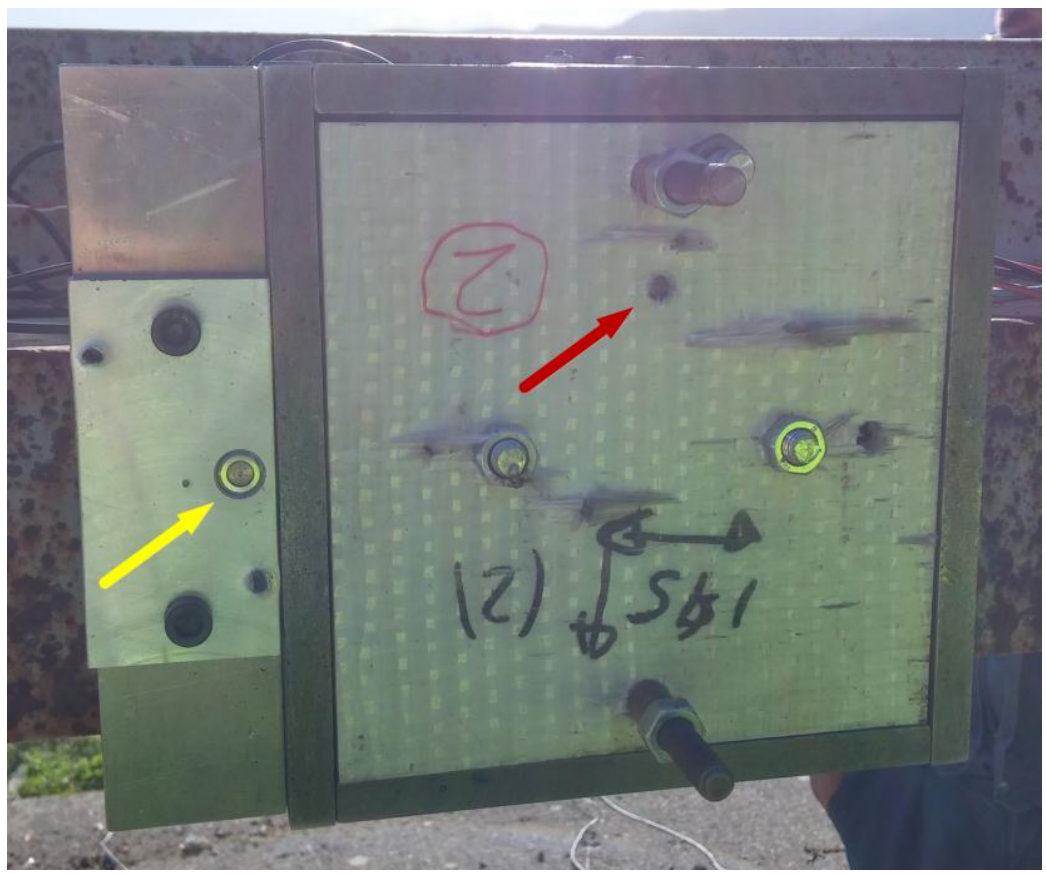

Figure 5.24. Experimental device with the piezoelectric pressure sensor (yellow narrow) and the accelerometer (red narrow) coupled to the cover of the device for fracture toughness explosive tests.

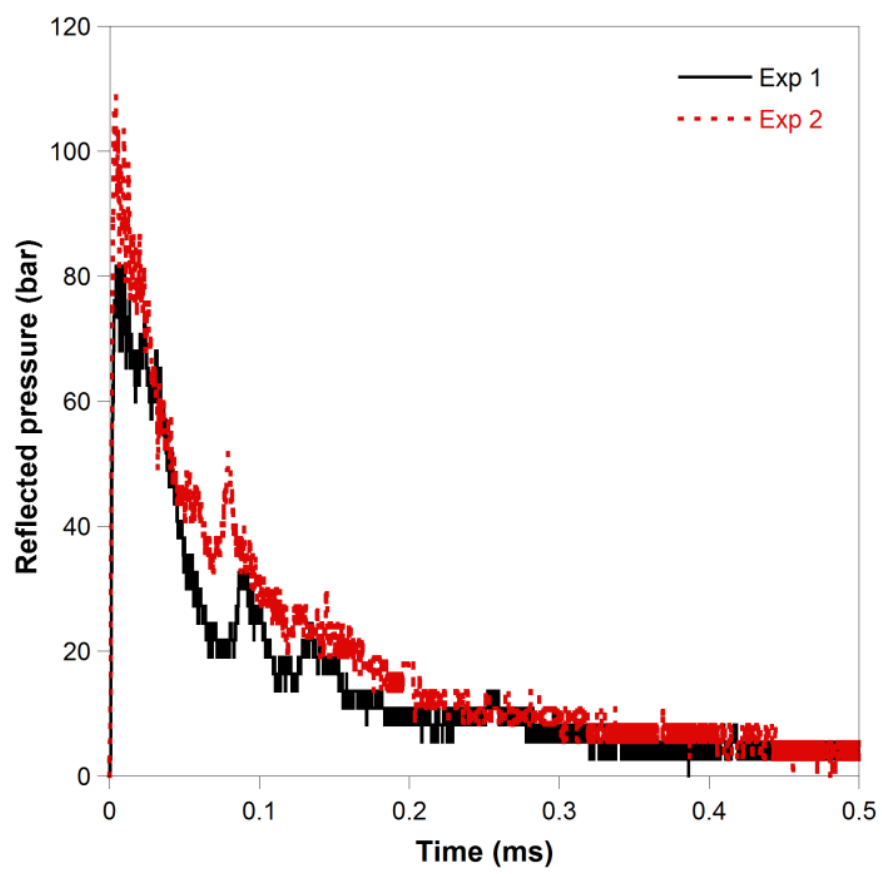

Figure 5.25. Reflected pressure histories of two detonations performed the same day with the same amount of explosive but with different atmospheric conditions. 
For determining the load application velocity a PCB Piezotronics model 350B21 accelerometer was coupled to the cover of the device (red arrow of Figure 5.24 points at the accelerometer). Since it was exposed directly to the blast wave and therefore more prone to fail than other measurement device, a slide potentiometer (Bourn, model PTL30-15G1-103B1) was also attached to the device: therefore the accelerometer signal could be verified (see Figure 5.26).
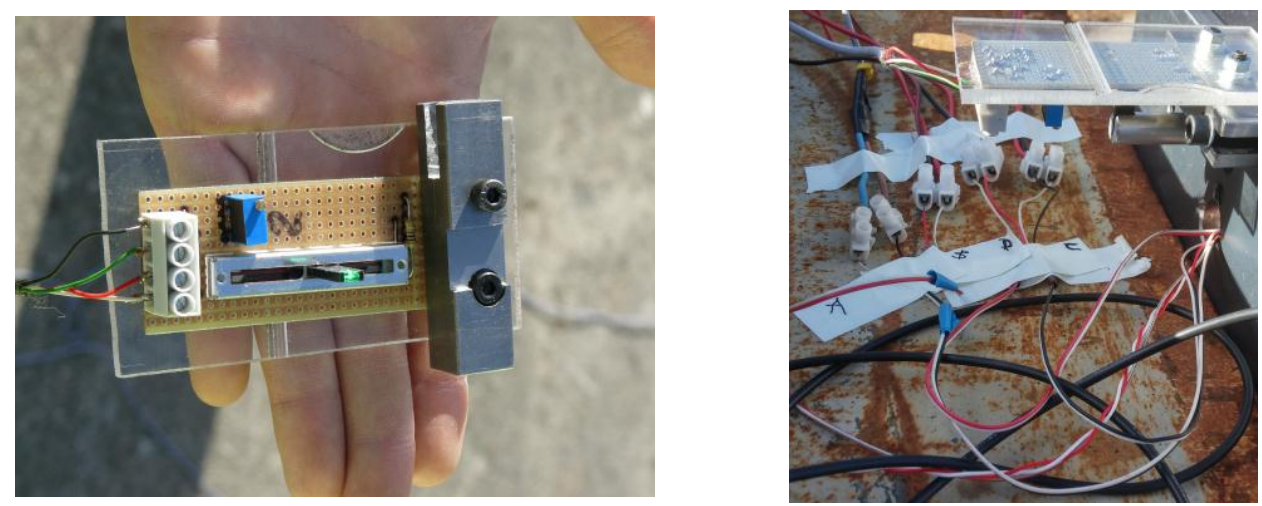

Figure 5.26. A slide potentiometer, attached to the device for fracture toughness explosive tests, used to verify the accelerometer signal.

The trigger signal used for the strain gauge, pressure sensors, the accelerometer, the slide potentiometer and the camera, was made by short-circuiting a DC electrical signal. A $4.5 \mathrm{~V}$ battery was connected to a cable wrapped around the explosive. When the explosion denonated, the circuit opened decaying the voltage and thus triggering the equipment. All of the signals were conditioned on an ICP signal conditioner (PB Piezotronics, model 482C05) and recorded by a Tektronix DPO2024 oscilloscope. The load was obtained by converting the strain gauge measurement, with the linear relationship calibrated previously for each specimen.

\subsection{Results}

Once all the fracture toughness tests were performed, the crack length of each specimen was measured (see Figure 5.27). After checking that the requirements of the standards were satisfied (see section 5.1.1 and Figure 5.28), the dynamic fracture-initiation toughness value for each specimen was determined. 

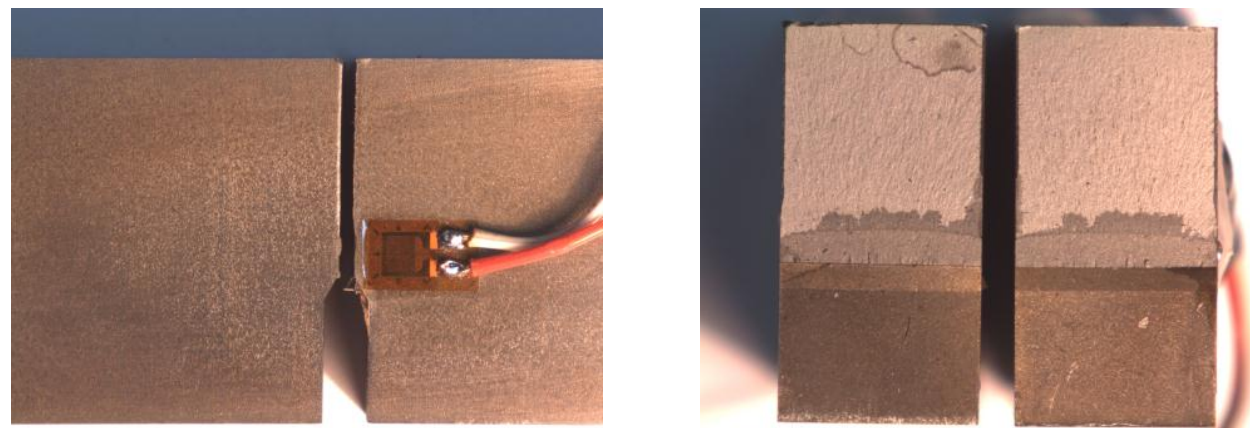

Figure 5.27. Post-mortem standard bend specimen. Fracture was brittle and the specimen satisfied the requirements of crack length and plane of fatigue precrack.
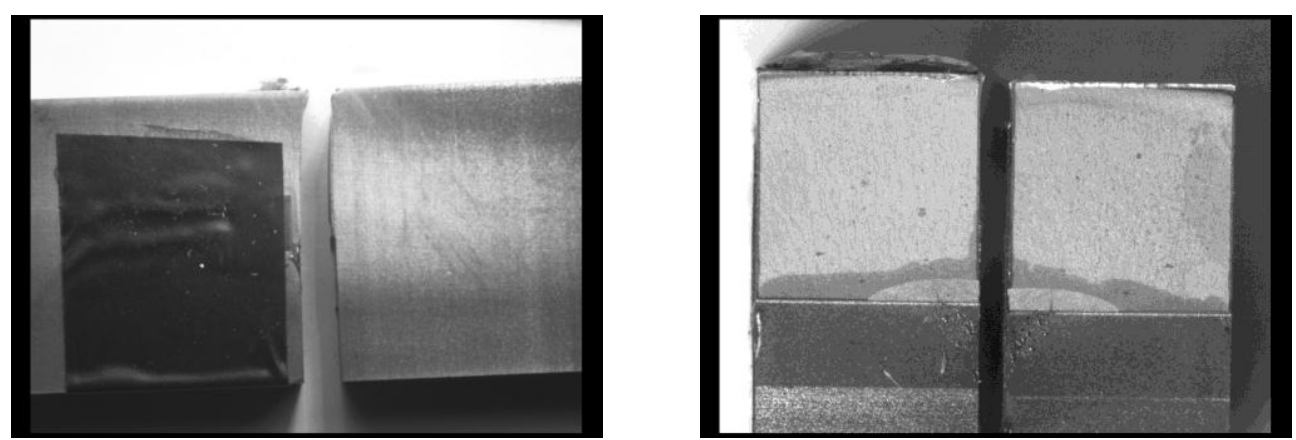

Figure 5.28. Post-mortem standard bend specimen. Fracture was brittle but the specimen did not satisfy the requirements of crack length.

Under quasi-static loading conditions, the applied load was calculated by both load cell and strain gauge signals showing no difference whatsoever between measurements, whereas under dynamic conditions it was obtained only by operating the strain gauge measurement with the linear relationship calibrated specifically for each specimen.

The presentation of the dynamic fracture-initiation toughness results from the three-point bending tests of pre-fatigued specimens at different loading rates is divided into two subsections. The first describes the results obtained for the AA7017-T73 alloy, while the second focuses on the results obtained for the Mars $® 240$ steel. 


\subsubsection{AA7017-T73}

Fracture toughness and dynamic fracture-initiation toughness values of the AA7017-T73 alloy at different loading-rates are shown in Figure 5.29. Such figure contains the results of the quasi-static tests at $3 \cdot 10^{-6} \mathrm{~m} / \mathrm{s}$ shown as green dots, the free-drop weight tower tests conducted at $4 \mathrm{~m} / \mathrm{s}$ depicted in blue triangles, the experiments performed using a modified split Hopkinson pressure bar that range from 9.5 to $11 \mathrm{~m} / \mathrm{s}$ represented as black diamonds and the experiments under impulsive loadings carried out at velocities from 20 to $50 \mathrm{~m} / \mathrm{s}$ shown as red squares. As shown in Figure 5.30, the four experimental set-ups provided a dynamic fracture-initiation toughness with mean values of $33,32,33$ and 32 $\mathrm{MPa} \cdot \mathrm{m}^{1 / 2}$ respectively.

The three experimental devices for high loading rates (free-drop tower, modified SHPB and set-up for explosive experiments) gave a slight scatter, whereas the quasi-static experiments revealed significantly lower variation. The possible misalignment between the load applier and the specimen as well as deviations between the bars and the specimen might have been a plausible reason for the scatter encountered in the results of the experiments carried out using the drop weight tower and the modified SHPB, respectively. In the case of the explosive experiments, the scatter was easier to explain due to the nature of the experiments. In that case, each experiment was subjected to a non-regulated environment out of the laboratory. The explosive depended on the atmospheric conditions and landscape configuration. The large scatter observed on the pressure histories measured by the transducers employed in the experiments was proof of that (see Figure 5.25). Additionally, the wave that reached the testing device could not have been completely spherical.

In any case, in light of the obtained results, it could be said that the dynamic fracture-initiation toughness of the AA7017-T73 remained virtually constant regardless of the velocity at which the load was applied. 


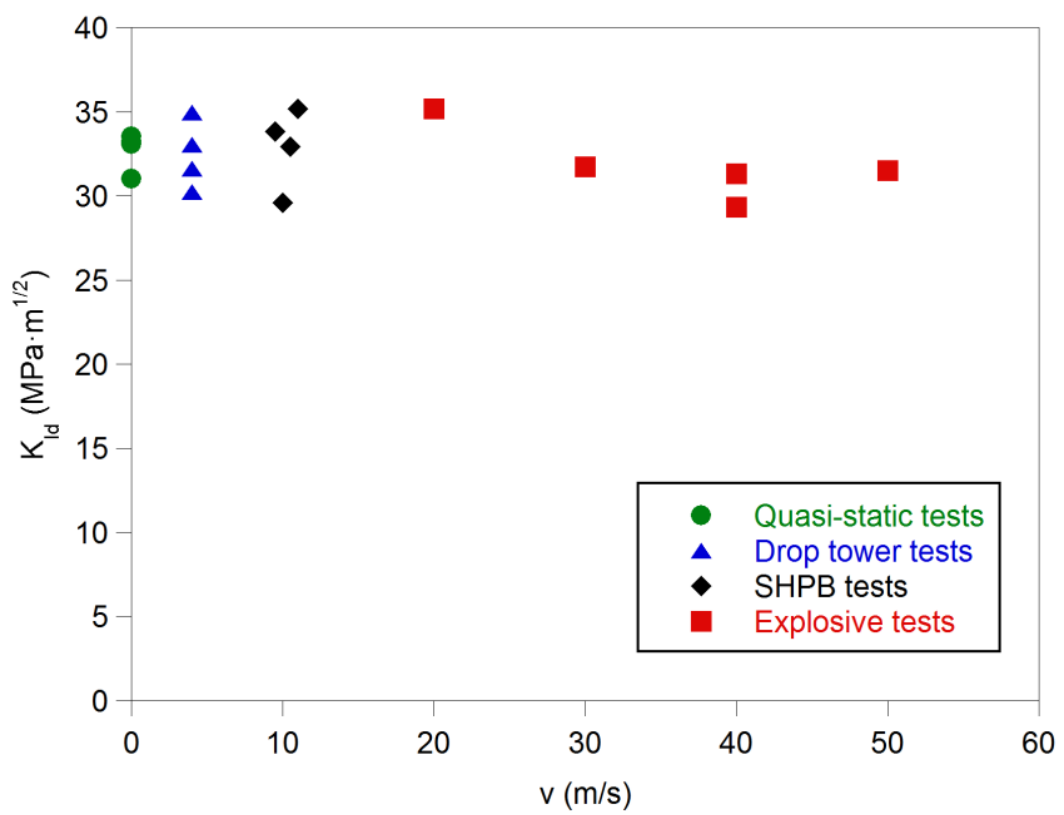

Figure 5.29. Dynamic fracture-initiation toughness of AA7017-T73 alloy at different loading rates.

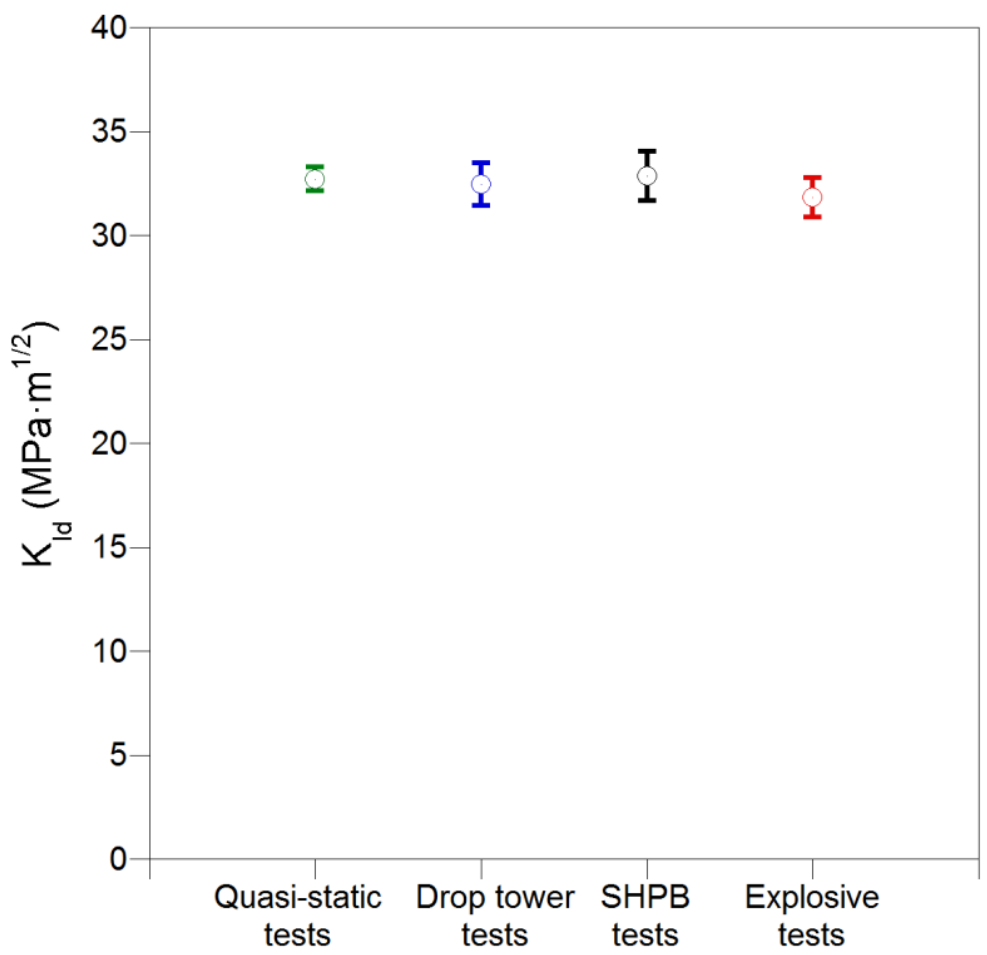

Figure 5.30. Dynamic fracture-initiation toughness mean value and its standard deviation of AA7017-T73 alloy using four different experimental set-ups. 


\subsubsection{Mars $® 240$ steel}

Fracture toughness and dynamic fracture-initiation toughness values of Mars $® 240$ steel at different loading-rates are shown in Figure 5.31. The results of the quasistatic tests, the modified SHPB and the experiments under impulsive loadings are shown as green dots, black diamonds and red squares respectively. Due to reasons that will be exposed in the subsequent chapter no specimens were tested employing the free-drop weight tower. Quasi-static tests were carried out at two different loading rates, $8.4 \cdot 10^{-7}$ and $1.6 \cdot 10^{-6} \mathrm{~m} / \mathrm{s}$, giving fracture toughness values of 41 and $42 \mathrm{MPa} \cdot \mathrm{m}^{1 / 2}$, respectively. Experiments in a modified SHPB were performed at loading rates ranging from 7.5 to $11 \mathrm{~m} / \mathrm{s}$, obtaining dynamic fractureinitiation toughness values from 54 to $61 \mathrm{MPa} \cdot \mathrm{m}^{1 / 2}$. Experiments under impulsive loadings were conducted at loading rates from 30 to $57 \mathrm{~m} / \mathrm{s}$, in which dynamic fracture-initiation toughness values from 76 to $117 \mathrm{MPa} \cdot \mathrm{m}^{1 / 2}$ were achieved. The results revealed that the dynamic fracture-initiation toughness of the Mars $₫ 240$ steel increased with the loading rate.

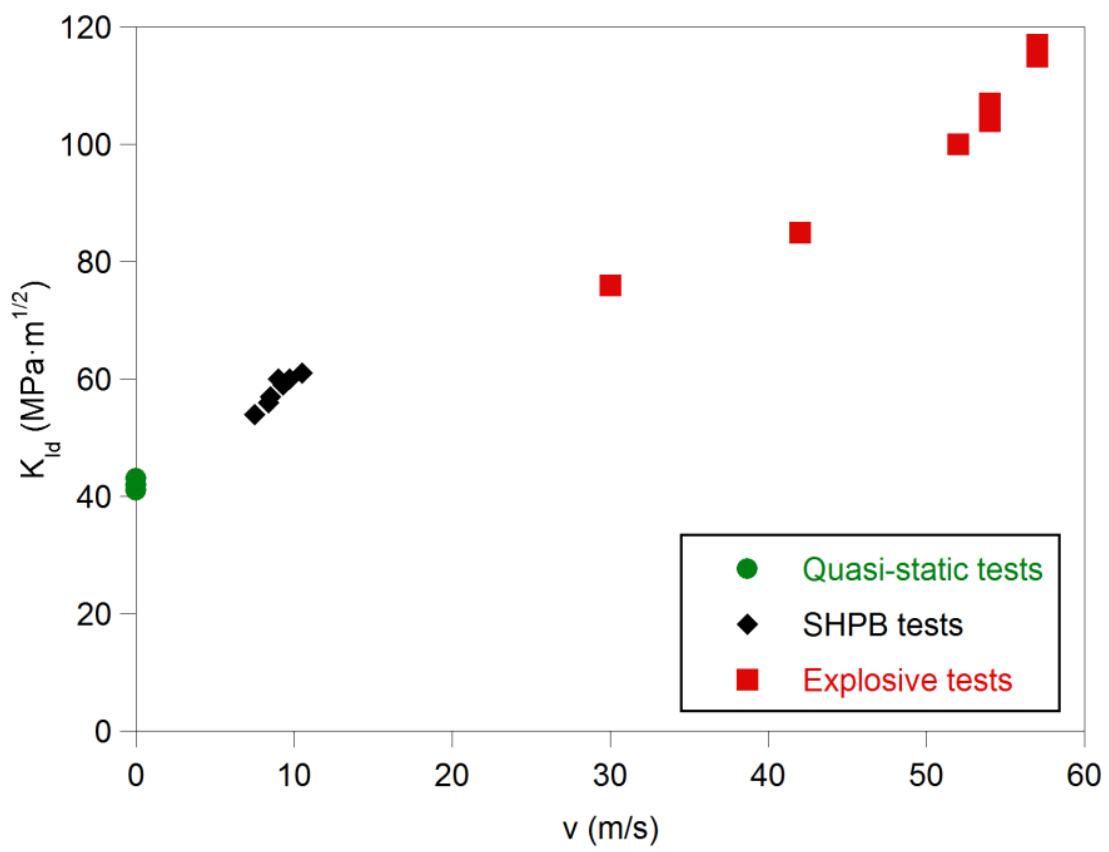

Figure 5.31. Dynamic fracture-initiation toughness of Mars ${ }^{\circledR} 240$ steel at different loading rates. 


\subsection{Concluding remarks}

Three-point bending tests of pre-fatigued specimens at different loading-rates were carried out employing four different set-ups: a servo-hydraulic universal testing machine, a free-drop tower, a modified split Hopkinson pressure bar and a new explosive load testing device. Such new experimental device was designed and developed for the purpose of performing fracture toughness tests under impulsive loadings.

A "virtually" rate-independent metallic material, AA7017-T73 alloy, was selected in order to validate the different techniques. The four experimental devices gave similar values of fracture-initiation toughness of the aluminium alloy, showing the reliability of the devices for such a purpose. The dynamic fracture-initiation toughness of AA7017-T73 alloy remained constant regardless of the velocity at which the load was applied. In light of the obtained results, the test procedures and devices that were used to test the materials under dynamic loading conditions were considered to be validated.

A rate-dependent metallic material, Mars $® 240$ steel, was selected in order to determine the evolution of its dynamic fracture-initiation toughness with the loading rate. For such a purpose, the previously-validated experimental techniques were employed being confident that the results were going to be reasonably accurate. The results revealed that the dynamic fracture-initiation toughness of the Mars $®$ 240 steel increased with the loading rate. 


\section{CHAPTER 6}

\section{A Numerical Study ON THREe-Point BENDING SPECIMENS UNDER DYNAMIC LOADINGS}

The evaluation of stress intensity factor by means of the finite element method is a technique widely used for standard and non-standard crack configurations. There are two kinds of estimation methods: those based on field extrapolation in the vicinity of the crack tip and methods which use the energy released when the crack propagates.

Basically, field extrapolation-based methods (Chan et al., 1970) for estimating the stress intensity factor are divided in two groups: those that analyse nodal displacements and those that analyse element stresses. Several authors, e.g. (Guinea et al., 2000) or more recently (Fu et al., 2012), have thoroughly studied the displacement extrapolation technique. Others, like (Qian et al., 2016), have even compared different other techniques appart from the extrapolation-based methods.

In this chapter, displacement and stress extrapolation methods were applied to estimate the dynamic fracture-initiation toughness of the studied materials, and both were compared with the results obtained experimentally in CHAPTER 5. 


\subsection{Extrapolation-based methods to determining fracture- initiation toughness}

The displacement extrapolation method involves a correlation of the finite element nodal point displacements with the well known crack tip displacement equations. Similarly, the stress extrapolation method does the proper with the element stresses located near the crack tip. Then, displacement and stress fields for stationary cracks under dynamic loadings in the vicinity of the crack tip for the particularly case of plane strain stress state need to be known. Such fields are expressed as

$$
\begin{gathered}
u_{i}(r, \theta)=\frac{K_{I}^{d y n}(t)}{G} \sqrt{\frac{r}{2 \pi}} g_{i}^{I s}(\theta) \\
\sigma_{i j}(r, \theta)=\frac{K_{I}^{d y n}(t)}{\sqrt{2 \pi r}} f_{i j}^{I s}(\theta)
\end{gathered}
$$

with the trigonometrical functions,

$$
\begin{aligned}
& g_{1}^{I s}(\theta)=\cos \frac{1}{2} \theta\left[1-2 v+\sin ^{2} \frac{1}{2} \theta\right] \\
& g_{2}^{I S}(\theta)=\sin \frac{1}{2} \theta\left[2-2 v+\cos ^{2} \frac{1}{2} \theta\right]
\end{aligned}
$$

and

$$
\begin{gathered}
f_{11}^{I s}(\theta)=\cos \frac{1}{2} \theta\left(1-\sin \frac{1}{2} \theta \sin \frac{3}{2} \theta\right) \\
f_{22}^{I s}(\theta)=\cos \frac{1}{2} \theta\left(1+\sin \frac{1}{2} \theta \sin \frac{3}{2} \theta\right) \\
f_{12}^{I s}(\theta)=\cos \frac{1}{2} \theta \sin \frac{1}{2} \theta \cos \frac{3}{2} \theta
\end{gathered}
$$

\subsubsection{Displacement extrapolation method}

For the particular case of a point located in the crack plane $(\theta=\pi)$ that has a displacement $u_{2}$ normal to such plane and close enough to the crack tip (see Figure 6.1), the dynamic stress intensity factor can be calculated as 


$$
K_{I}^{d y n}(t)=\sqrt{\frac{2 \pi}{r}} G \frac{u_{2}(r, \pi)}{g_{2}^{I s}(\pi)}=\sqrt{\frac{2 \pi}{r}} G u_{2}(r, \pi) \quad r \rightarrow 0
$$

In order to compute the dynamic fracture-initiation toughness through numerical simulations, two points ( $A$ and $B$ in red in Figure 6.1) located in the vicinity of the crack tip were selected to determine the dynamic stress intensity factor at the fracture time $t_{f}$

$$
K_{I(k)}^{d y n}\left(t_{f}\right)=K_{I d(k)}=\sqrt{\frac{2 \pi}{r}} G u_{2(k)}\left(l_{u(k)}, \pi\right) \text { with } k=\{A, B\}
$$

being $l_{u(k)}$ the distance between the crack tip and the point $k$.

Then, the dynamic fracture-initiation toughness can be calculated by a simple linear displacement extrapolation

$$
K_{I d}^{u}=K_{I d(A)}-\frac{K_{I d(B)}-K_{I d(A)}}{l_{u(B)}-l_{u(A)}} l_{u(A)}
$$

\section{Equivalent plastic strain}
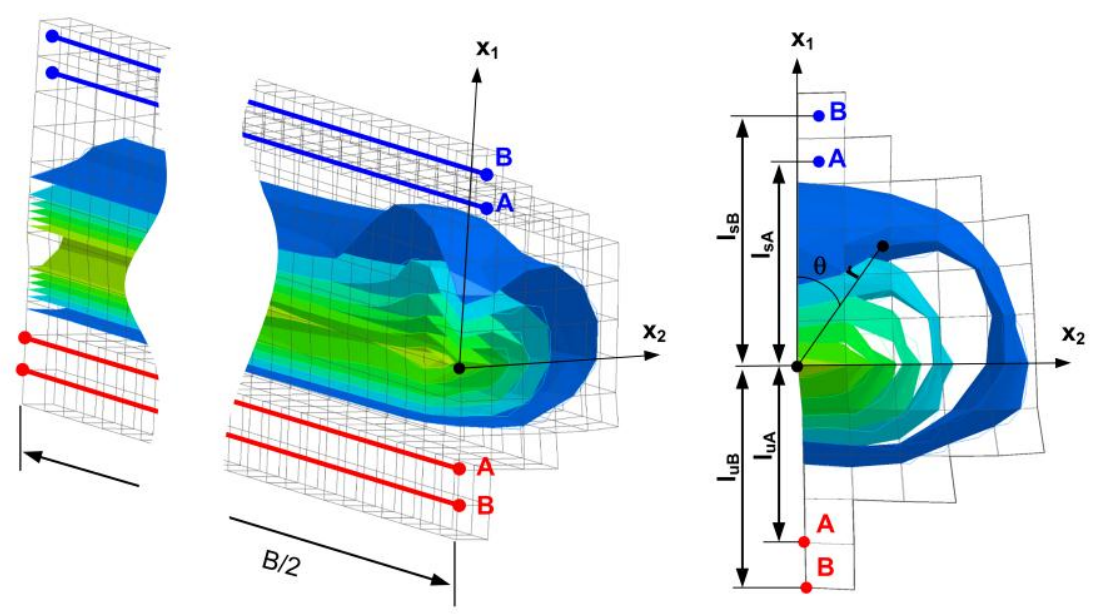

3.568e-02

$3.211 \mathrm{e}-02$

2.854e-02

2.497e-02

2.141e-02

$1.784 \mathrm{e}-02$

$1.427 \mathrm{e}-02$

$1.070 \mathrm{e}-02$

7.136e-03

$3.568 \mathrm{e}-03$

$0.000 e+00$

Figure 6.1. Isocontours of equivalent plastic strain in the crack tip vicinity of the AA7017-T73 quasi-static simulation. Points $A$ and $B$ were used for the displacement (in red) and stress (in blue) extrapolation methods. 


\subsubsection{Stress extrapolation method}

Following the approach of (Chan et al., 1970), the stress $\sigma_{22}$ of a point located in the crack plane $\theta=0$ and close enough to the crack tip was chosen to calculate the dynamic stress intensity factor as

$$
K_{I}^{d y n}(t)=\frac{\sqrt{2 \pi r}}{f_{22}^{I s}(0)} \sigma_{22}(r, 0)=\sqrt{2 \pi r} \sigma_{22}(r, 0) \quad r \rightarrow 0
$$

As in the displacement extrapolation method two points $(A$ and $B$ in blue in Figure 6.1) located in the vicinity of the crack tip were selected to determine the dynamic stress intensity factor at the fracture time $t_{f}$

$$
K_{I(k)}^{d y n}\left(t_{f}\right)=K_{I d(k)}=\sqrt{2 \pi r} \sigma_{22(k)}\left(l_{\sigma(k)}, 0\right) \text { with } k=\{A, B\}
$$

being $l_{\sigma(k)}$ the distance between the crack tip and the point $k$.

Extrapolating the stresses, the dynamic fracture-initiation toughness can be computed as

$$
K_{I d}^{\sigma}=K_{I d(A)}-\frac{K_{I d(B)}-K_{I d(A)}}{l_{\sigma(B)}-l_{\sigma(A)}} l_{\sigma(A)}
$$

\subsection{Numerical simulations of pre-fatigued three-point bending specimens}

Numerical simulations of the three-point bending experiments at different strain rates were performed in order to estimate the dynamic-fracture initiation toughness of the studied materials. To calculate the dynamic fracture-initiation toughness based on the displacement and stress extrapolation methods, the $u_{2}$ nodal displacement histories and $\sigma_{22}$ stress histories up to lowest fracture-initiation times detected in the experiments were recordered from locations $A$ and $B$ throughout the thickness of the specimens as shown in Figure 6.1. Note that locations $A$ and $B$ were chosen such that they remained in elastic regime at all times. 
Eventhough the validity of the constitutive models was previously established by means of uniaxial tensile tests (see CHAPTER 4), experimentally measured magnitudes were monitored in the simulations to make sure that the finite element models for the three-point bending tests were accurate enough. In the quasi-static tests, load versus DIC measured cross-head displacement was used to check the mechanical response. Unfortunately, limited experimental measurements were available for some experiments, such as the explosive tests. For the sake of consistency, in the rest of the tests the strain histories normal to the crack plane measured by the strain gauges attached to the specimens were compared to the numerical simulations (see Figure 6.3).

\subsubsection{Numerical set-up}

The numerical simulations were performed by using LS-DYNA (LSTC, 2014) nonlinear finite element code. The dimensions and geometry of the specimens can be found in section 5.1.1. The material data was the one obtained in sections 4.3.2. and 4.3.3. and the material models were the same as the ones used in section 4.3. Due to the symmetry of the model, only one fourth of the bend specimens was modelled. The supports and the load applier were simulated as rigid solids. The experimentally-measured velocity was prescribed to the load applier in the quasistatic case, while a representative velocity within the range of those tested was chosen for the rest of the cases.

The three-point-bending specimens were discretised using eight-node solid elements with one integration point and stiffness-based hourglass control. The approximate size of the elements was $0.15 \times 0.15 \times 0.15 \mathrm{~mm}^{3}$, slightly larger than those in section 4.3. Finite element meshes used to simulate the bend specimens are shown in Figure 6.2. Uniform mass scaling was applied in quasi-static experiments simulations assuming stable time increment of $t_{f} \cdot 10^{-6}$. 


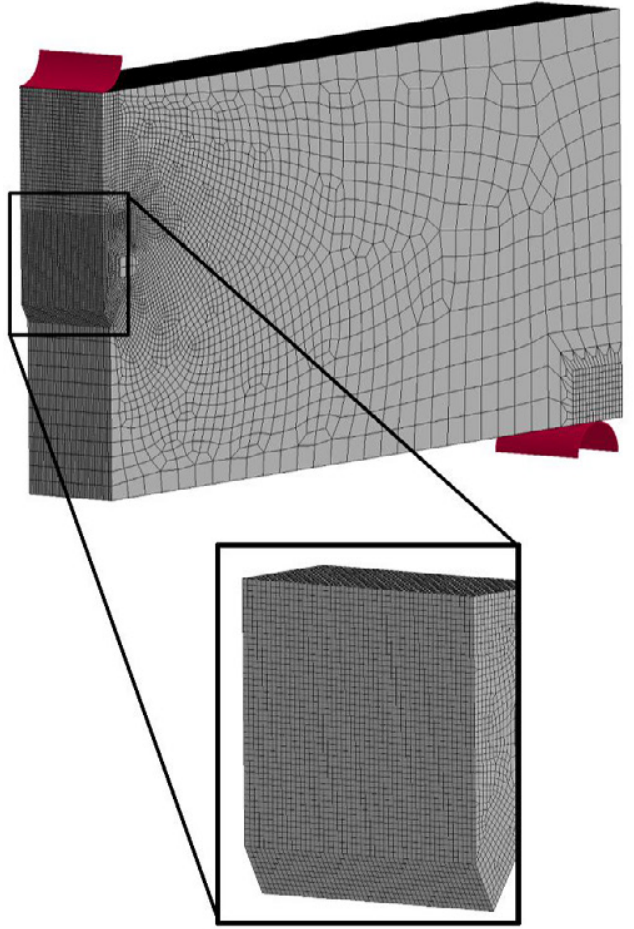

(a)

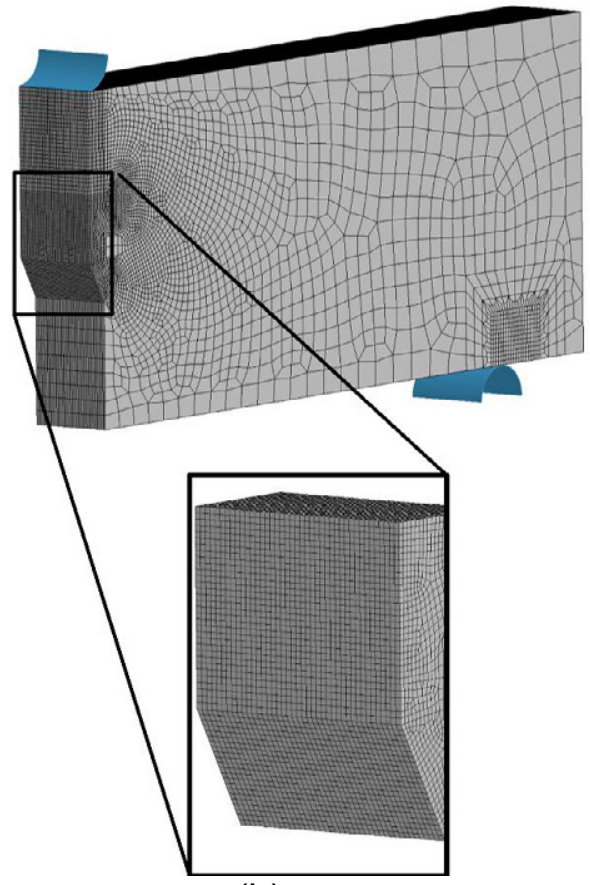

(b)

Figure 6.2. Finite element meshes used to simulate the pre-fatigued three-point bending specimens of (a) AA7017-T73 alloy and (b) Mars $₫ 240$ steel.

\subsubsection{Results and discussion}

In order to evaluate the extension of the plastic zone close to the tip of the crack, the equivalent plastic strain fields at the time when the fracture was detected $\left(t_{f}\right)$ was depicted along with the strain gauge position for all of the experiments (plotted in purple in Figure 6.3.). Note that that time was measured from an arbitrary origin. Its purpose was not to compare the fracture time among different loading rate experiments but to measure it as accurate as possible for future finite element analysis. Hence, one can notice the lack of physical meaning when comparing the times to fracture corresponding to experiments conducted at different loading rates.

Plasticity in the crack tip region was expected. However, as it can be seen in Figure 6.3., the plastic zone close to the tip of the crack was always relatively small compared even to the size of the strain gauge and far enough from it. Therefore, it was considered that the LEFM still held valid. 


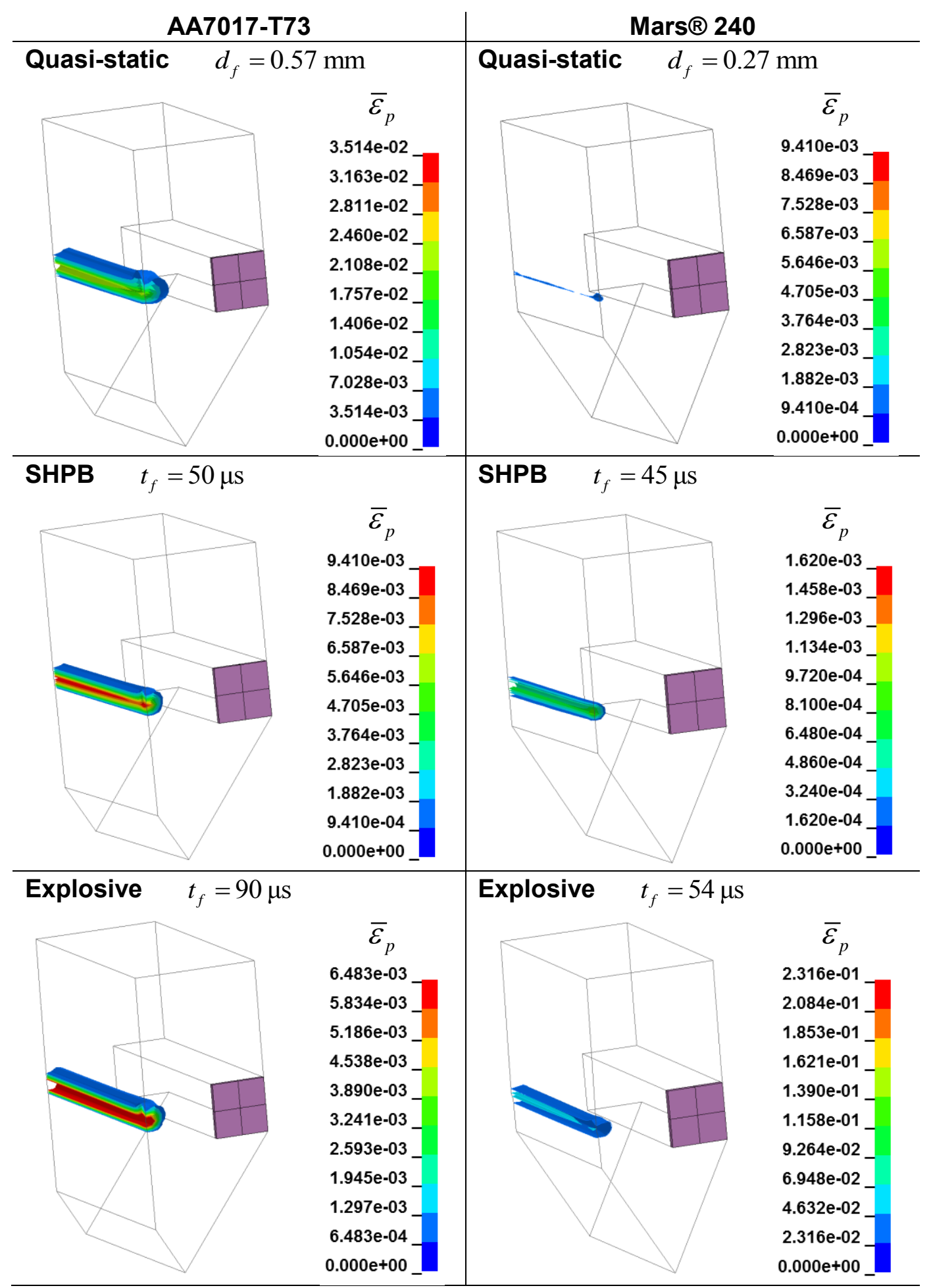

Figure 6.3. Equivalent plastic strain iso-contours in the crack tip vicinity compared to the elements used to extract the strain histories. 
In order to analyse the obtained experimental results, for every loading rate two representative experimental curves (black dashed curves) were compared to the ones extracted from the numerical simulations (red solid lines) (see left part of Figure 6.4. and Figure 6.6). It was estimated that the fracture occurred within the limits of the shaded red bands.

In quasi-static regime, force-displacement curves were compared in Figure 6.4.(a) and Figure 6.6.(a). From the experiments, force signal was obtained from the load cell while the cross-head displacement was extracted by DIC analysis in order to avoid the stiffness of the machine. From the numerical simulations, both force and displacement were extracted from the load applier simulated as a rigid solid. The reaction force extracted from the load applier and the supports were identical, confirming that the specimen was under quasi-static equilibrium.

For the rest of loading regimes, strain histories extracted experimentally from the strain gauge were compared to the average of the histories extracted from the four finite elements which composed the virtual strain gauge (Figure 6.4.(c) and (e), Figure 6.6.(c) and (e)). Note that the measured strain component was parallel to the crack front; in other words, it was parallel to the load applying axis.

For all of the cases, the dynamic fracture-initiation toughness values extracted from the crack tip throughout the thickness $(z / B)$ were compared to the range of experimental values, plotted as black triangles (see Figure 6.4.(b), (d) and (f); and Figure 6.6. (b), (d) and (f)). $K_{I d}$ values obtained by displacement extrapolation method were plotted in red dots, while in blue squares were the $K_{I d}$ values obtained by stress extrapolation method. It should be noted that experimental $K_{I d}$ values were measured on the surface of the specimens. Generally, since the displacement from the nodes was a direct measurement, it was considered as a more accurate measurement than the interpolated measurement on stresses that used the elements integration point where the magnitudes were interpolated. 


\subsubsection{1. $A A 7017-T 73$}

Under quasi-static conditions (Figure 6.4.(a) and (b)), the experimental forcedisplacement curves were in good agreement with the numerical prediction. Since all of the experiments were performed at the same loading rate of $3.3 \cdot 10^{-6} \mathrm{~m} / \mathrm{s}$, the fracture displacement band was relatively narrow. $K_{I d}$ value obtained by displacement extrapolation method on the surface of the specimen was identical to the experimental $K_{I d}$ value. Both extrapolation methods provided similar values while close to the surface of the specimen.

Experiments performed in a modified SHPB (Figure 6.4.(c) and (d)) were simulated at one representative loading rate of $10 \mathrm{~m} / \mathrm{s}$, being the fracture time band slightly wider since the experiments were performed at velocities from 9.5 to $11 \mathrm{~m} / \mathrm{s}$. The numerically predicted strain curve remained in perfect agreement with the experimental curves almost until failure. $K_{I d}$ values obtained by extrapolation methods on the surface of the specimen were within the range of those measured experimentally.

In the case of the experiments performed under impulsive loadings (Figure 6.4.(e) and $(f))$, the numerical prediction matched the experimental strain vs. time curves only when load started to increase. Although the $K_{I d}$ values obtained by both extrapolation methods on the surface of the specimen were within the limits of the experimental $K_{I d}$ value range. In this case, the $K_{I d}$ values through the thickness obtained from the displacement extrapolation method were at least $5 \mathrm{MPa} \cdot \mathrm{m}^{1 / 2}$ higher than the $K_{I d}$ values from the stress extrapolation method.

The results of the AA7017-T73 experiments carried out in a drop-weight tower are presented separately in Figure 6.5. As it is shown in both experimental and numerical strain histories, the experiments were carried out under two loading stages. It was in the second loading stage when the fracture occurred. Numerical simulations provided a loss of contact between the specimen and the load applier between both loading stages. 


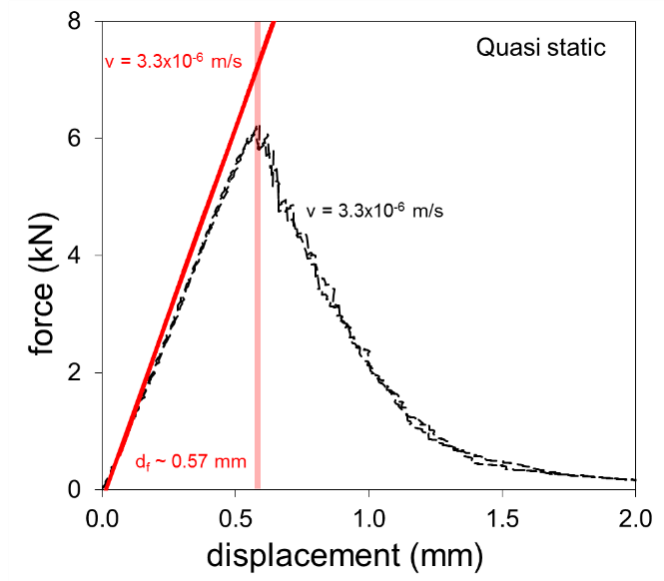

(a)

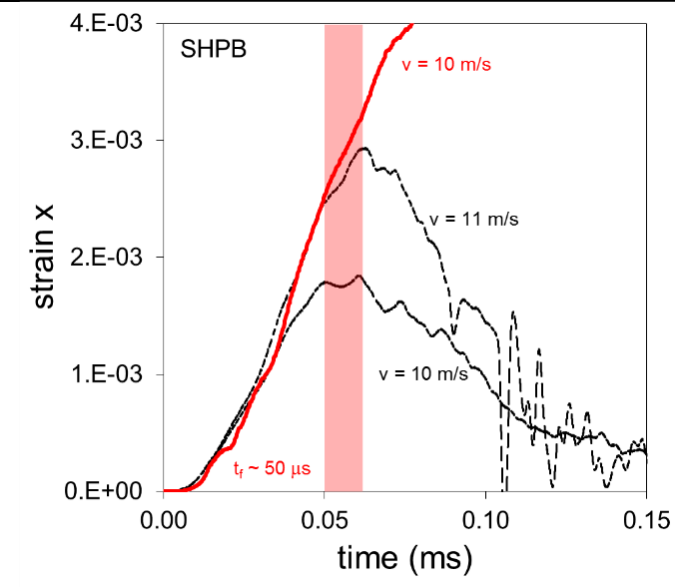

(c)

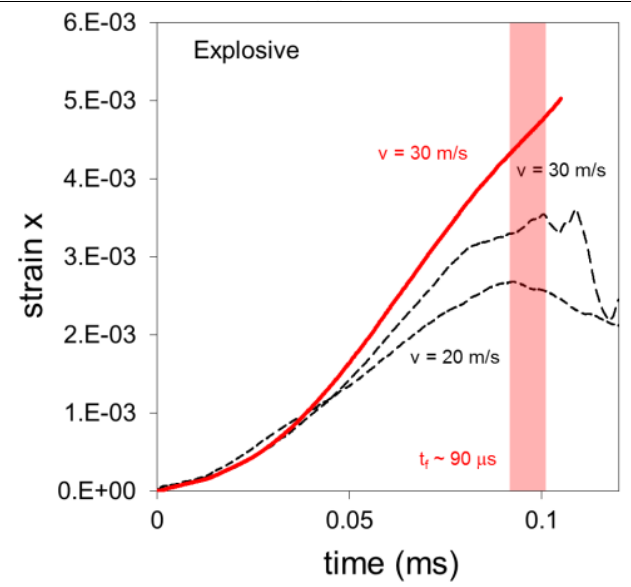

(e)

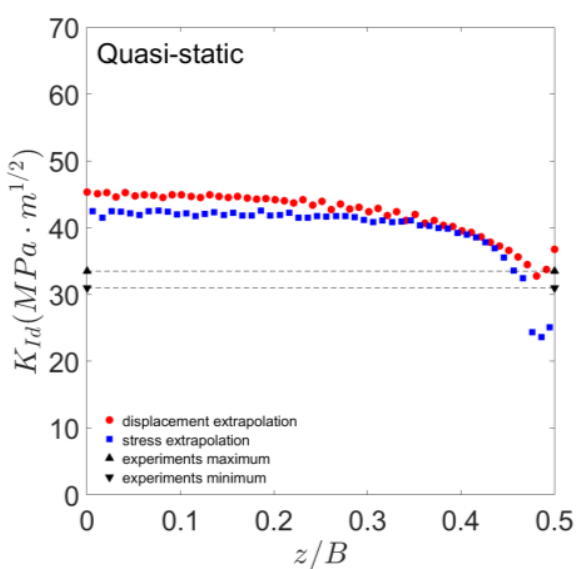

(b)

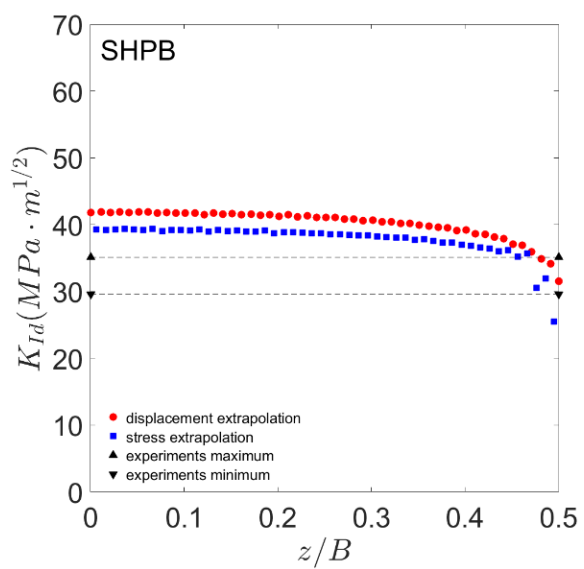

(d)

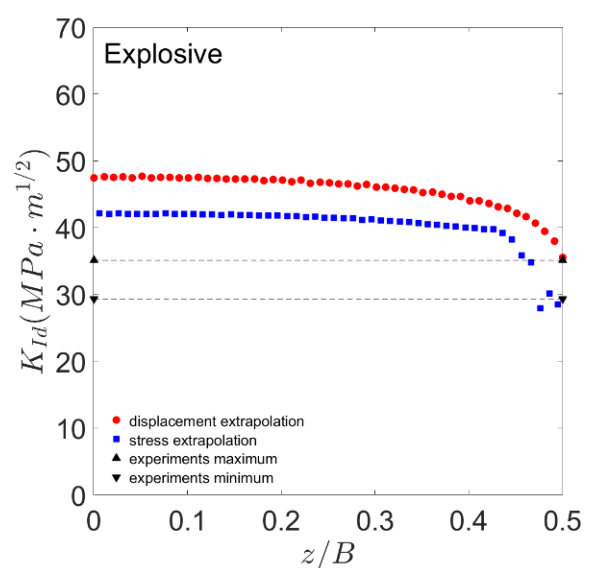

(f)

Figure 6.4. (Left) Comparison between the experimental and numerical response of AA7017-T73. (Right) The dynamic fracture-initiation toughness value computed with DEM and SEM compared to those obtained experimentally. Results for quasistatic, SHPB and explosive tests are reported in (a-b), (c-d) and (e-f) respectively. 
(a)

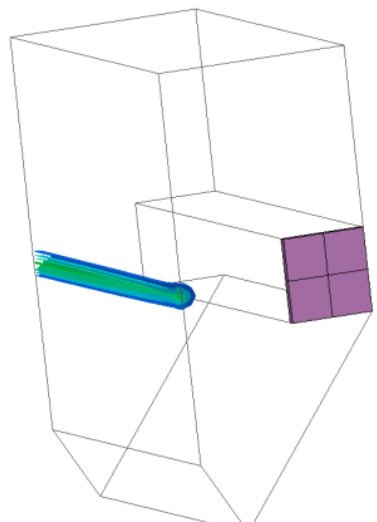

$\bar{\varepsilon}_{p}$

6.892e-03

$6.203 \mathrm{e}-03$

$5.514 \mathrm{e}-03$

4.825e-03

$4.135 \mathrm{e}-03$

$3.446 \mathrm{e}-03$

$2.757 \mathrm{e}-03$

2.068 -03

$1.378 \mathrm{e}-03$

$6.892 \mathrm{e}-04$

$0.000 \mathrm{e}+00$

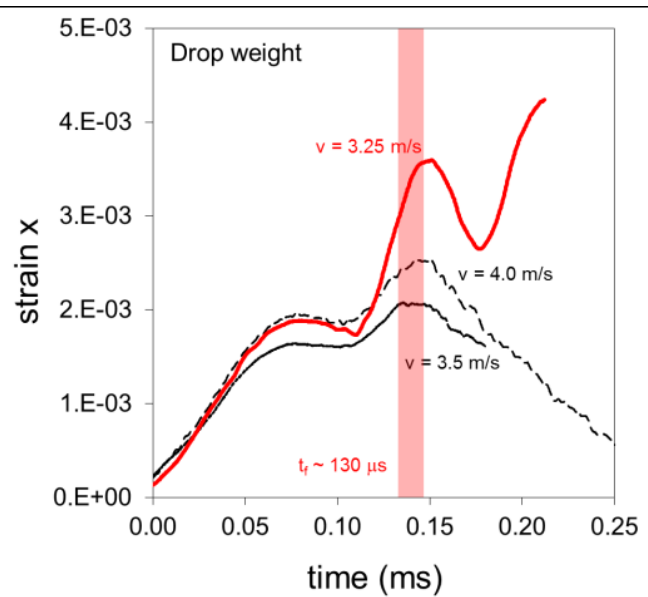

(b)

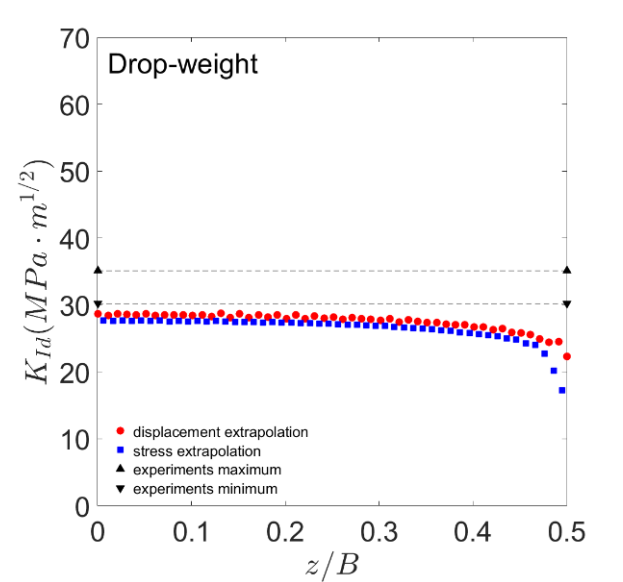

(c)

Figure 6.5. Drop-weight tower tests and simulations of the AA7017-T73. (a) Equivalent plastic strain iso-contours near the crack tip. (b) Numerical vs. experimental strain histories extracted from the strain gauges. (c) DEM and SEM vs. experimental results.

Since the fracture did not occur with the first loading stage and the specimen could be moved out of position between loadings, those experiments and therefore their results were considered not representative of the mechanical behaviour of the material. In order to avoid the same circumstance while studying the fracture behaviour of the Mars $® 240$ steel, experiments in a drop-weight tower were not performed. 


\subsubsection{Mars® 240 steel}

Under quasi-static conditions (Figure 6.6.(a) and (b)), the numerical prediction was in good agreement with the experimental force-displacement response. $K_{I d}$ value obtained by displacement extrapolation method remained almost constant through the thickness and was identical to the experimental $K_{I d}$ value on the surface of the specimen. The stress extrapolation method provided similar values.

Experiments performed in a modified SHPB (Figure 6.6.(c) and (d)) were simulated at a representative loading rate of $8 \mathrm{~m} / \mathrm{s}$, being the fracture time band slightly wider since the experiments were performed at velocities from 7.5 to $11 \mathrm{~m} / \mathrm{s}$. The numerically predicted curve remained in agreement with the experimental curves almost until failure. $K_{I d}$ values obtained by the extrapolation methods on the surface of the specimen were lower than the experimental $K_{I d}$ value range. In this case, the $K_{I d}$ values obtained by the stress extrapolation method were closer to the experimental values.

In the case of the experiments performed under impulsive loadings (Figure 6.6.(e) and (f)), the numerical prediction matched the experimental strain-time curves only at the beginning of it when the load started increasing. There was a difference of almost $30 \mathrm{MPa} \cdot \mathrm{m}^{1 / 2}$ among the $K_{I d}$ values throughout the thickness obtained by both extrapolation methods. Displacement extrapolation method provided higher values than the experimental $K_{I d}$, while stress extrapolation method provided $K_{I d}$ values within the limits of the experimental scatter. It should be noted that the numerical predictions were performed at a velocity of $30 \mathrm{~m} / \mathrm{s}$, while the experiments were performed at velocities from 30 to $57 \mathrm{~m} / \mathrm{s}$. 


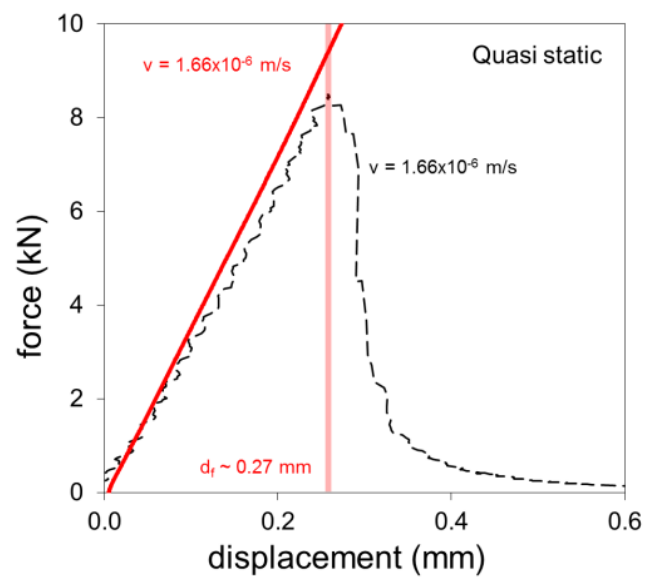

(a)

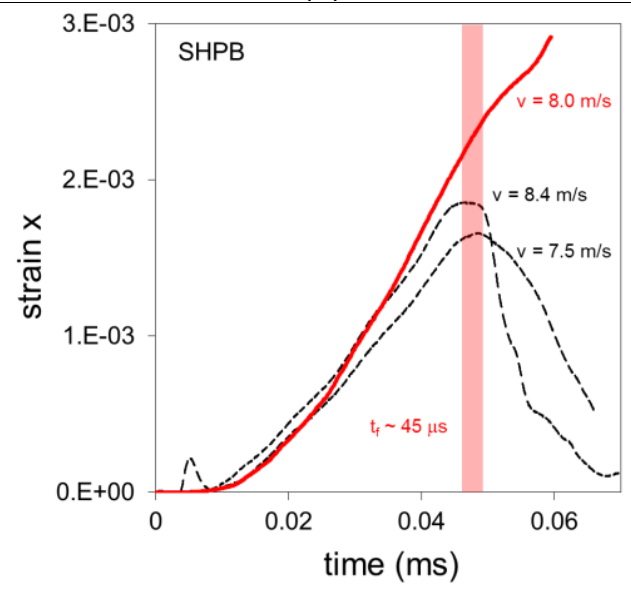

(c)

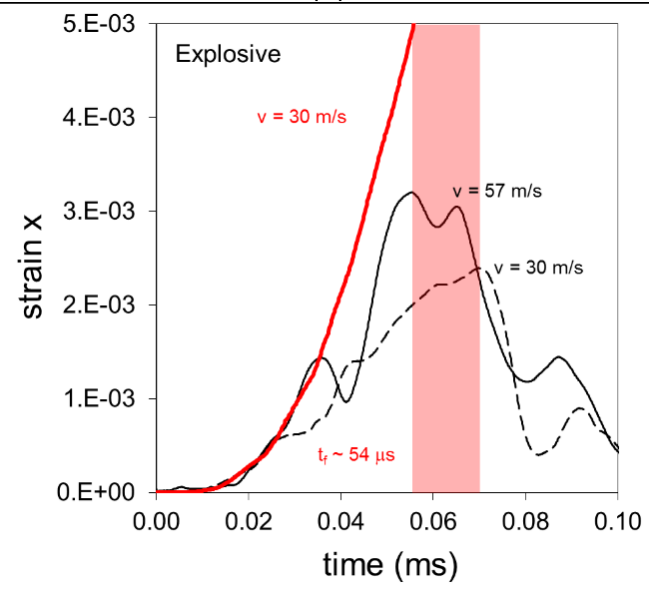

(e)

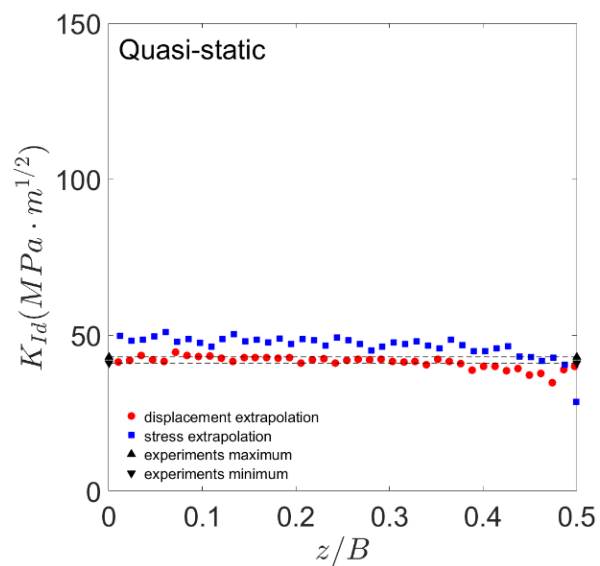

(b)

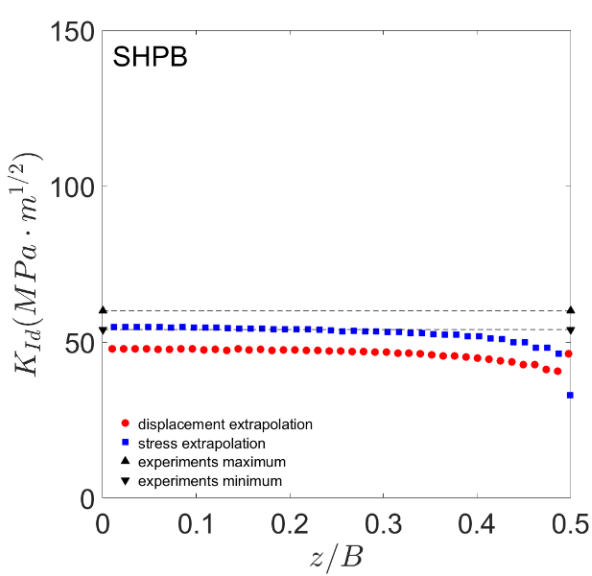

(d)

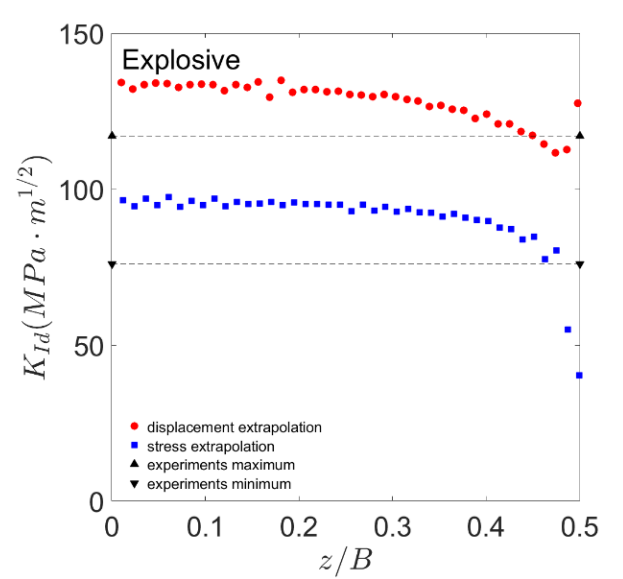

(f)

Figure 6.6. (Left) Comparison between the experimental and numerical response of Mars ${ }^{\circledR} 240$. (Right) The dynamic fracture-initiation toughness value computed with DEM and SEM compared to those obtained experimentally. Results for quasistatic, SHPB and explosive tests are reported in (a-b), (c-d) and (e-f) respectively 


\subsection{Concluding remarks}

Numerical simulations of the three-point bending experiments at different loading rates were performed in order to estimate the dynamic-fracture initiation toughness of the AA7017-T73 and Mars $® 240$ steel. Displacement and stress extrapolation methods were applied to estimate such a parameter and their results were compared with the experimental values.

Under quasi-static conditions, numerical predictions from both extrapolation-based methods were identical to the experimental results. When increasing the loading rate, some scatter was found; being larger in the case of impulsive loadings.

Drop-weight tower tests were considered not valid since a loss of contact between the load applier and the specimen was found before the fracture onset. In addition, two loading stages were observed both experimentally and numerically. 


\section{CHAPTER 7}

\section{FRACTURE MODELLING}

Uniaxial tensile tests and three-point bending tests have been experimentally studied, in CHAPTER 3 and CHAPTER 5 respectively, and numerically analised until failure, in CHAPTER 4 and CHAPTER 6 respectively.

In this chapter, a study on fracture modelling is presented. Two different fractureinitiation criteria are presented. Since both criteria are stress-based, the strain rate and temperature dependency are implicitly formulated through the elastic-plastic constitutive relationships. Two stress-based fracture-initiation criteria that take into account the stress state dependency are being analised; the Cockroft-Latham failure criterion and the Mohr-Coulomb criterion. The anisotropic version of both models is explored, presented and applied in order to predict the fracture toughness tests for AA7017-T73 and Mars $\otimes 240$. Both criteria are calibrated through a hybrid numerical-experimental procedure that uses the UT specimen results. 


\subsection{Description of the stress state for isotropic materials}

The stress state of an isotropic material can be described with:

- The Cauchy stress $\boldsymbol{\sigma}$ and deviatoric stress $\mathbf{s}=\boldsymbol{\sigma}-1 / 3 \operatorname{tr}(\boldsymbol{\sigma})$ invariants $\left\{I_{1}, J_{2}, J_{3}\right\}$

- The principal stresses of the Cauchy stress tensor $\left\{\sigma_{I}, \sigma_{I I}, \sigma_{I I I}\right\}$ with $\sigma_{I} \geq \sigma_{I I} \geq \sigma_{I I I}$

- The coordinates of the modified Haigh-Westergaard space $\left\{\eta, \bar{\theta}, \bar{\sigma}_{V M}\right\}$

$I_{1}$ is the first invariant of the Cauchy stress tensor, while $J_{2}$ and $J_{3}$ the second and third invariants of the deviatoric stress tensor defined as:

$$
\begin{gathered}
I_{1}=\operatorname{tr}(\boldsymbol{\sigma}) \\
J_{2}=\frac{1}{2} \operatorname{tr}\left(\mathbf{s}^{2}\right) \\
J_{3}=\operatorname{det}(\mathbf{s})
\end{gathered}
$$

$\eta$ is the stress triaxiality, $\bar{\theta}$ is the Lode angle parameter and $\bar{\sigma}_{V M}$ is the von Mises stress. These can be expressed in terms of the stress tensor invariants $I_{1}, J_{2}$ and $J_{3}$ as follows,

$$
\begin{gathered}
\eta=\frac{1 / 3 I_{1}}{\sqrt{3 J_{2}}} \\
\bar{\theta}=1-\frac{2}{\pi} \arccos \left(\frac{3 \sqrt{3}}{2} \frac{J_{3}}{J_{2}^{3 / 2}}\right) \text { with }-1 \leq \bar{\theta} \leq 1 \\
\bar{\sigma}_{V M}=\sqrt{3 J_{2}}
\end{gathered}
$$

Based on such coordinates one can define the principal stresses as,

$$
\begin{aligned}
\sigma_{I} & =\bar{\sigma}\left\{\eta+\frac{2}{3} \cos \left[\frac{\pi}{6}(1-\bar{\theta})\right]\right\} \\
\sigma_{I I} & =\bar{\sigma}\left\{\eta+\frac{2}{3} \cos \left[\frac{\pi}{6}(3+\bar{\theta})\right]\right\}
\end{aligned}
$$




$$
\sigma_{I I I}=\bar{\sigma}\left\{\eta-\frac{2}{3} \cos \left[\frac{\pi}{6}(1+\bar{\theta})\right]\right\}
$$

\subsection{Anisotropic Cockroft-Latham fracture-initiation criterion}

In order to take into account, the anisotropic fracture behaviour experimentally observed, an anisotropic version of the Cockcroft-Latham failure initiation criterion (Cockcrof and Latham, 1968) was proposed. Let us define the damage indicator $D$ as

$$
D=\int_{0}^{\bar{\varepsilon}^{f}} \frac{1}{W_{c r}}\left\langle\hat{\sigma}_{1}\right\rangle d \bar{\varepsilon}_{\mathrm{VM}}
$$

being

$$
\dot{\bar{\varepsilon}}_{\mathrm{VM}}=\sqrt{\frac{2}{3} \dot{\boldsymbol{\varepsilon}}^{T} \dot{\boldsymbol{\varepsilon}}} \text { with } \quad \bar{\varepsilon}_{\mathrm{VM}}=\int \dot{\bar{\varepsilon}}_{\mathrm{VM}} d t
$$

where $0 \leq D \leq 1,\langle\bullet\rangle=\max [0, \bullet]$ are the Macaulay brackets and $\hat{\sigma}_{1}$ is the maximum principal stress of the Cauchy stress tensor. Taking inspiration from the plasticity models shown earlier, the Cauchy stress vector is linearly transformed using a weighting matrix. However, since the the failure criterion is uncopled none of the uniqueness or stability rules apply. Therefore, theoretically there is no limitation in the shape of the matrix. We define the modified Cauchy stress vector as,

$$
\hat{\boldsymbol{\sigma}}=\mathbf{M \sigma}
$$

being

$$
\mathbf{M}=\left[\begin{array}{cccccc}
1 & m_{12} & 0 & 0 & 0 & 0 \\
m_{21} & m_{22} & 0 & 0 & 0 & 0 \\
0 & 0 & 1 & 0 & 0 & 0 \\
0 & 0 & 0 & m_{44} & 0 & 0 \\
0 & 0 & 0 & 0 & 1 & 0 \\
0 & 0 & 0 & 0 & 0 & 1
\end{array}\right]
$$


This matrix contains the anisotropic constants $m_{12}, m_{21}, m_{22}$ and $m_{44}$. Note that when using $m_{12}=m_{21}=0, m_{22}=1$ and $m_{44}=1$ the criterion collapses into the isotropic Cockroft-Latham failure criterion and a single constant is necessary. According to equation (7.10) when the plastic work $W_{c l}=\left\langle\hat{\sigma}_{1}\right\rangle \dot{\bar{\varepsilon}}$ reaches a critical value $W_{c r}$ the fracture initiates, i.e. $D=1$ and the element is eroded.

\subsection{Anisotropic Mohr-Coulomb fracture-initiation criterion}

The second failure criterion chosen to describe the observed fracture behaviour of the materials was an anisotropic version of the Mohr-Coulomb fracture-initiation criterion. Although it is normally used for describing the fracture behaviour of brittle materials such as concrete, soil or rock; some authors e.g. (Mohr and Marcadet, 2015) have successfully applied the strain-based version of it for describing the fracture behaviour of advanced high strength steels.

When a solid is subjected to a stress state (see Figure 7.1), failure takes place across a plane in which the linear combination of normal stress $\sigma_{n}$ and shear stress $\tau$ is maximum,

$$
\max _{N}\left[\tau+c_{1} \sigma_{n}\right]=c_{2}
$$

where $\mathrm{N}$ is the number of possible fracture planes.

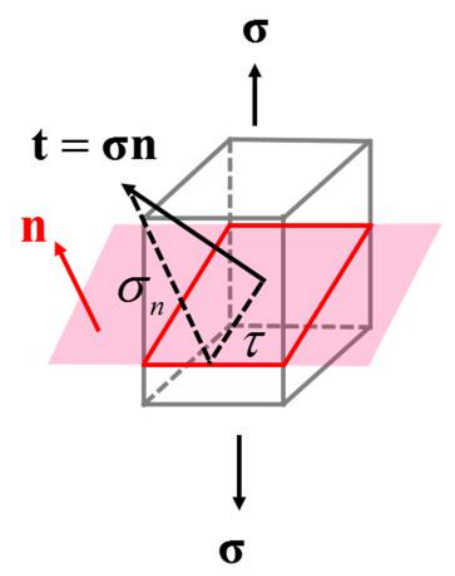

Figure 7.1. Ilustrative sketch of the fracture plane on a solid loaded with a tensile stress. 
The isotropic Mohr-Coulomb fracture-initiation criterion, considered as a contribution from (Coulomb, 1776) and (Mohr, 1900), can be rewritten in terms of principal stresses of the Cauchy stress tensor,

$$
\left(\sigma_{I}-\sigma_{I I I}\right)+c\left(\sigma_{I}+\sigma_{I I I}\right)=b
$$

As in the previous case (see section 7.2.), in order to take into account the anisotropic fracture behaviour of the materials, we define the modified Cauchy stress vector as

$$
\hat{\boldsymbol{\sigma}}=\mathbf{M \sigma}
$$

being $\mathbf{M}$ the matrix that contains the anisotropic constants and it is homologous as that used in equation (7.13).

Now, the anisotropic Mohr-Coulomb fracture-initiation criterion can be expressed as follows

$$
\left(\hat{\sigma}_{I}-\hat{\sigma}_{I I I}\right)+C\left(\hat{\sigma}_{I}+\hat{\sigma}_{I I I}\right)=B
$$

Please note that when $m_{12}=m_{21}=0, m_{22}=1$ and $m_{44}=1$ the criterion recovers the isotropy where only two constants are necessary, $B$ and $C$. In this case, we define the damage indicator $D$ as

$$
D=\frac{\left(\hat{\sigma}_{I}-\hat{\sigma}_{I I I}\right)+C\left(\hat{\sigma}_{I}+\hat{\sigma}_{I I I}\right)}{B}
$$

where $0 \leq D \leq 1$. When $D=1$ then the fracture initiates.

\subsection{Calibration procedure}

The parameters $\left\{W_{c r}, m_{12}, m_{21}, m_{22}, m_{44}\right\}$ of the anisotropic Cockroft-Latham failure criterion (ACL) and $\left\{B, C, m_{12}, m_{21}, m_{22}, m_{44}\right\}$ of the anisotropic MohrCoulomb fracture-initiation criterion (AMC) were identified using the results from the uniaxial tensile quasi-static experiments along the $0^{\circ}, 45^{\circ}$ and $90^{\circ}$ orientations. It should be noted that the rest of the UT tests were not used to calibrate the 
fracture criteria since, as stated before, strain rate and temperature dependency is implicitly given by the stresses. An optimisation process was performed using a derivative-free simplex algorithm (Matlab) which minimised the difference between the strains to fracture predicted by equations (7.10) and (7.18) for ACL and AMC criteria respectively, with those extracted from the numerical simulations. The latter strains histories were extracted from the element with the highest equivalent plastic strain and recorded until the averaged displacement corresponding to fracture was reached, see Figure 7.2. for AA7017-T73 alloy and Figure 7.3 for Mars $® 240$ steel. The final parameters of the ACL and AMC fracture-initiation criteria for the AA7017T73 alloy are given in Table 7.1. and in Table 7.2. for the Mars ${ }^{\circledR} 240$ steel.

Table 7.1. Calibrated parameters for the anisotropic Cockcroft-Latham and MohrCoulom failure criteria of AA7017-T73 alloy.

\begin{tabular}{|c|c|c|c|c|}
\hline \multicolumn{5}{|c|}{ Anisotropic Cockcroft-Latham failure criterion } \\
\hline$W_{c r}(\mathrm{MPa})$ & $m_{12}=m_{21}$ & & $m_{22}$ & $m_{44}$ \\
\hline 123.6 & -1.7731 & & 2.0859 & 0.6699 \\
\hline \multicolumn{5}{|c|}{ Anisotropic Mohr-Coulomb failure criterion } \\
\hline$B(\mathrm{MPa})$ & $C$ & $m_{12}=m_{21}$ & $m_{22}$ & $m_{44}$ \\
\hline 674.9 & 0.1267 & -0.0618 & 1.0868 & 0.9357 \\
\hline
\end{tabular}

Table 7.2. Calibrated parameters for the anisotropic Cockcroft-Latham and MohrCoulom failure criteria of Mars $\circledR 240$ steel.

\begin{tabular}{ccccc}
\hline \multicolumn{5}{l}{ Anisotropic Cockcroft-Latham failure criterion } \\
\hline$W_{c r}(\mathrm{MPa})$ & $m_{12}$ & $m_{21}$ & $m_{22}$ & $m_{44}$ \\
\hline 1080.4 & 0.0712 & 0.0 & 1.4815 & 1.3381 \\
\hline \hline Anisotropic Mohr-Coulomb failure criterion & & \\
\hline$B(\mathrm{MPa})$ & $C$ & $m_{12}=m_{21}$ & $m_{22}$ & $m_{44}$ \\
\hline 4109.1 & 0.0891 & 1.1597 & 1.1850 & -0.3380 \\
\hline
\end{tabular}




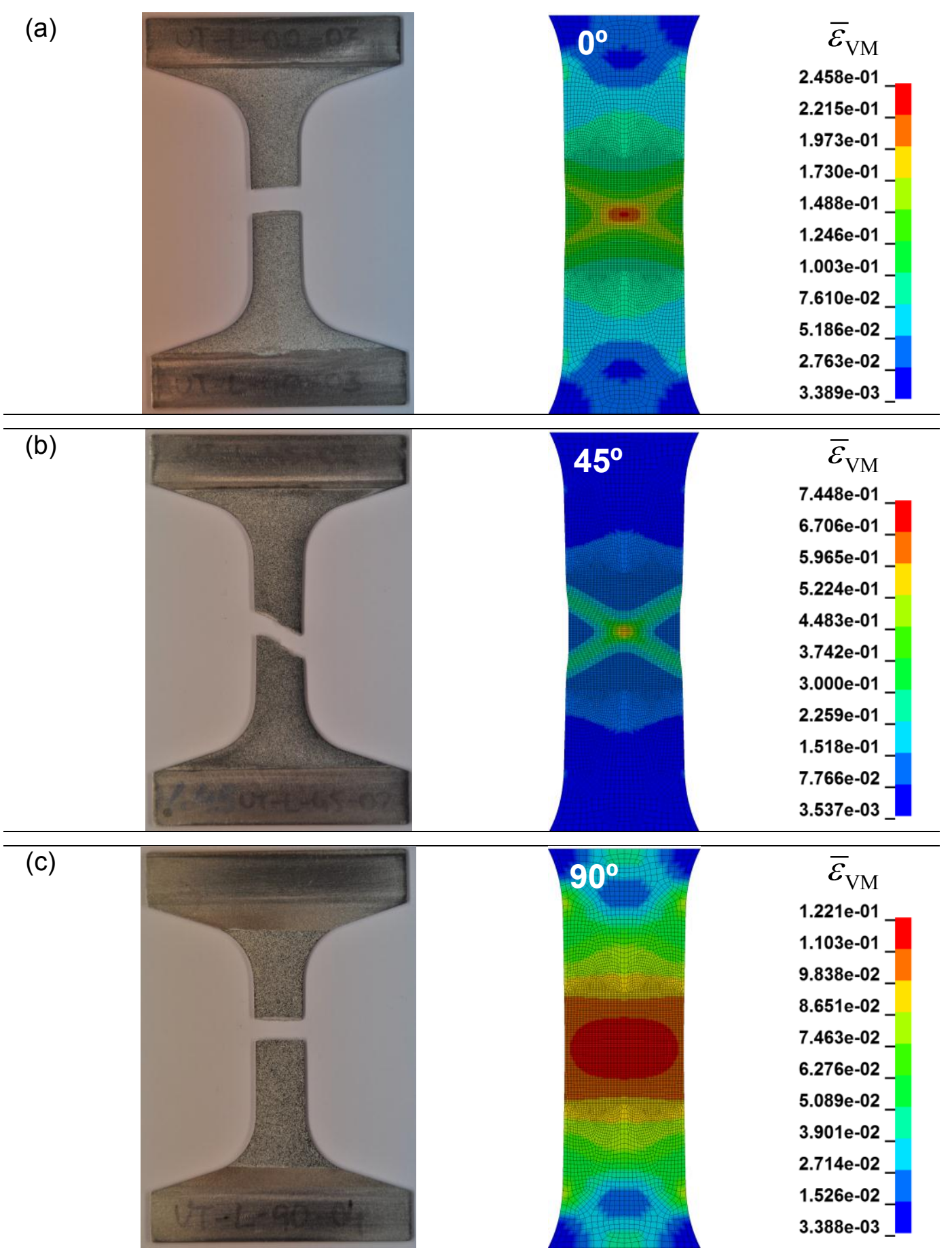

Figure 7.2. AA7017-T73 alloy UT specimens extracted at $0^{\circ}(\mathrm{a}), 45^{\circ}(\mathrm{b})$ and $90^{\circ}(\mathrm{c})$ with respect to the rolling direction. On the left, post-mortem pictures of the specimens. On the right, von Mises equivalent strain corresponding to fracture. 


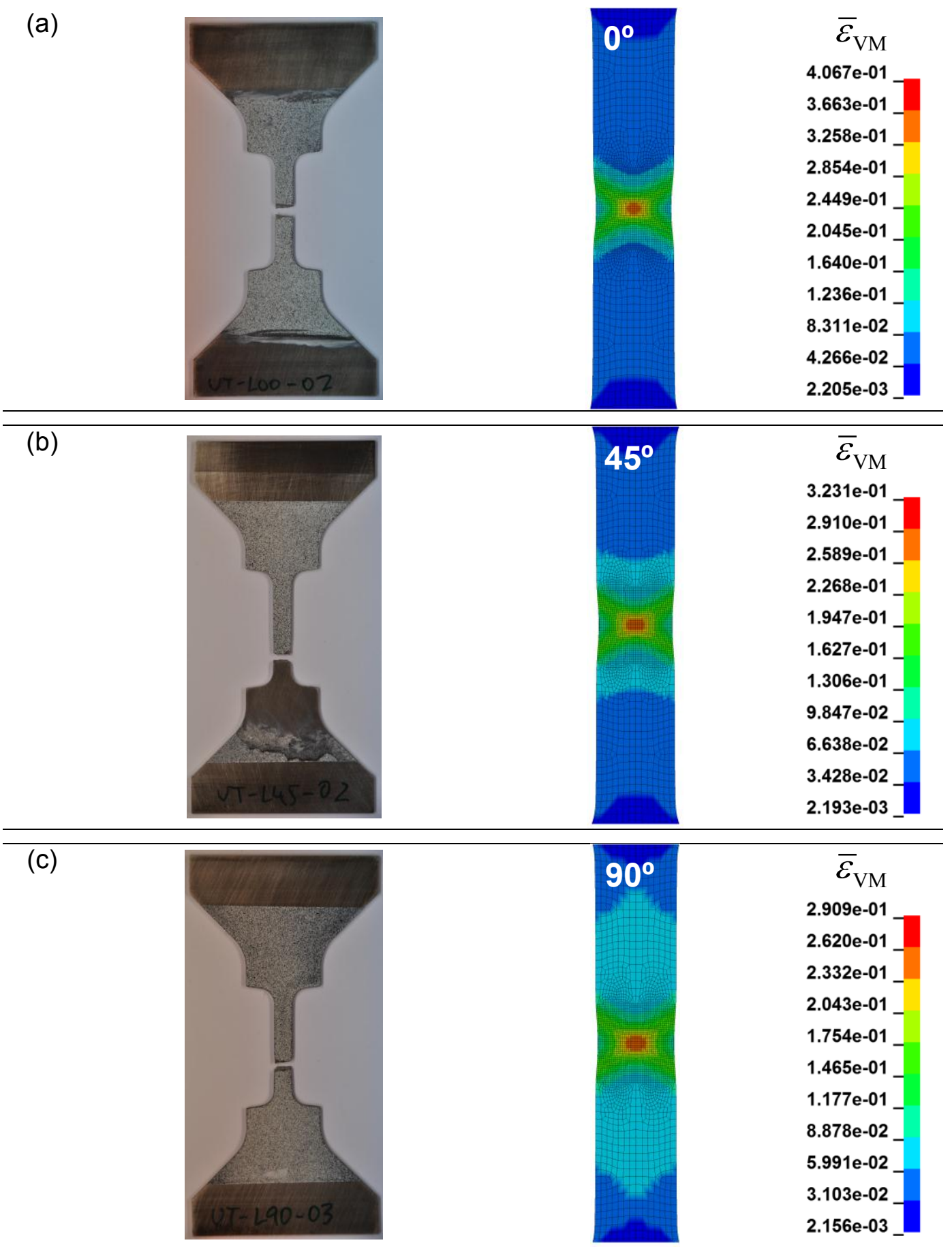

Figure 7.3. Mars ${ }^{\circledR} 240$ steel UT specimens extracted at $0^{\circ}(\mathrm{a}), 45^{\circ}(\mathrm{b})$ and $90^{\circ}(\mathrm{c})$ with respect to the rolling direction. On the left, post-mortem pictures of the specimens. On the right, von Mises equivalent strain corresponding to fracture. 


\subsubsection{Visualisation}

A loading path to fracture describes the evolution of the stress state and internal variables at the location within the specimen where fracture initiates. Tipically for an isotropic material, it can be represented as the evolution of the equivalent plastic strain, the stress triaxiality and the Lode angle parameter, or a combination of them, until the instant of fracture initiation. Therefore, the loading path to fracture can be visualised in 2D or 3D plots, as in (Gruben et al., 2011; Gu and Mohr, 2015; Marcadet and Mohr, 2015). The stress state of an anisotropic material is given by the six stress tensor components and not by the three magnitudes that describe it in the isotropic case, making the visualisation of the loading paths to fracture extremely challenging. To overcome this issue, here the approach followed by ( $\mathrm{Gu}$ and Mohr, 2015) was pursued.

In order to do so, the stress components related with the through thickness stress $\left\{\sigma_{33}, \sigma_{23}, \sigma_{13}\right\}$ were not taken into account. To visualise the anisotropic effect on the loading paths, two planes were constructed in polar coordinates (see Figure 7.4):

- $\left\{\sigma_{11}, \sigma_{22}\right\}$ plane with an argument $r=\bar{\varepsilon}_{V M}$ and an angle $\varphi=\arctan \left(\sigma_{22} / \sigma_{11}\right)$, giving in Cartesian coordinates an abscissa $x=\bar{\varepsilon}_{V M} \cos \varphi=\bar{\varepsilon}_{V M} \sigma_{11} / \sqrt{\sigma_{11}^{2}+\sigma_{22}^{2}} \quad$ and $\quad$ an ordinate $y=\bar{\varepsilon}_{V M} \sin \varphi=\bar{\varepsilon}_{V M} \sigma_{22} / \sqrt{\sigma_{11}^{2}+\sigma_{22}^{2}}$. Loading paths and fracture prediction in this plane are indicated in blue lines and blue dots respectively.

- $\left\{\sigma_{12}, \sigma_{d}\right\}$ plane with an argument $r=\bar{\varepsilon}_{V M}$ and an angle $\theta=\arctan \left(\sigma_{12} / \sigma_{d}\right)$ being $\sigma_{d}=\sqrt{\sigma_{11}^{2}+\sigma_{22}^{2}}$ and giving an abscissa $x=\bar{\varepsilon}_{V M} \cos \theta=\bar{\varepsilon}_{V M} \sigma_{d} / \sqrt{\sigma_{12}^{2}+\sigma_{d}^{2}} \quad$ and an ordinate $y=\bar{\varepsilon}_{V M} \sin \theta=\bar{\varepsilon}_{V M} \sigma_{12} / \sqrt{\sigma_{12}^{2}+\sigma_{d}^{2}}$ in Cartesian coordinates. Loading paths and fracture prediction corresponding to this plane are indicated in green lines and green dots respectively. 


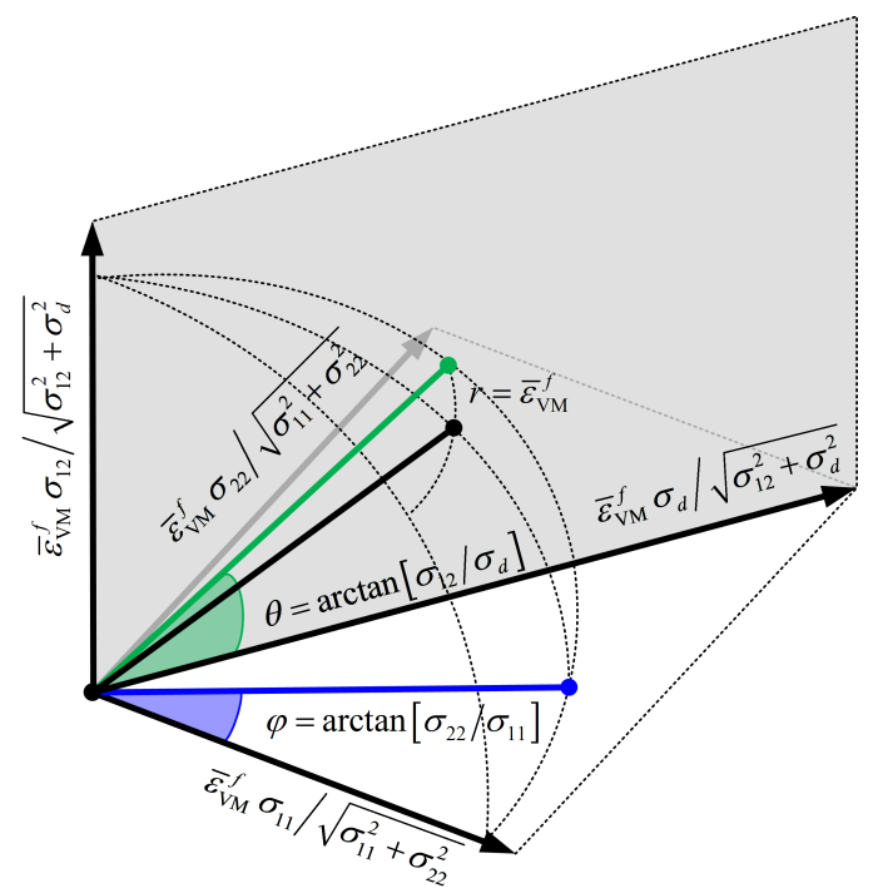

Figure 7.4. Schematical illustration of polar figures used to visualise the loading paths to fracture of an anisotropic material.

The first plane $\left\{\sigma_{11}, \sigma_{22}\right\}$ showed the bi-axial state of the UT tests, while the second $\left\{\sigma_{12}, \sigma_{d}\right\}$ tried to represent the shear response in a plane where $\sigma_{11} \approx \sigma_{22}$ . This latter condition was often fullfiled in tensile tests with $45^{\circ}$ orientation.

Figure 7.5. and Figure 7.6. show the loading paths to fracture depicted in solid lines of AA7017-T73 and Mars $® 240$ steel, respectively. In both figures, hybrid numerical-experimental fracture is given by the end of the solid lines. The anisotropic Cockroft-Latham model predictions are plotted in hollow dots in (a) and (b), while the anisotropic Mohr-Coulomb model predictions are plotted in solid dots in (c) and (d). As it can be seen, both models gave excellent predictions for UT experiments of both materials.

As expected, $0^{\circ}$ and $90^{\circ}$ oriented UT specimens followed their respective uniaxial paths $\bar{\varepsilon}_{V M} \sigma_{11} / \sqrt{\sigma_{11}^{2}+\sigma_{22}^{2}}$ and $\bar{\varepsilon}_{V M} \sigma_{22} / \sqrt{\sigma_{11}^{2}+\sigma_{22}^{2}}$ in the $\left\{\sigma_{11}, \sigma_{22}\right\}$ plane until they became bi-axial before fracture (see Figure 7.5.(a) and (c), and Figure 7.6.(a) and (c)). In the same plane, it can be seen that the $45^{\circ}$ oriented UT specimens 
manteined $\sigma_{11} \approx \sigma_{22}$ condition up to fracture. Those specimens presented a monotonic increase in $\sigma_{12}$ that can be seen in the $\left\{\sigma_{12}, \sigma_{d}\right\}$ plane and is depicted in Figure 7.5.(b) and (d), and Figure 7.6.(b) and (d).

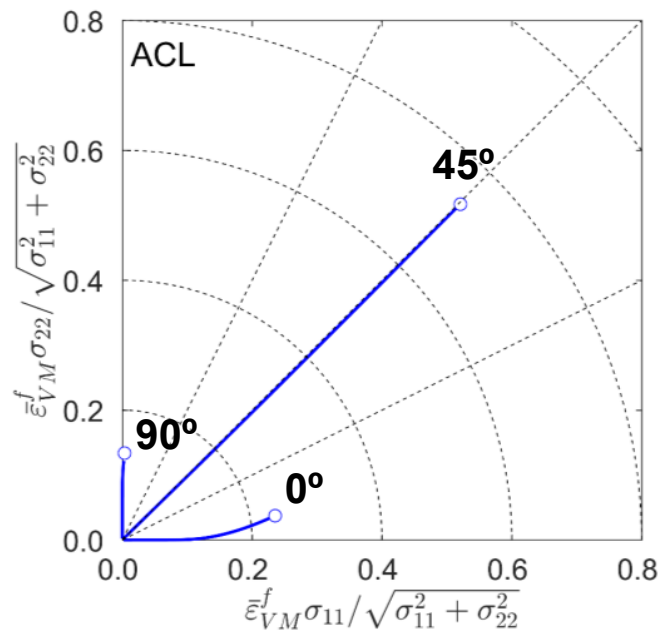

(a)

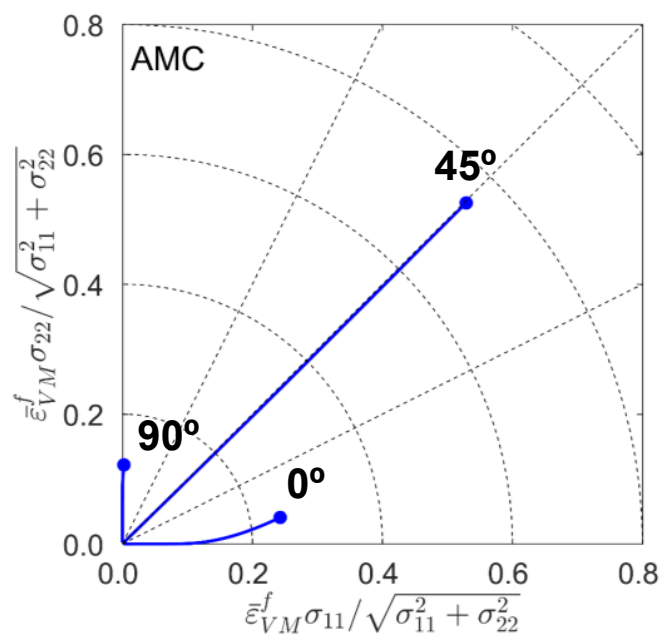

(c)

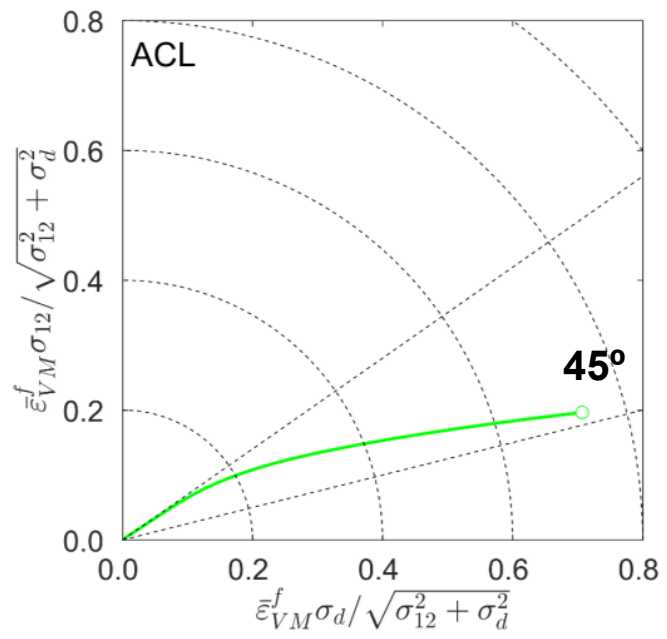

(b)

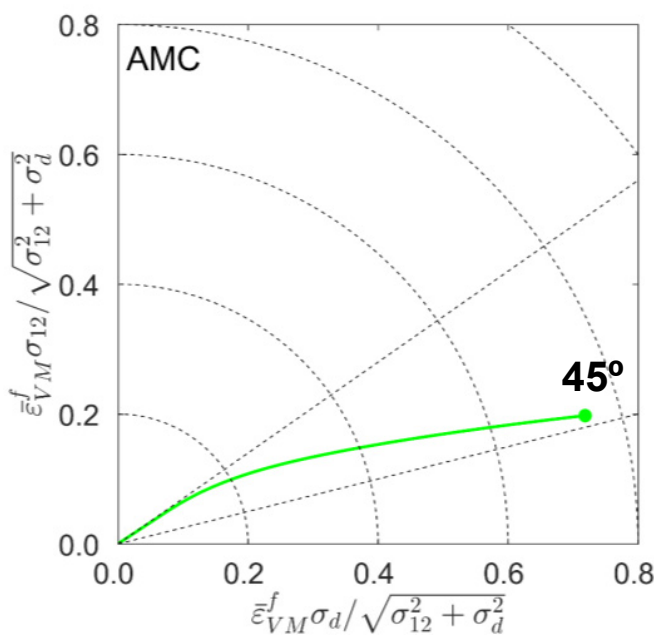

(d)

Figure 7.5. Loading paths to fracture of AA7017-T73. ACL model predictions (a) in plane $\left\{\sigma_{11}, \sigma_{22}\right\}$ and (b) in plane $\left\{\sigma_{12}, \sigma_{d}\right\}$. AMC model predictions (c) in plane $\left\{\sigma_{11}, \sigma_{22}\right\}$ and $(\mathrm{d})$ in plane $\left\{\sigma_{12}, \sigma_{d}\right\}$. 


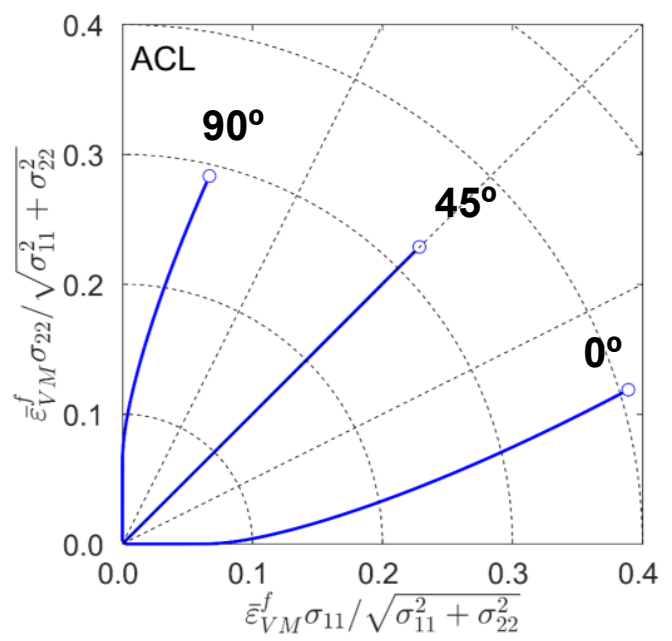

(a)

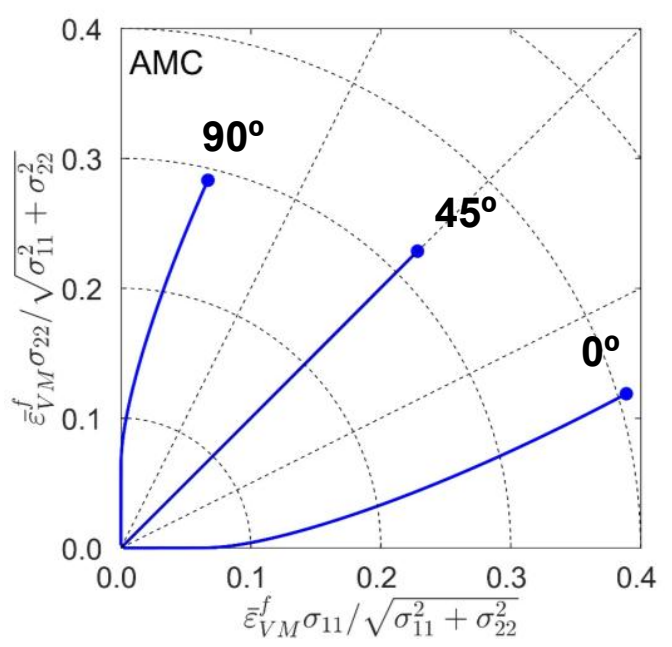

(c)

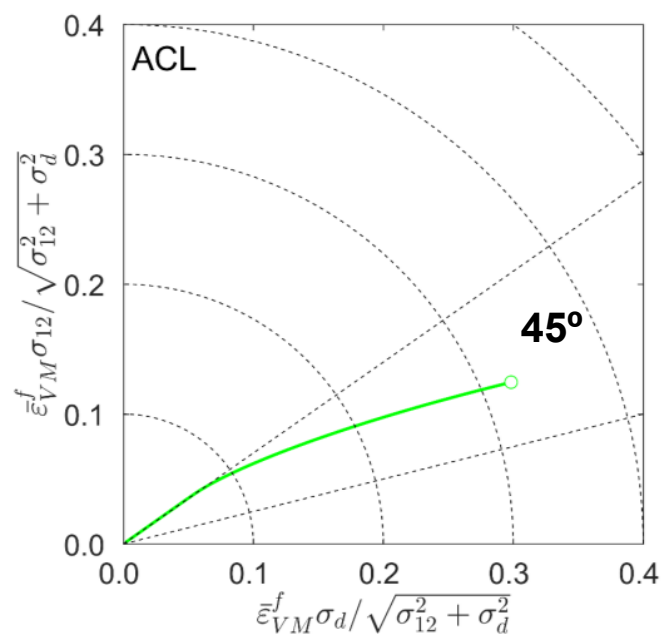

(b)

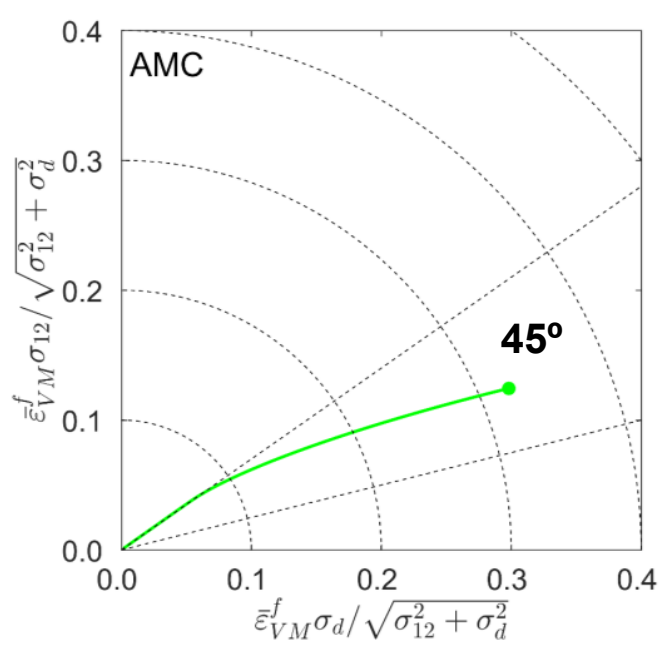

(d)

Figure 7.6. Loading paths to fracture of Mars $® 240$ steel. ACL model predictions (a) in plane $\left\{\sigma_{11}, \sigma_{22}\right\}$ and (b) in plane $\left\{\sigma_{12}, \sigma_{d}\right\}$. AMC model predictions (c) in plane $\left\{\sigma_{11}, \sigma_{22}\right\}$ and (d) in plane $\left\{\sigma_{12}, \sigma_{d}\right\}$. 


\subsection{Numerical study}

\subsubsection{Numerical set-up}

The same numerical set-up as that used in section 6.2.1. was employed to perform numerical simulations of three-point bending tests at different loading rates with the two fracture models ACL and AMC.

\subsubsection{Results}

As it was presented in CHAPTER 6, in order to analyse the obtained experimental results, for every loading rate two representative experimental curves (black dashed lines) were compared to the extracted from the numerical simulations (red solid lines) (see Figure 7.7. and Figure 7.10.). Fracture onset was shown as a shaded red band. In addition, the anisotropic Cockroft-Latham (in blue dashed line) and anisotropic Mohr-Coulomb (in blue solid line) damage indicators extracted from the element located ahead the crack tip and adjacent to the vertical symmetry plane were plotted.

Similarly to CHAPTER 6, force-displacement curves from quasi-static conditions were compared in Figure 7.7.(a) for AA7017-T73 and Figure 7.10.(a) for Mars ${ }^{\circledR}$ 240 steel. For the rest of loading regimes (see Figure 7.7.(b) and (c), and Figure 7.10.(b) and (c)), strain histories extracted experimentally from the strain gauge were compared to the average of the histories extracted from the four finite elements which composed the virtual strain gauge (as presented in Figure 6.3). Note that as it was mentioned in sections 7.2 and 7.3 , when $D=1$ then the fracture initiated.

For all of the cases, the damage indicator contours of ACL and AMC failure criteria are plotterd at onset of fracture on the left of Figure 7.8. for AA7017-T73 and Figure 7.11. for Mars ${ }^{\circledR} 240$ steel. For the sake of completion, polar plots in the $\left\{\sigma_{22}, \sigma_{33}\right\}$ plane that depicted the loading paths to fracture from the element located ahead the crack tip and adjacent to the vertical symmetry plane were presented, in the right part of Figure 7.8. and Figure 7.11. for AA7017-T73 and Mars $® 240$ steel, 
respectively. The ACL predictions were plotted as hollow dots, while solid dots showed the AMC predictions.

\subsubsection{1. $A A 7017-T 73$}

As it can be seen in Figure 7.7., fracture never occurred when the anisotropic Cockroft-Latham fracture criterion was applied. Under quasi-static conditions (Figure 7.7.(a)) and in the modified SHPB experiments (Figure 7.7.(b)), failure was perfectly predicted by the anisotropic Mohr-Coulomb failure criterion since $D=1$ at the fracture time. In the case of the experiments with explosives (Figure 7.7.(c)), the AMC model predicted fracture earlier but close to the shaded red band. In the left part of Figure 7.8, the ACL and AMC predictions were plotted in terms of damage indicator contours at fracture onset. It can be noticed that ACL damage contours were almost indistinguishable. The same conclusions were obtained from the right part of Figure 7.8 that, quantitatively in terms of von Mises equivalent strain, showed the loading paths to fracture in polar plots along with the ACL and AMC criteria predictions. The strain to fracture was slightly overpredicted with the AMC model in the case of the explosive tests, while it was spot-on for the rest of the tests. 
(a) Quasi-static

$d_{f}=0.57 \mathrm{~mm}$

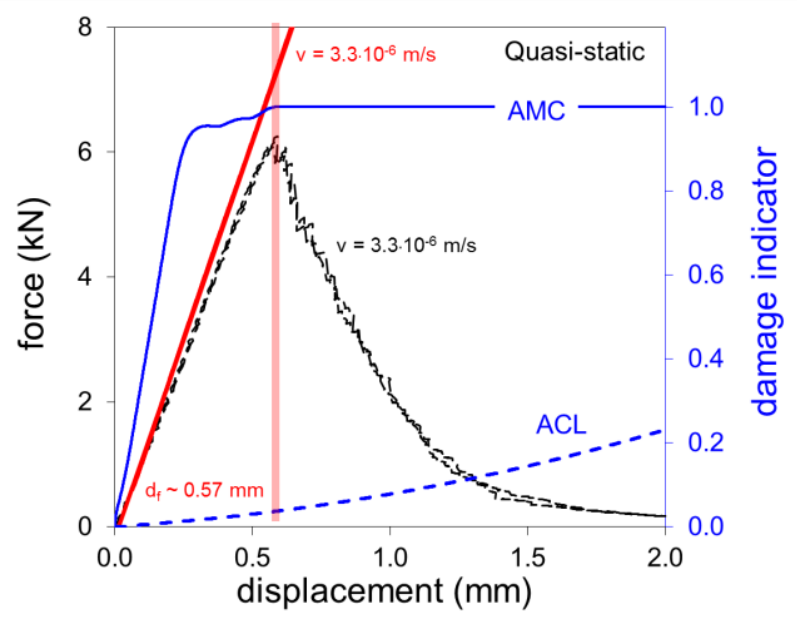

\section{(b) SHPB \\ $t_{f}=50 \mu \mathrm{s}$}

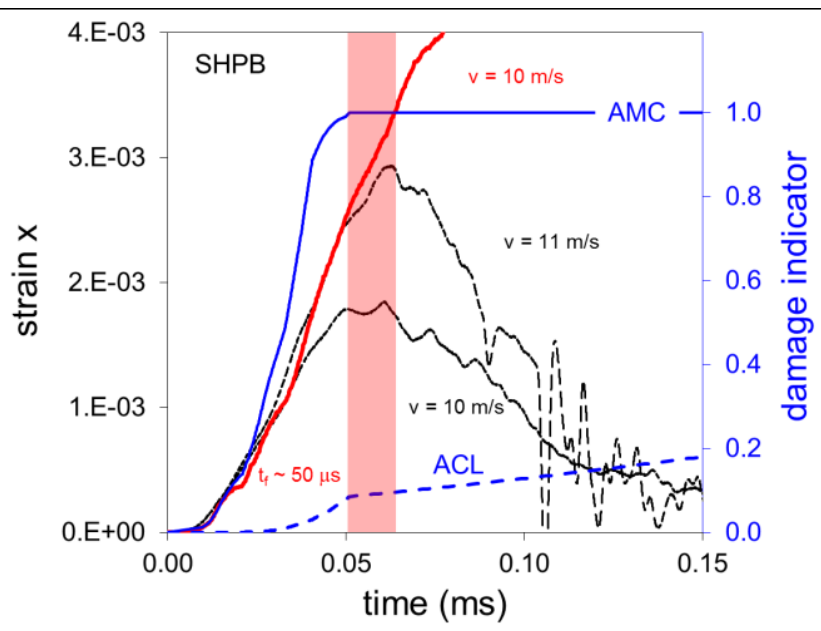

(c) Explosives

$t_{f}=90 \mu \mathrm{s}$

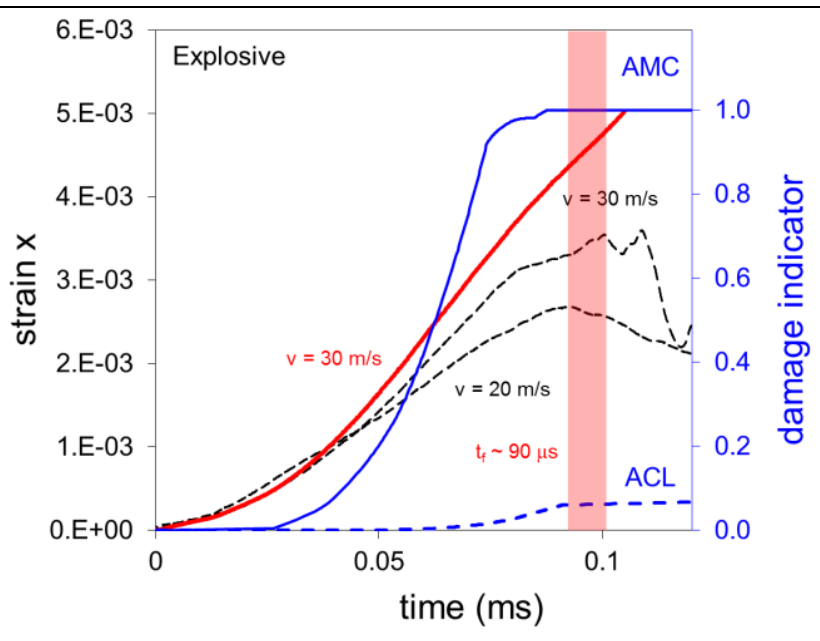

Figure 7.7. ACL and AMC damage indicators extracted from the element located ahead the crack tip and adjacent to the vertical symmetry plane for the TPB (a) quasi-static, (b) SHPB and (c)explosive tests of the AA7017-T73 compared to the results in Figure 6.4. 
Quasi-static $\quad d_{f}=0.57 \mathrm{~mm}$

ACL

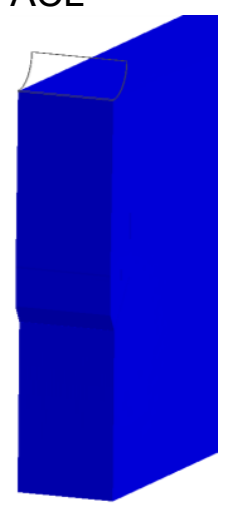

$\mathrm{AMC}$

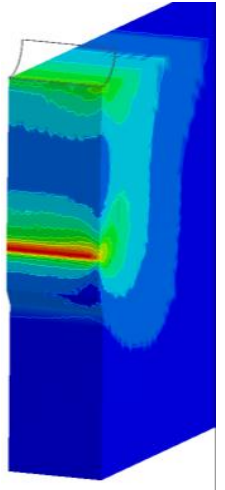

\section{$D$}

0.9

0.8

0.7

0.6

0.5

$0.4-$

$0.3-$

0.2

0.1

$0.0-$

\section{SHPB $\quad t_{f}=50 \mu \mathrm{s}$}

$\mathrm{ACL}$

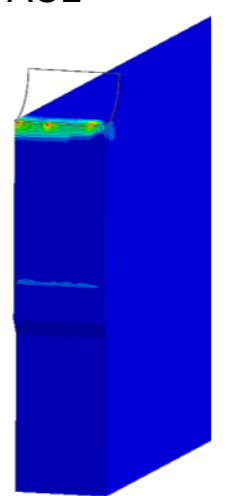

AMC

Explosives $\quad t_{f}=90 \mu \mathrm{s}$

ACL

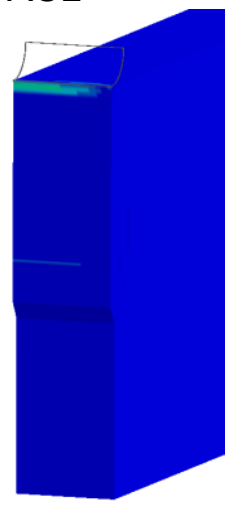

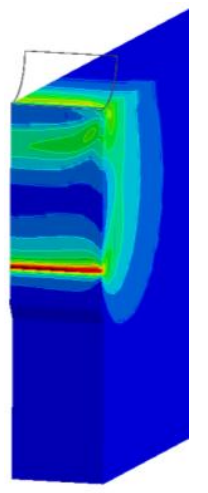

AMC

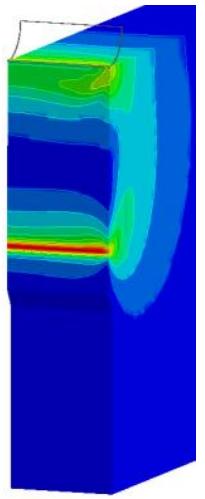

\section{D}

1.0

0.9

0.8

0.7

0.6

0.5 -

$0.4-$

0.3

0.2

0.1

$0.0-$
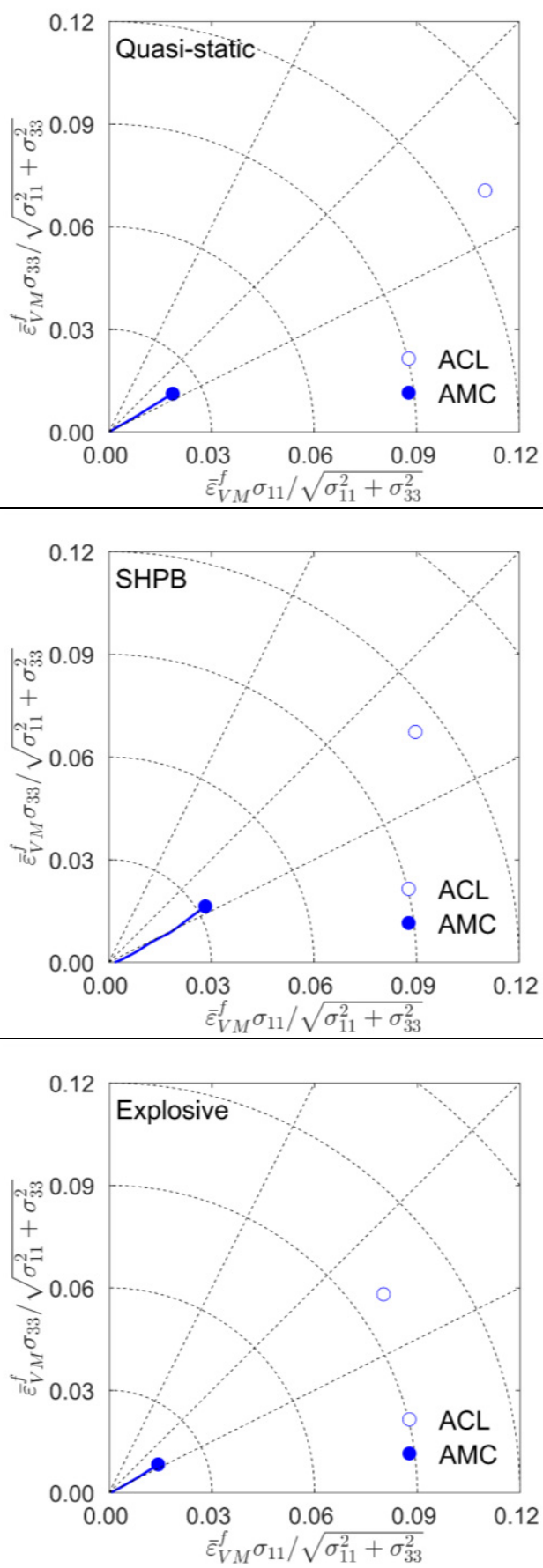

Figure 7.8. (Left) Damage indicator contours of $A C L$ and $A M C$ failure criteria plotted at fracture onset for AA7017-T73. (Right) Polar plots in $\left\{\sigma_{22}, \sigma_{33}\right\}$ plane depicting the loading paths to fracture from the element located ahead the crack tip and adjacent to the vertical symmetry plane. Hollow and solid dots are the ACL and AMC predictions. 
The ACL and AMC failure predictions of the AA7017-T73 experiments performed in a drop-weight tower were plotted in Figure 7.9. As it happened for the rest of loading rates, failure never occurred with the ACL prediction. It was not either predicted with the AMC model (as it can be seen in Figure 7.9.(c)). The AMC damage indicator almost was close to $D=1$, when suddenly it decreased due to the unloading phase. This was another reason, appart from the ones mentioned in section 6.2.2.1., that demonstrated the experiments performed in the drop-weight tower could not be considered valid experiments for the purpose.

Drop-weight $\quad t_{f}=130 \mu \mathrm{s}$

(a)
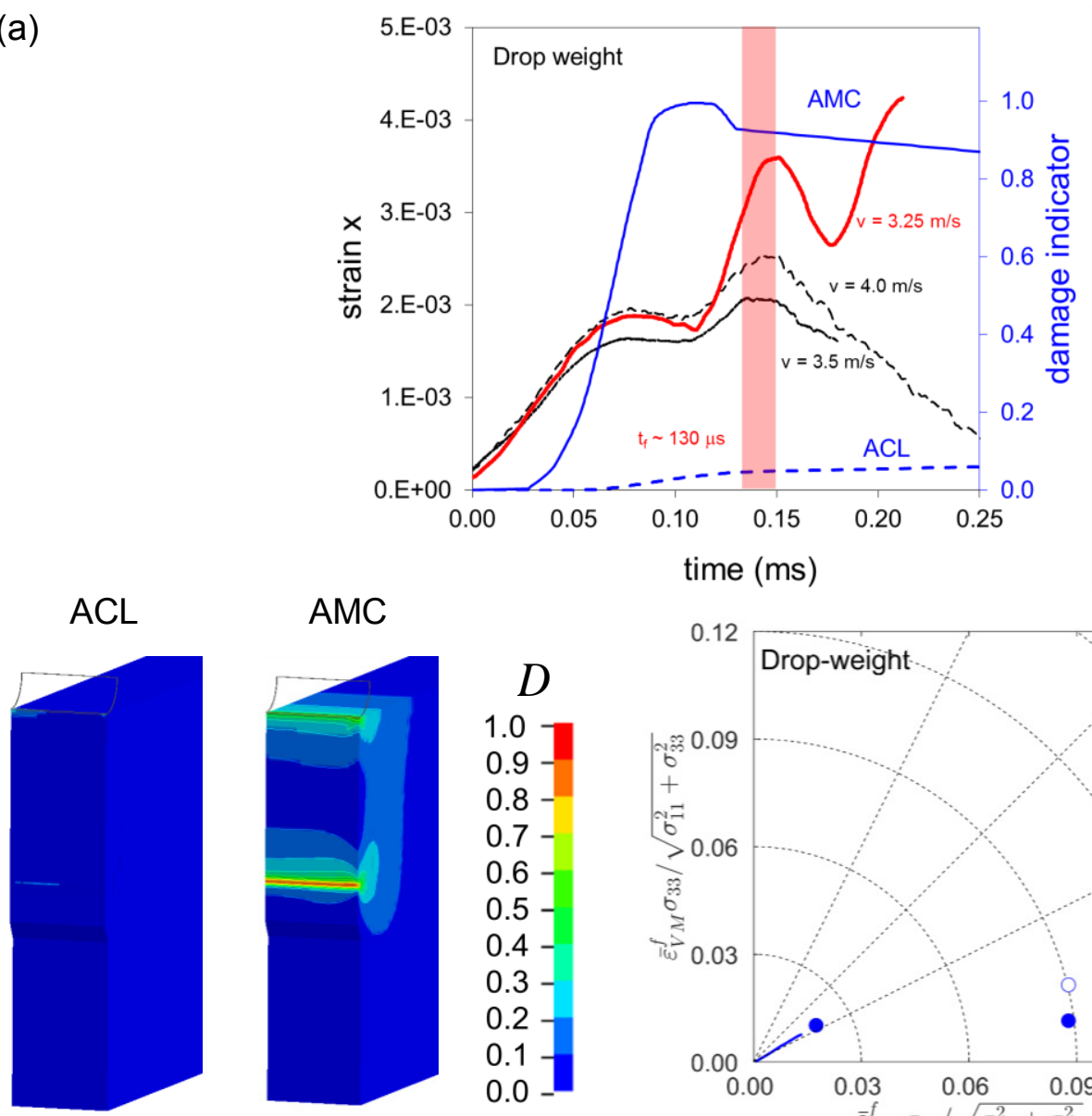

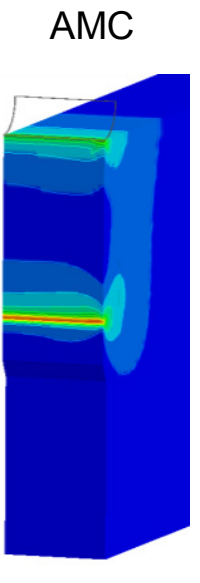

(b)

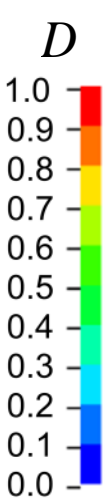

0.0

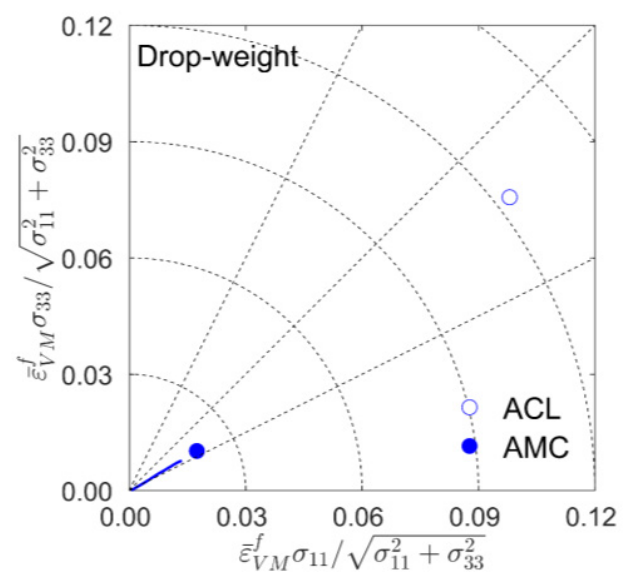

(c)

Figure 7.9. (a) Damage indicator extracted from the critical element compared against the results from Figure 6.5. (b) Damage indicator contours at onset of fracture for $A C L$ and $A M C$ models. (c) Loading paths to fracture from the most critical element in the $\left\{\sigma_{22}, \sigma_{33}\right\}$ plane. 
(a) Quasi-static $d_{f}=0.27 \mathrm{~mm}$

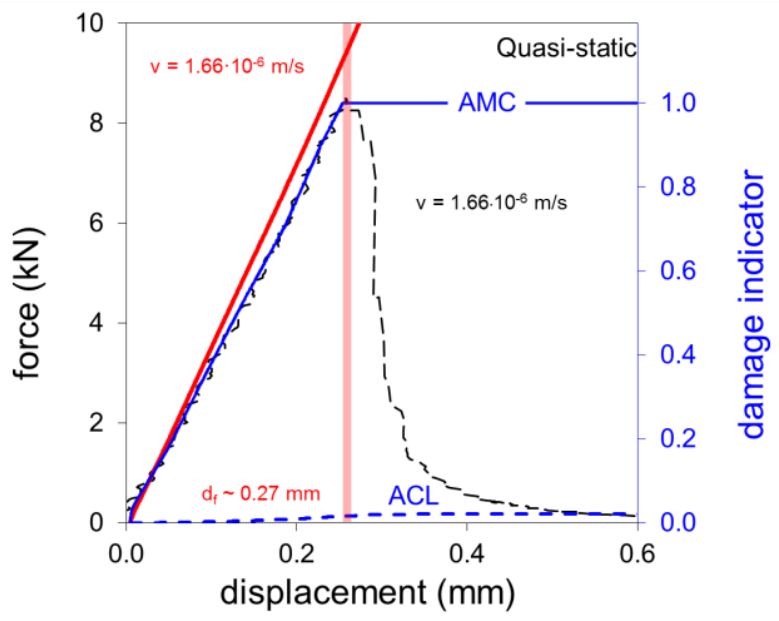

(b) SHPB

$t_{f}=45 \mu \mathrm{S}$

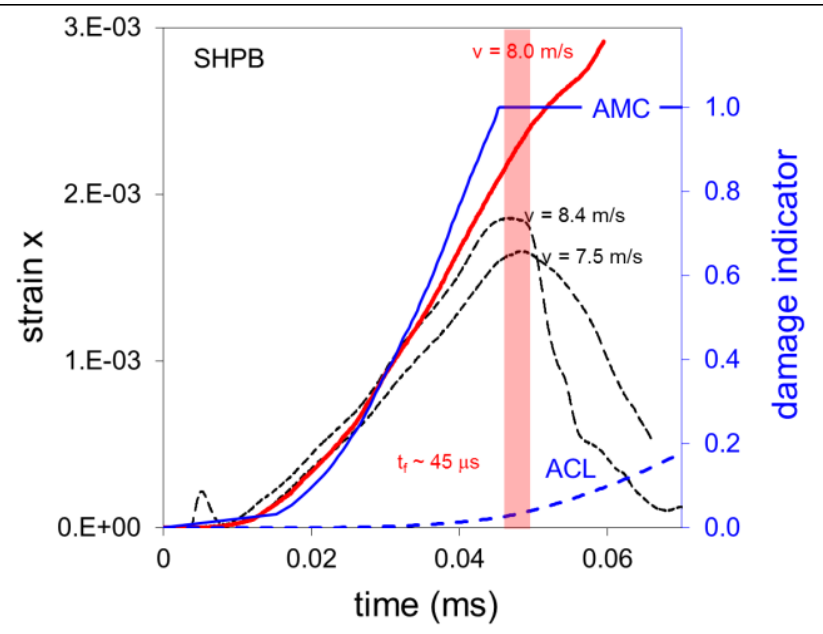

(c) Explosives

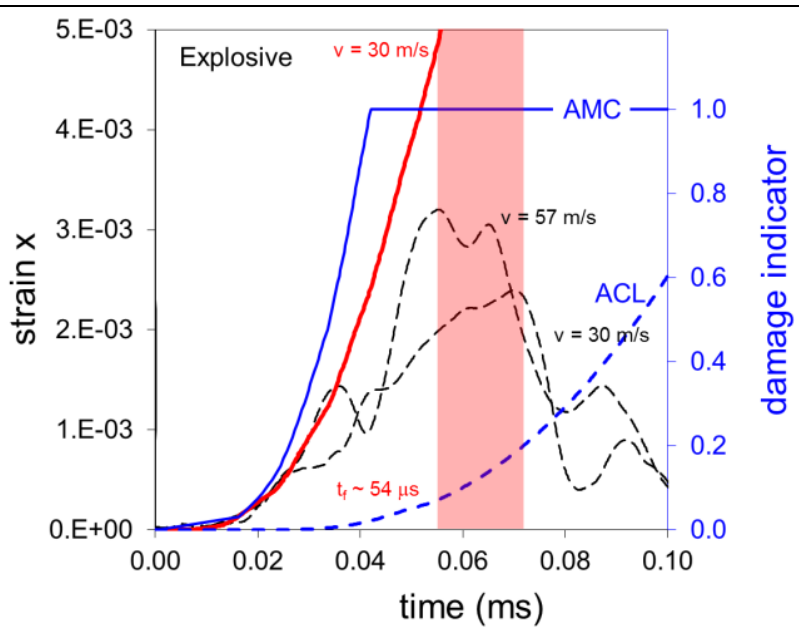

Figure 7.10. ACL and AMC damage indicators extracted from the element located ahead the crack tip and adjacent to the vertical symmetry plane for the TPB (a) quasi-static, (b) SHPB and (c)explosive tests of Mars ${ }^{\circledR} 240$ steel compared to the results in Figure 6.6. 
Quasi-static $\quad d_{f}=0.27 \mathrm{~mm}$

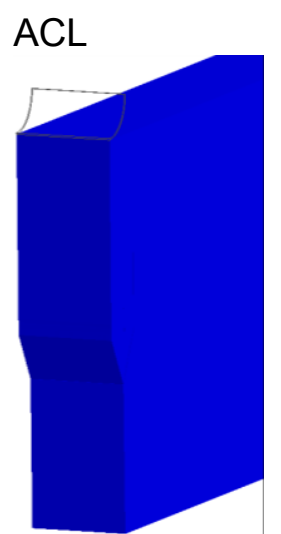

AMC

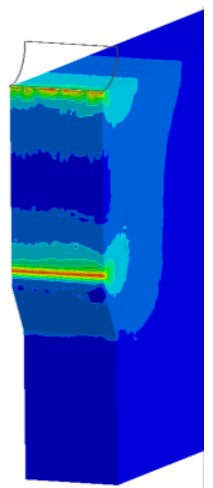

SHPB $\quad t_{f}=45 \mu \mathrm{s}$

$A C L$

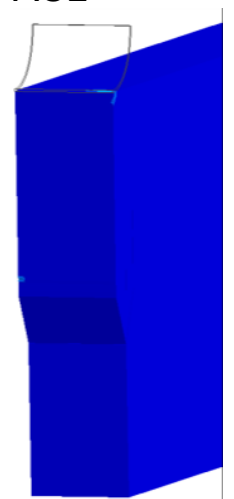

Explosives $t_{f}=54 \mu \mathrm{s}$

ACL

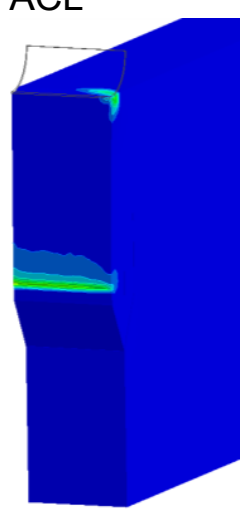

AMC

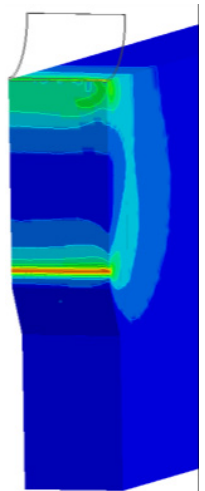

AMC

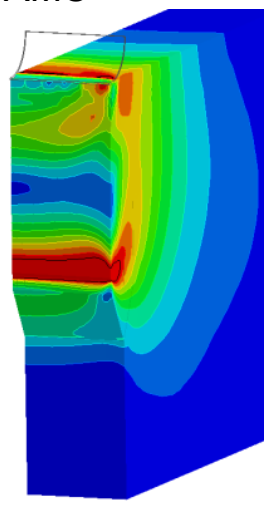

\section{$D$}

0.9

0.8

0.7

0.6

$0.5-$

$0.4-$

$0.3-$

0.2

0.1

0.0
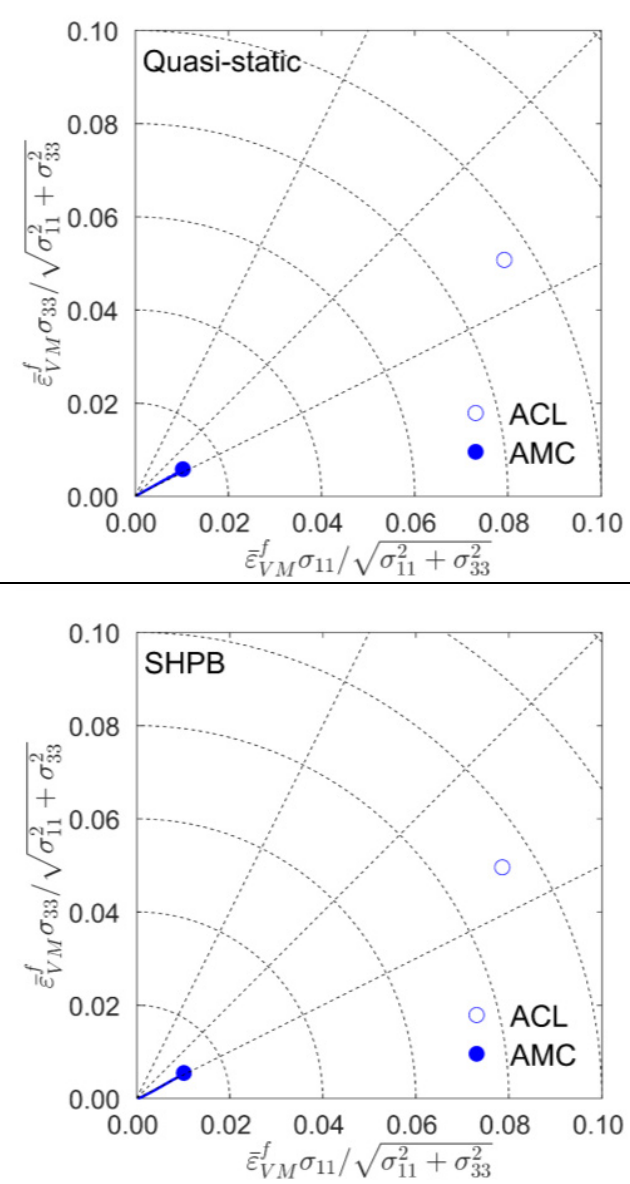

\section{$D$}

1.0
0.9

0.8

0.7

$0.6-$

$0.5-$

$0.4-$

$0.3-$

0.2

0.1

$0.0-$

$D$
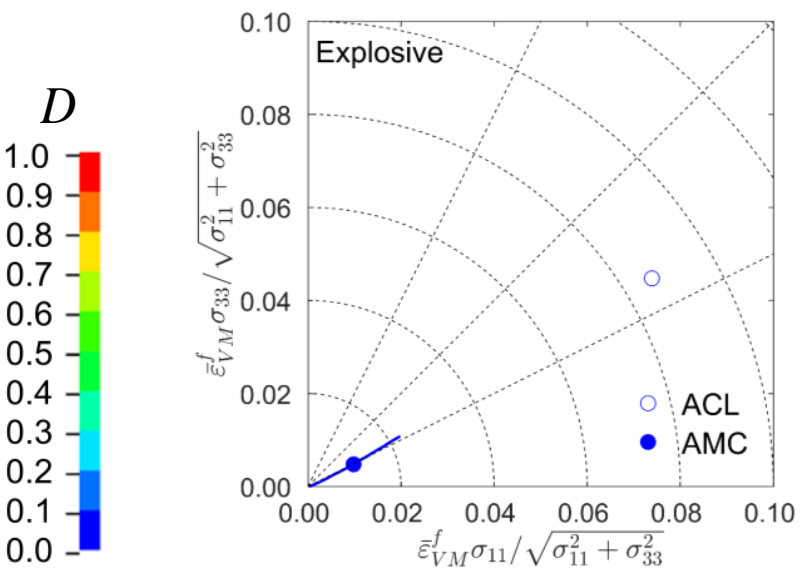

Figure 7.11. (Left) Damage indicator contours of $A C L$ and $A M C$ failure criteria plotted at fracture onset for Mars ${ }^{2} 240$ steel. (Right) Polar plots in $\left\{\sigma_{22}, \sigma_{33}\right\}$ plane depicting the loading paths to fracture from the element located ahead the crack tip and adjacent to the vertical symmetry plane. Hollow and solid dots are the ACL and AMC predictions. 


\subsubsection{Mars $₫ 240$ steel}

As it happened for the AA7017-T73 before and can be observed now for the Mars ${ }^{\circledR}$ 240 steel in Figure 7.10., fracture never occurred when the ACL failure criterion was applied. Failure of the quasi-static (Figure 7.10.(a)) and of the modified SHPB experiments (Figure 7.10.(b)), was accurately predicted by the AMC fracture criterion. However, failure of the experiments under impulsive loadings (Figure 7.10.(c)) was predicted earlier that expected by the AMC model. As it can be observed in the left part of Figure 7.11, for the AMC prediction at the experimentally measured fracture onset, even several elements in contact with the load applier were also fully fractured. In the left part of Figure 7.11, it can be noticed that at the onset of fracture the ACL damage indicator contours of some elements of the specimen in contact with the load applier were showing larger values than the elements of the crack tip zone.

The right part of Figure 7.11., that shows the loading paths to fracture along with the $A M C$ and $A C L$ predictions, illustrates quantitatively what was observed in the left part of the same figure. The AMC model gave good strain to fracture predictions under quasi-static condition and for the SHPB tests, but it was underestimated in the case of explosive tests.

\subsection{Concluding remarks}

The fracture strains measured from the simulations of the UT tests for different loading orientations showed large differences. Both, the anisotropic versions of the Cockcroft-Latham and Mohr-Coulomb failure-initiation criteria were successfully used to describe such large differences in the fracture strains observed in the uniaxial tensile experiments.

Same anisotropic fracture-initiation criteria were used in order to predict failure of the three-point bending fracture tests. The AMC model gave relatively accurate predictions; while failure was never predicted when using the ACL model. 


\section{CHAPTER 8}

\section{CONCLUSIONS AND FUTURE WORK}

\subsection{Conclusions}

The design and development of a novel experimental technique that allowed measuring the dynamic fracture-initiation toughness in a systematic manner for a wide range of loading rates was presented.

A uniaxial tensile experimental campaign was designed to characterise the ratedependent plasticity and fracture response, as well as to study the effect of anisotropy of two high-strength metallic materials. The experimental results revealed that the AA7017-T73 alloy presented a very mild strain rate hardening, while the Mars $® 240$ steel exhibited a significant strain rate dependency.

In order to describe the anisotropic behaviour of AA7017-T73 and Mars $® 240$, the rate and temperature dependent Yld2000-3D and the quadratic non-associated Hill 48 ' yield criteria combined with an isotropic Voce hardening model were used. 
Finite element simulations showed that the plasticity models implemented as a user material subroutine provided accurate predictions.

Three-point bending tests of pre-fatigued specimens of AA7017-T73 and Mars ${ }^{\circledR}$ 240 at different loading-rates were carried out employing four different set-ups: a servo-hydraulic universal testing machine, a free-drop tower, a modified split Hopkinson pressure bar and a new explosive load testing device. In light of almost rate independent behaviour of AA7017-T73, the test procedures under dynamic loading conditions were validated. Then, the evolution of the dynamic fractureinitiation toughness with the loading rate of the Mars ${ }^{\circledR} 240$ steel was studied. The results revealed that the dynamic fracture-initiation toughness of the Mars $® 240$ steel increased with the loading rate.

Numerical simulations of the three-point bending experiments at different loading rates were performed in order to estimate the dynamic-fracture initiation toughness of the AA7017-T73 and Mars $® 240$ steel. Displacement and stress extrapolation methods were applied to estimate such a parameter. Under quasi-static conditions, numerical predictions from both extrapolation-based methods were identical to the experimental results. When increasing the loading rate, some scatter was found; being larger in the case of impulsive loadings.

The fracture strains measured from the simulations of the uniaxial tensile tests for different loading orientations showed large differences. Both, the anisotropic versions of the Cockcroft-Latham and Mohr-Coulomb failure-initiation criteria were successfully used to describe such large differences observed in the fracture strains. Both anisotropic fracture-initiation criteria were used in order to predict the failure of the three-point bending fracture tests. The anisotropic Mohr-Coulomb failure-initiation criteria presented a relatively accurate fracture prediction of the materials. However, the failure of both materials never occurred in the anisotropic Cockcroft-Latham failure-initiation predictions. 


\subsection{Future research lines}

The next research lines are proposed in order to continue the research presented in this $\mathrm{PhD}$ thesis.

\subsubsection{Further experimental improvements}

The fracture toughness experiments under impulsive loadings were subjected to a non-regulated environment out of the laboratory, being heavily dependent on the atmospheric conditions and landscape configuration. Fracture toughness experiments under a controlled enviroment such as in a shock tube could be extremely interesting to perform. Ultra-high speed cameras could be used in order to record the crack tip field. Then, both the dynamic fracture-initiation and propagation toughness at a wide strain range could be determined.

Since the novel experimental technique gave successful results, an extension to Mode-II and even Mixed-Mode I/II could be easily done using the same experimental procedure by simply changing the specimen geometry.

Although its effect was considered negligible, additionally a through-thickness characterisation of both materials could be carried out.

\subsubsection{Extensive numerical study}

Since every fracture toughness experiment was performed at different loading rates, in order to accurately analyse the numerical response, an extensive numerical analysis could be conducted simulating every loading rate at which the materials were tested.

Other rate-dependent fracture-initiation strain-based fracture criteria, such as Johnson-Cook, J3-dependent Johnson-Cook (Erice and Gálvez, 2014) or HosfordCoulomb (Roth and Mohr, 2014), could be used. However, this comes with a downside since a more extensive experimental campaign would be needed in order to calibrate those models. 
Other approaches to fracture modelling could have been considered, such as extended finite element method (X-FEM), cohesive zone models (CZM) or nodesplitting. 


\section{BIBLIOGRAPHY}

Anderson, D.D., Rosakis, A.J., 2005. Comparison of three real time techniques for the measurement of dynamic fracture initiation toughness in metals. Engineering Fracture Mechanics 72, 535-555.

Aretz, H., 2005. A non-quadratic plane stress yield function for orthotropic sheet metals. Journal of Materials Processing Technology 168, 1-9.

ASM-International, 2012. Mars $® 240$ (Armor Steel). The Materials Information Society. ASM International.

Barlat, F., Brem, J.C., Yoon, J.W., Chung, K., Dick, R.E., Lege, D.J., Pourboghrat, F., Choi, S.H., Chu, E., 2003. Plane stress yield function for aluminum alloy sheets_part 1: theory. International Journal of Plasticity 19, 1297-1319.

BOE-A-2003-20976, 2003. Ley 37/2003, del Ruido, Spain.

Böhme, W., 1990. Dynamic key-curves for brittle fracture impact tests and establishment of a transition time., in: Gudas, J.P., Hackett, E.M. (Eds.), Fracture Mechanics: 21st Symposium, ASTM STP 1074. American Society for Testing and Materials, Philadelphia, pp. 144-156.

Böhme, W., Kalthoff, J.F., 1982. The behavior of notched bend specimens in impact testing. International Journal of Fracture 20, R139-R143.

Chan, S.K., Tuba, I.S., Wilson, W.K., 1970. On the finite element method in linear fracture mechanics. Engineering Fracture Mechanics 2, 1-17. 
Cockcrof, Latham, D.J., 1968. Ductility and workability of metals. Journal of the Institute Of Metals 96.

Coulomb, C.A., 1776. Sur une application des regles maximis et minimis a quelques problems de statique, relatives a l'architecture. Acad. Sci. Paris Mem. Math. Phys. 7, 343-382.

Couque, H., 1994. Effect of loading rate on the plane stress fracture toughness properties of an aluminum alloy. J. Phys. IV France 04, C8-747-C748-752.

Couque, H., Dexter, R.J., Hudak, S.J., 1992a. Using smaill specimens to measure dynamic fracture properties of high-toughness steels. American Society for Testing and Materials. Rapid Load Fracture Testing, ASTM STP 1130., 24-36.

Couque, H., Dexter, R.J., Leung, C.P., Jr., S.J.H., 1992b. Dynamic ductile fracture of a low-strength steel. J. Phys. III France 2, 2239-2246.

Creusot-Loire, Registered trade mark of Creusot-Loire. France.

Crisfield, M.A., 1997. Non-linear Finite Element Analysis of Solids and Structures. Volume 2: Advanced Topics. Wiley.

Dunand, M., Gary, G., Mohr, D., 2013. Load-Inversion Device for the High Strain Rate Tensile Testing of Sheet Materials with Hopkinson Pressure Bars. Experimental Mechanics 53, 1177-1188.

Dunand, M., Maertens, A.P., Luo, M., Mohr, D., 2012. Experiments and modeling of anisotropic aluminum extrusions under multi-axial loading - Part I: Plasticity. International Journal of Plasticity 36, 34-49.

E399-12e3, 2012. ASTM E399-12e3. Standard Test Method for Linear-Elastic Plane-Strain Fracture Toughness KIC of Metallic Materials. ASTM International, West Conshohocken, PA.

Erice, B., Gálvez, F., 2014. A coupled elastoplastic-damage constitutive model with Lode angle dependent failure criterion. International Journal of Solids and Structures 51, 93-110.

Erice, B., Roth, C.C., Mohr, D., 2017. Stress-state and Strain-Rate Dependent Ductile Fracture of Dual and Complex Phase Steel. Accepted for publication. Mechanics of Materials.

Faye, A., Parameswaran, V., Basu, S., 2016. Dynamic fracture initiation toughness of PMMA: A critical evaluation. Mechanics of Materials 94, 156-169.

Foster, J.T., Chen, W., Luk, V.K., 2011. Dynamic crack initiation toughness of 4340 steel at constant loading rates. Engineering Fracture Mechanics 78, 1264-1276.

Freund, L.B., 1990. Dynamic Fracture Mechanics. Cambridge University Press, Cambridge. 
Freund, L.B., Duffy, J., Rosakis, A.J., 1981. Dynamic fracture initiation in metals and preliminary results on the method of caustics for crack propagation measurements. ASME Paper No. 81-PVP-15.

Fu, P., Johnson, S.M., Settgast, R.R., Carrigan, C.R., 2012. Generalized displacement correlation method for estimating stress intensity factors. Engineering Fracture Mechanics 88, 90-107.

Gálvez, F., Cendón, D., García, N., Enfedaque, A., Sánchez-Gálvez, V., 2009. Dynamic fracture toughness of a high strength armor steel. Engineering Failure Analysis $16,2567-2575$.

Gary, G., 2005. DAVID Instruction Manual, Palaiseau, France.

Gruben, G., Fagerholt, E., Hopperstad, O.S., Børvik, T., 2011. Fracture characteristics of a cold-rolled dual-phase steel. European Journal of Mechanics A/Solids 30, 204-218.

Gu, G., Mohr, D., 2015. Anisotropic Hosford-Coulomb fracture initiation model: Theory and application. Engineering Fracture Mechanics 147, 480-497.

Guinea, G.V., Planas, J., Elices, M., 2000. KI evaluation by the displacement extrapolation technique. Engineering Fracture Mechanics 66, 243-255.

Guo, C., Jiang, F., Liu, R., Yang, Y., 2011. Size effect on the contact state between fracture specimen and supports in Hopkinson bar loaded fracture test. International Journal of Fracture 169, 77-84.

Henschel, S., Krüger, L., 2015. Dynamic crack initiation measurements in a fourpoint split Hopkinson bending device. Engineering Fracture Mechanics 133, 62-75.

Hill, R., 1948. A theory of the yielding and plastic flow of anisotropic metals. Proceedings of the Royal Society of London Series a-Mathematical and Physical Sciences 193, 281-297.

Hopperstad, O.S., Børvik, T., Berstad, T., Lademo, O.G., Benallal, A., 2007. A numerical study on the influence of the Portevin-Le Chatelier effect on necking in an aluminium alloy. Modelling and Simulation in Materials Science and Engineering 15, 747.

Ireland, D.R., 1976. Critical review of instrumented impact testing, International Conference on Dynamic Fracture Toughness, London.

Irwin, G.R., 1957. Analysis of Stresses and Strains Near the End of a Crack Traversing a Plate. Journal of Applied Mechanics 24, 361-364.

Jiang, F., Ruitang, L., Xiaoxin, Z., Vecchio, K.S., Rohatgi, A., 2004. Evaluation of dynamic fracture toughness KId by Hopkinson pressure bar loaded instrumented Charpy impact test. Engineering Fracture Mechanics 71, 279-287. 
Jiang, F., Vecchio, K.S., 2007. Dynamic Effects in Hopkinson Bar Four-Point Bend Fracture. Metallurgical and Materials Transactions A 38, 2896.

Johnson, G.R., Cook, W.H., 1983. A constitutive model and data for metals subjected to large strains, high strain rates and high temperatures, 7 th International Symposium on Ballistics, The Hague, pp. 541-547.

Joudon, V., Portemont, G., Lauro, F., Bennani, B., 2014. Experimental procedure to characterize the mode I dynamic fracture toughness of advanced epoxy resins. Engineering Fracture Mechanics 126, 166-177.

Kalthoff, J.F., 1985. On the measurement of dynamic fracture toughnesses - a review of recent work. International Journal of Fracture 27, 277-298.

Kalthoff, J.F., 1986. The Shadow Optical Method of Caustics, in: Nisida, M., Kawata, K. (Eds.), Photoelasticity: Proceedings of the International Symposium on Photoelasticity, Tokyo, 1986. Springer Japan, Tokyo, pp. 109-120.

Kalthoff, J.F., 1990. Experimental Fracture Dynamics, in: Klepaczko, J.R. (Ed.), Crack Dynamics in Metallic Materials. Springer Vienna, Vienna, pp. 69-253.

Kolsky, H., 1949. An Investigation of the Mechanical Properties of Materials at very High Rates of Loading. Proceedings of the Physical Society. Section B 62, 676.

Liu, C., Knauss, W.G., Rosakis, A.J., 1998. Loading Rates and the Dynamic Initiation Toughness in Brittle Solids. International Journal of Fracture 90, 103-118.

Logan, R.W., Hosford, W.F., 1980. Upper-bound anisotropic yield locus calculations assuming $\langle 111\rangle$-pencil glide. International Journal of Mechanical Sciences 22, 419-430.

Loya, J., Fernandez-Saez, J., Navarro, C., 2003. Numerical simulation of dynamic TPB fracture test in a modified Hopkinson bar. J. Phys. IV France 110, 305-310.

Loya, J.A., Fernández-Sáez, J., 2008. Three-dimensional effects on the dynamic fracture determination of Al 7075-T651 using TPB specimens. International Journal of Solids and Structures 45, 2203-2219.

LSTC, 2014. LS-DYNA Keyword User's Manual. Version R7.1. Livermore Software Technology Corporation (LSTC), Livermore, California.

LSTC, 2015. LS-OPT User's Manual. A design optimization and probabilistic analysis tool for the engineering Analyst. Version 5.2. Livermore Software Technology Corporation (LSTC), Livermore, California.

Luo, M., Dunand, M., Mohr, D., 2012. Experiments and modeling of anisotropic aluminum extrusions under multi-axial loading - Part II: Ductile fracture. International Journal of Plasticity 32-33, 36-58. 
Manogg, P., 1964. Schattenoptische Messung der spezifischen Bruchenergie während des Bruchvorgangs bei Plexiglas, Int Conf Physics Non-Crystalline Solids, Delft, pp. 481-490.

Marcadet, S.J., Mohr, D., 2015. Effect of compression-tension loading reversal on the strain to fracture of dual phase steel sheets. International Journal of Plasticity $72,21-43$.

Mohr, D., Marcadet, S.J., 2015. Micromechanically-motivated phenomenological Hosford-Coulomb model for predicting ductile fracture initiation at low stress triaxialities. International Journal of Solids and Structures 67, 40-55.

Mohr, O., 1900. Welche Umstände bedingen die Elastizitätsgrenze und den Bruch eines Materials? Zeit des Ver Deut Ing. 44, 1524-1530.

Morales-Alonso, G., 2013. Experimental and numerical analysis of reinforced concrete elements subjected to blast loading, Department of Materials Science. Technical University of Madrid, Madrid, Spain.

Morales-Alonso, G., Cendon, D.A., Galvez, F., Erice, B., Sanchez-Galvez, V., 2011a. Blast response analysis of reinforced concrete slabs: Experimental procedure and numerical simulation. Ballistics 2011: 26th International Symposium on Ballistics, Vol 1 and Vol 2, 1679-1682.

Morales-Alonso, G., Cendón, D.A., Gálvez, F., Erice, B., Sánchez-Gálvez, V., 2011b. Blast Response Analysis of Reinforced Concrete Slabs: Experimental Procedure and Numerical Simulation. Journal of Applied Mechanics 78, 051010051010-051012.

Nahme, H., Lach, E., 1997. Dynamic Behavior of High Strength Armor Steels. J. Phys. IV France 07, C3-373-C373-378.

NordNorsk, 2003. NordNorsk Goma-2 ECO fact sheet, in: S.A., U.E.d.E. (Ed.), MSDS UN EXP 9001 (GOMA 2 ECO / MYTREX).

Owen, D.M., Zhuang, S., Rosakis, A.J., Ravichandran, G., 1998. Experimental Determination of Dynamic Crack Initiation and Propagation Fracture Toughness in Thin Aluminum Sheets. International Journal of Fracture 90, 153-174.

Qian, G., González-Albuixech, V.F., Niffenegger, M., Giner, E., 2016. Comparison of KI calculation methods. Engineering Fracture Mechanics 156, 52-67.

Ravi-Chandar, K., 2004. Dynamic Fracture. Elsevier, Oxford.

Ravi-Chandar, K., Knauss, W.G., 1984. An experimental investigation into dynamic fracture: I. Crack initiation and arrest. International Journal of Fracture 25, 247262. 
Rittel, D., Frage, N., Dariel, M.P., 2005. Dynamic mechanical and fracture properties of an infiltrated TiC-1080 steel cermet. International Journal of Solids and Structures 42, 697-715.

Rittel, D., Maigre, H., 1996. An investigation of dynamic crack initiation in PMMA. Mechanics of Materials 23, 229-239.

Rittel, D., Pineau, A., Clisson, J., Rota, L., 2002. On testing of charpy specimens using the one-point bend impact technique. Experimental Mechanics 42, 247-252.

Rittel, D., Rosakis, A.J., 2005. Dynamic fracture of berylium-bearing bulk metallic glass systems: A cross-technique comparison. Engineering Fracture Mechanics 72, 1905-1919.

Rittel, D., Weisbrod, G., 2001. Dynamic fracture of tungsten base heavy alloys. International Journal of Fracture 112, 87-98.

Rodríguez, J., Navarro, C., Sánchez-Gálvez, 1994. Some corrections to the data analysis of the dynamic tensile tests in the Hopkinson bar. J. Phys. IV France 04, C8-83-C88-88.

Rokach, I.V., 2005. Discussion on the paper "Evaluation of dynamic fracture toughness Kld by Hopkinson pressure bar loaded instrumented Charpy impact test" by Jiang Fengchun, Liu Ruitang, Zhang Xiaoxin, Kenneth S. Vecchio and Aashish Rohatgi, Engineering Fracture Mechanics, 71 (2004) pp. 279-287. Engineering Fracture Mechanics 72, 1107-1111.

Rosakis, A.J., 1993. Experimental techniques in fracture. VCH Publishers Inc, New York.

Roth, C.C., Gary, G., Mohr, D., 2015. Compact SHPB System for Intermediate and High Strain Rate Plasticity and Fracture Testing of Sheet Metal. Experimental Mechanics 55, 1803-1811.

Roth, C.C., Mohr, D., 2014. Effect of strain rate on ductile fracture initiation in advanced high strength steel sheets: Experiments and modeling. International Journal of Plasticity 56, 19-44.

Rubio-González, C., Gallardo-González, J.A., Mesmacque, G., Sanchez-Santana, U., 2008. Dynamic fracture toughness of pre-fatigued materials. International Journal of Fatigue 30, 1056-1064.

Rubio, L., Fernández-Sáez, J., Navarro, C., 2003. Determination of dynamic fracture-initiation toughness using three-point bending tests in a modified Hopkinson pressure bar. Experimental Mechanics 43, 379-386.

Shuter, D.M., 2002. Dynamic fracture toughness determination using precracked Charpy specimens. European Structural Integrity Society 30, 237-244. 
The Aluminum Association, I., 2001. Aluminum Standards and Data 2000.

Tippur, H.V., Krishnaswamy, S., Rosakis, A.J., 1991a. A coherent gradient sensor for crack tip deformation measurements: analysis and experimental results. International Journal of Fracture 48, 193-204.

Tippur, H.V., Krishnaswamy, S., Rosakis, A.J., 1991b. Optical mapping of crack tip deformations using the methods of transmission and reflection coherent gradient sensing: a study of crack tip K-dominance. International Journal of Fracture 52, 91117.

Tronskar, J.P., Mannan, M.A., Lai, M.O., 2002. Measurement of fracture initiation toughness and crack resistance in instrumented Charpy impact testing. Engineering Fracture Mechanics 69, 321-338.

Viehrig, H.W., Boehmert, J., Dzugan, J., 2002. Use of instrumented Charpy impact tests for the determination of fracture toughness values. European Structural Integrity Society 30, 245-252.

Voce, E., 1948. The relationship between stress and strain for homogeneous deformation. Journal of the Institute of Metals 74, 537-562.

Wallin, K., 1998. Master curve analysis of ductile to brittle transition region fracture toughness round robin data - The EURO fracture toughness curve, in: 367, V.P. (Ed.), VTT Espoo, Finland.

Wang, Q.Z., Yang, J.R., Zhang, C.G., Zhou, Y., Li, L., Zhu, Z.M., Wu, L.Z., 2015. Sequential determination of dynamic initiation and propagation toughness of rock using an experimental-numerical-analytical method. Engineering Fracture Mechanics 141, 78-94.

Weerasooriya, T., Moy, P., Casem, D., Cheng, M., Chen, W., 2006. A Four-Point Bend Technique to Determine Dynamic Fracture Toughness of Ceramics. Journal of the American Ceramic Society 89, 990-995.

Weisbrod, G., Rittel, D., 2000. A method for dynamic fracture toughness determination using short beams. International Journal of Fracture 104, 89-103.

Williams, M.L., 1957. On the stress distribution at the base of a stationary crack. Journal of Applied Mechanics 24, 109-114.

Xing, M.-z., Wang, Y.-g., Jiang, Z.-X., 2013. Dynamic Fracture Behaviors of Selected Aluminum Alloys Under Three-point Bending. Defence Technology 9, 193-200.

Xu, Z.-J., Li, Y.-L., Huang, F.-L., 2012. Application of split Hopkinson tension bar technique to the study of dynamic fracture properties of materials. Acta Mechanica Sinica 28, 424-431. 
Yokoyama, T., 1993. Determination of Dynamic Fracture-Initiation Toughness Using a Novel Impact Bend Test Procedure. Journal of Pressure Vessel Technology 115, 389-397. 